
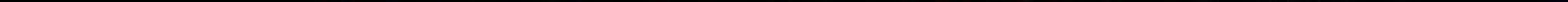
THE FIELD MUSEUM LIBRAAY
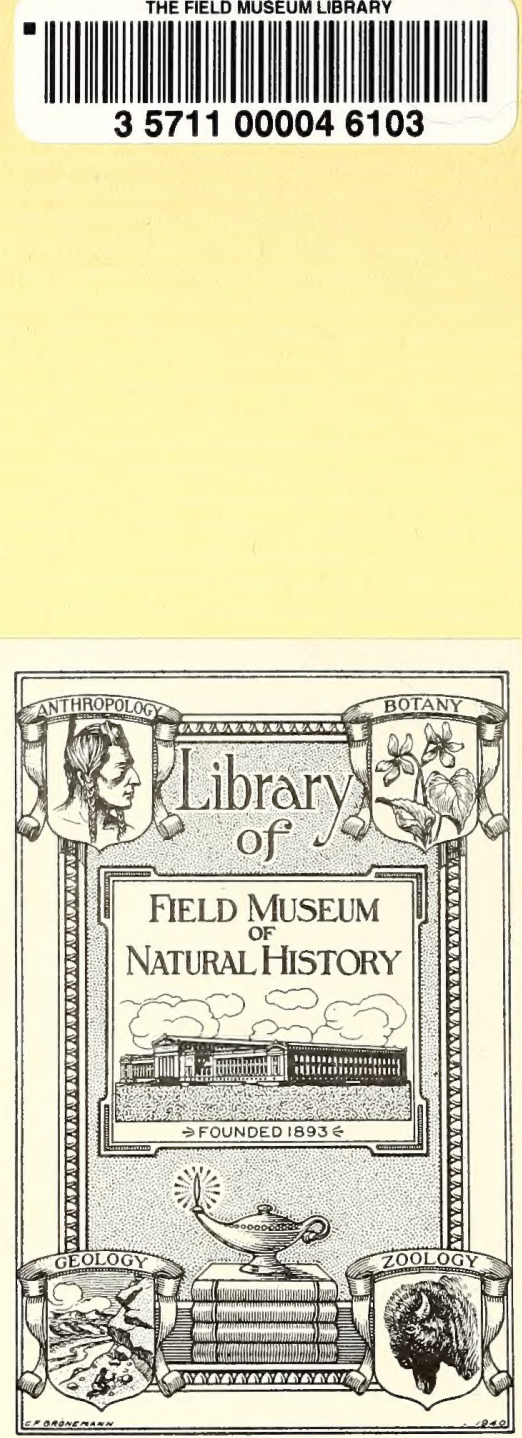


\section{Digitized by the Internet Archive}

in 2013 


\title{
Die Gehirnnerven der Saurier
}

\author{
anatomisch untersucht
}

von

\section{Mischer Ir.}

ordentl. Lehrer an der Realschule des Johanneums. 


\section{$Q L$ \\ 669 \\ F47}

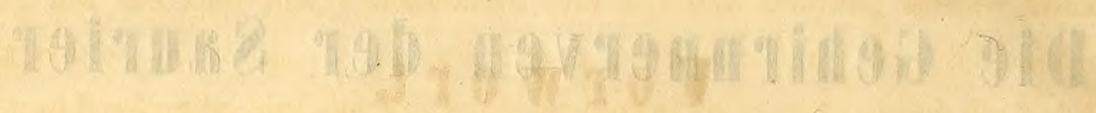

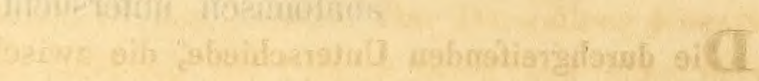

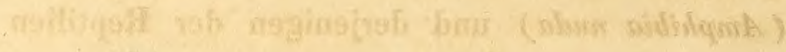

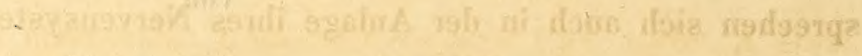

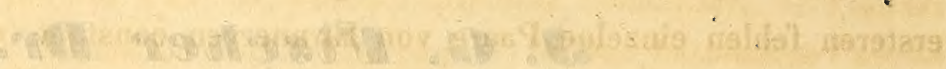

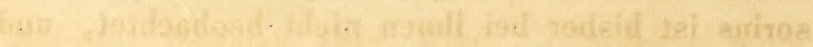

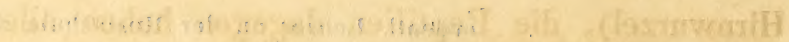

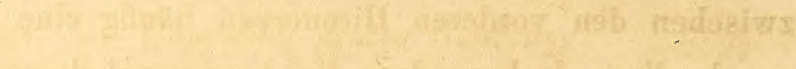
16. 9540798

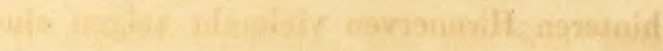

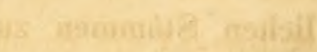

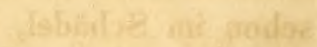

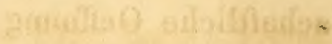

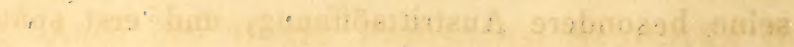

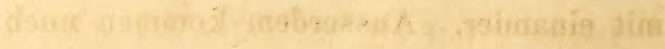

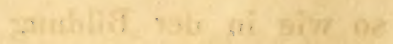
Gib bous soy shaviloe

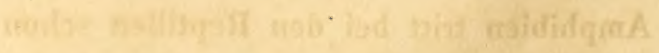

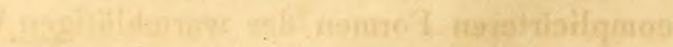

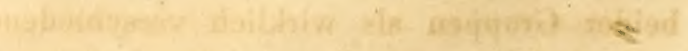




\section{Vor w o r t.}

Die durchgreifenden Unterschiede, die zwischen der Klasse der Amphibien (Amphibia nuda) und derjenigen der Reptilien (Amphibia squamata) bestehen, sprechen sich auch in der Anlage ihres Nervensystems so deutlich aus, als es nur immer der allen Wirbelthieren gemeinschaftliche Plan verstattet. Bei den ersteren fehlen einzelne Paare von Hirnnerven constant (eine Wurzel des Accessorius ist bisher bei ihnen nicht beobachtet, und der Hypoglossus hat nie eine Hirnwurzel), die Reptilien dagegen haben alle zwölf Paare; bei jenen findet zwischen den vorderen Hirnnerven häufig eine Verschmelzung statt, hier sind gerade diese, insbesondere die Augenmuskelnerven beständig ganz frei, und die hinteren Hirnnerven vielmehr zeigen eine grosse Neigung, sich zu gemeinschaftlichen Stämmen zu verbinden; dort findet fast jede derartige Verschmelzung schon im Schädel, in Folge des Durchtrittes mehrerer Nerven durch eine gemeinschaftliche Oeffnung statt, - hier hat jeder Nerv (mit Ausnahme des Accessorius) seine besondere Austrittsöffnung, und erst später verwachsen einzelne Stämme mit einander. Ausserdem kommen noch in der Verbreitung der einzelnen Nerven so wie in der Bildung der sympathischen Schlingen so durchgreifende Unterschiede vor, und die grosse Einfachheit in der Anlage der Gehirnnerven der Amphibien tritt bei den Reptilien schon so sehr hinter der Annäherung an die complicirteren Formen der warmblütigen Wirbelthiere zurück, dass die Trennung beider Gruppen als wirklich verschiedener Klassen auch hier sich nicht verkennen lässt. 
Gerade diese, schon früher von Stannius in Bezug auf die Nerven der Krokodile hervorgehobene Annäherung der Reptilien an die Formen der höheren Wirbelthiere erregte in mir zuerst den Plan einer vergleichenden Arbeit über die Gehirnnerven der Reptilien und Vögel, - der grosse Mangel an genügenden Specialbeschreibungen veranlasste mich jedoch bald, von diesem Plan wieder abzustehen, und selbst eine Zahl von Reptilien genauer zu untersuchen. Alle Ordnungen dieser Klasse zu bearbeiten liessen indessen die Schranken, die mir in Bezug auf die Zeit des Erscheinens und auf den Umfang dieser Abhandlung gesteckt waren, nicht zu, - ja selbst von der Darstellung der Gehirnnerven der Saurier und Krokodile, auf die ich mich beschränken musste, blieb die Schilderung der drei höheren Sinnesnerven namentlich aus dem Grunde ausgeschlossen, weil nur Weingeistexemplare untersucht werden konnten, eine Darstellung jener Nerven aber ohne mikroskopische Untersuchung der Primitivfasern und ohne detaillirte Beschreibung des Gehirns immer unvollkommen bleiben wird.

Folgende Arten wurden untersucht: Chamaeleo vulgaris Cuv. variet. A. Dum. Bibr. - Platydactylus guttatus Cuv. - Varanus Niloticus Dum. Bibr. - Varanns Bengalensis Dum. Bibr. - Iguana tuberculata Laurenti. - Istiurus Amboinensis Cuv. Agama spinosa Dum. Bibr. - Salvator Merianae Dum. Bibr. - Salvator nigropunctatus Dum. Bibr. - Lacerta ocellata Daudin. - Euprepes Sebae Dum. Bibr. - Crocodilus biporcatus Cuv. - Crocodilus acutus Geoffroy. - Alligator punctulatus Spix.

Die untersuchten Formen waren Weingeistexemplare, die mir aus dem Doublettenvorrathe des hiesigen naturhistorischen Museums durch die Liberalität der Museums-Commission zur Verfügung gestellt wurden. Sei hiefür den Mitgliedern der letzteren, deren College zu sein ich selbst die Ehre habe, hiemit der wärmste Dank abgestattet. Auch den Herren Professoren Stannius in Rostock und Eschricht in Kopenhagen fühle ich mich für die Bereitwilligkeit verpflichtet, mit welcher Sie mich durch die Schätze Ihrer Bibliotheken zu unterstützen die Güte hatten. 


\section{Erster Abschnitt.}

\section{Von den Augenmuskelnerven.}

\section{Vom Nervus oculomotorius.}

Der Oculomotorius entspringt überall dicht hinter der Hypophysis cerebri an der vordersten Grenze der Grundfläche des verlängerten Markes als einfacher Nervenstrang sehr nahe der Mittellinie (Lacerta ocellata, Varanus Bengalensis, Chamaeleo vulgaris u. A.), bei einigen sogar von der Mittellinie selbst (Iguana tuberculata, Platydactylus guttatus u. A.) Die einfache Wurzel wendet sich nach vorn und etwas nach aussen, und verlässt in abgeplatteter Form die Schädelhöhle durch ein an der unteren Seite der häutigen Seitenwand des Schädels gelegenes Loch.

Wie dieser Ursprung, so ist auch die fernere Verbreitung des Oculomotorius bei allen Sauriern von derselben Form. Folgendes ist, als Typus seines Verlaufes, die Schilderung seiner Ausbreitung bei Varanus Bengalensis:

Nach dem Eintritt des Stammes in die Orbita, in welcher er über dem M. rectus externus, unter dem $M$. suspensorius nach vorn läuft, giebt er nach und nach folgende Zweige ab:

a) Der erste wendet sich nach aussen und oben, läuft über den gleich zu beschreibenden Ast $b$ fort, und verzweigt sich im M. rectus superior.

b) Der zweite Ast ist der Ramus ciliariș, unmittelbar nach dem Ast $a$ entspringend. Derselbe tritt über den M. rectus externus fort zwischen die Fasern des M. suspensorius, und schwillt zu einem spindelförmigen Ganglion an, in dessen hintere Seite von aussen her der Ramus ciliaris vom ersten Ast des Trigeminus eindringt. Aus diesem Ganglion geht ein einfacher Stamm hervor, der hinter und etwas unter der Eintrittsstelle des Opticus in den Augapfel sich einsenkt.

c) Der folgende, in fünf feinere Zweige sich spaltende Ast geht ausschliesslich in den $M$. rectus inferior, in den er von unten her eindringt.

Nach Abgabe dieser Zweige ist der Stamm des Oculomotorius längs des Knorpelstiels des Keilbeins bis vor den M. rectus inferior nach vorn getreten, und theilt sich hier in $2 \mathrm{Zweige:}$

d) gerade nach vorn unter dem Bulbus verlaufend, bis zum hinteren Rande des M. obliquus inferior, in welchem er endigt;

e) wendet sich an der Innenwand der Orbita längs des knorplichen Septum aufwärts und endigt im M. rectus externus.

Ganz dieselbe Form, mit geringen Abweichungen in, dem etwas früheren oder späteren Abgang der einzelnen Zweige zeigt der Oculomotorius bei den 
übrigen Eidechsen. Die einzigen Verschiedenheiten, die der Erwähnung bedürfen, betreffen höchstens die Form des, überall vorhandenen, Ganglion ciliare. Dies ist fast immer eine länglich-spindelförmige Anschwellung im Stamm des zweiten Astes (R. ciliaris) des Oculomotorius, und der Ciliarzweig des Trigeminus mündet meist von der Seite her in die Mitte oder den vorderen Theil des Ganglions ein (Varanus Niloticus, Lacerta ocellata, Iguana tuberculata, Platydactylus guttatus). Bei Salvator Merianae treten dagegen der R. ciliaris Oculomotorii und der nur halb so starke Ciliarast des Trigeminus schon vor der Bildung des Ganglions zusammen. Aehnlich bei Euprepes Sebae. Hier sind beide Aeste von gleicher Stärke und treten gleichzeitig ins Ganglion ein. Letzteres ist sehr länglich und so schwach, dass es kaum noch eine Anschwellung genannt werden kann.

Aus dem Ganglion tritt meist ein einfacher Stamm aus. Bei Varanus Niloticus ward eine Neigung zur Theilung insofern bemerkt, als gleich nach seinem Ursprunge ein feiner Nebenzweig von ihm abgeht, der parallel mit dem Stamme verlaufend, vor dessen Eintritt in den Bulbus wieder in denselben einmündet.

Die Einsenkung in den Augapfel erfolgt beständig eben ausser- und unterhalb vom Sehnerven.

Dis Krokodile (Crocod. biporcatus) zeigen ein ziemlich abweichendes Verhältniss. Der einfache Stamm des Oculomotorius, ganz ähnlich wie bei den Sauriern hinter dem Hirnanhang nahe der Mittellinie entsprungen, giebt sogleich nach seinem Eintritt in die Orbita einen längs der inneren Fläche des Bulbus aufsteigenden Zweig für den $M$. rectus superior ab. Nach seinem Abgange legt sich der Stamm hart an den eben aus seinem Ganglion entsprungenen $R$. nasalis des ersten Astes des Trigeminus, und schwillt ganz, an der Innenseite desselben liegend, zu einem flachen, länglichen Ganglion an. In den vorderen Theil des letzteren tritt ein nicht unbedeutender Zweig des R. nasalis ein, der sich fast unmittelbar in den aus dem Ganglion austretenden Ciliarnerven verfolgen lässt. Aus dem angeschwollenen Stamme des Oculomotorius selbst gehen folgende Zweige hervor: a) am weitesten nach innen der Ast für den M. rectus externus; $-b$ ) weiter nach aussen der unter dem Augapfel nach vorn verlaufende Ast für den M. obliquus inferior; - c) noch weiter nach aussen der von unten her in den $\mathbf{R}$. inferior gehende Zweig; $-d$ ) am weitesten nach aussen der, fast als Fortsetzung des erwähnten Astes vom Trigeminus erscheinende Nervus ciliaris. Dieser dringt nicht sogleich mit allen seinen Fasern in den Augapfel ein, sondern entlässt, unter dem Opticus fort nach aussen tretend, einen feinen Zweig, der neben dem Sehnerven in die Sclerotica eindringt; der grössere Theil des Nerven geht in zwei feine Zweige gespalten unter dem Bulbus und demselben hart anliegend schräg nach aussen und vorn bis zur Cornea, um hier, wie es scheint, in's Auge einzudringen.

Die Unterschiede der Krokodile bestehen also darin:

1) Dass hier kein eigentliches Ganglion ciliare im Stamm des vom Oculomotorius abgegebenen R. ciliaris sich findet, sondern dass der ganze Stamm des dritten Paares vor dem Abgang des Ciliarnerven eine ganglienartige Anschwellung zeigt, an der die Fasern des Trigeminus keinen oder nur einen sehr geringen Antheil nehmen;

2) dass der aus dem Ganglion hervorgehende Truncus ciliaris nicht wie bei den Eidechsen neben dem Opticus, sondern grösstentheils erst viel weiter nach aussen in den Augapfel eindringt. 


\section{$-5-$}

\section{Vom Nervus patheticus.}

Die Wurzel dieses Nerven ist, wie es scheint, immer einfach, und entspringt beständig von der oberen und hinteren Grenze der Vierhügelmasse. In einem sanften Bogen schmiegt sich dieselbe dieser Gehirnabtheilung dicht anliegend nach unten und vorn, läuft von der Seite her über die Wurzel des Trigeminus fort und tritt aus einem besonderen Loche in der häutigen Seitenwand des Schädels etwas vor und über dem Ramus primus Trigemini in die Orbita ein. Eben hervorgetreten läuft der Patheticus, der Seitenwand des Schädels dicht anliegend, etwas über dem benachbarten $R$. nasalis paris quinti nach vorn, um endlich in seinem Muskel, dem M. obliquus superior, sich zu verbreiten.

Eine Abweichung von diesem Verlauf ist mir bei keiner der untersuchten Formen bekannt geworden.

\section{Vom Nervus abducens.}

(Auf den Abbildungen mit 6 hezeichnet.)

Der Abducens entspringt immer als einfacher Nerv von der Grundfläche des verlängerten Markes ziemlich nahe der Mittellinie, nicht ganz in gleicher Höhe mit dem Ursprung des Trigeminus*). Die feine Wurzel wendet sich nach vorn und etwas nach aussen, und tritt durch einen feinen, von oben und hinten nach unten und vorn gerichteten Kanal aus dem Schädel. Gleich nach seinem Austritt läuft der feine Abducens zwischen die Bündel des M. suspensorius, giebt demselben 2 bis 3 feine aber deutliche $Z$ weige, durchbohrt dann diesen Muskel, und tritt von hinten her an den M. rectus externus, in welchem er sich ausbreitet**).

Auch in der Form dieses Nerven stimmen alle untersuchten Arten überein.

\section{Zweiter Abschnitt. Vom Nervus Trigeminus. I. Vom Ursprunge des Trigeminus.}

Vom vordersten Theil der Seitenfläche des verlängerten Markes entspringt der Trigeminus beinahe in gleicher Höhe mit dem von der Mittellinie entspringenden Oculomotorius. Sein Ursprung ist immer getrennt von demjenigen anderer Hirnnerven und ein Uebergang von Wurzelbündeln des fünften Paares an das siebente oder umgekehrt, wie ihn viele Amphibien und Fische zeigen, findet sich

*) Einen Ursprung in der Mittellinie selbst, wie ich ihn früher bei den Amphibien gefunden (vgl. meine frühere Schrift: Amphibiorum nudorum neurologiae specimen, Berol. 1843, Taf. I und II, sämmtlicbe Figuren No.6), zeigen die Saurier und Krokodile nicht.

**) Es ist mir nicht geglückt, die Nerven für die Muskeln der Nickbaut aufzufinden. Eben so wenig konnte ich den Verbindungszweig des Abdusens zum N. vidianus (unserem N.palatinus) finden, der nach Vogts Angaben bei Chelonia, Lacerta, Monitor u. A. existiren soll. 
nicht. Bei den Sauriern gelang es mir bei der grössten Aufmerksamkeit auch bei ansehnlichen Exemplaren nicht, eine ohne Theilnahme am Ganglion verlaufende Portio minor zu entdecken. Mit Leichtigkeit sieht man dieselbe dagegen auch bei den kleinsten Krokodilen.

Bei Crocodilus biporcatus entspringt der Trigeminus mit 4 gesonderten Wurzeln. Eine, die stärkste von allen, ist ihrem Ursprunge nach vordere oder untere, die drei anderen entspringen höher (d. h. der Rückseite näher), in gleicher Linie neben einander, und werden von unten erst gesehen, wenn man die dieselben verdeckende untere Wurzel aufhebt. Diese 3 oberen Wurzeln sind von ungleicher Stärke. Von ihnen gehen die zweite und dritte ins Ganglion Gasseri über, ohne dass sich entscheiden liesse, wie grossen Antheil jede an der Bildung des zweiten und dritten Astes hat. Die erste dieser 3 oberen Wurzeln ist dagegen allein etwas stärker, als die beiden anderen zusammen, und theilt sich, obgleich einfach entspringend, in zwei gleiche Hälften, von denen die hintere mit den zwei ersteren (oberen) Wurzeln ins Ganglion Gasseri übergeht, während die vordere sich von den übrigen Wurzeln des fünften Paares abwendet, nach vorn durch eine besondere Oeffnung aus dem Schädel tritt, und allein den ersten Ast des Trigeminus bildet. Die zuerst genannte untere Wurzel hat weder an der Bildung dieses ersten Astes noch an derjenigen des Ganglion Gasseri einigen Antheil, sondern, an dies letztere sich von unten her anlegend, lässt sie sich unter demselben fort nach aussen in den dritten Ast hinein verfolgen, zu dessen Muskelästen sie insbesondere die Fasern hergiebt.*)

\section{Von dem Ganglion des Trigeminus.}

Fine Eigenthümlichkeit der Reptilien gegenüber den Amphibien ist der Umstand, dass der erste Ast des Trigeminus ein besonderes Ganglion hat, getrennt von dem gemeinschaftlichen Ganglion des zweiten und dritten Astes. Bei den Sauriern ist dasselbe bisweilen eine besondere Anschwellung, welche die Wurzel des ersten Astes bildet, nachdem sie sich vom zweiten und dritten Aste getrennt (Platydactylus guttatus, Salvator Merianae und S. nigropunctatus), oft aber ist sie auch mit dem Ganglion des zweiten und dritten Astes so verwachsen, dass sie nur durch einen Einschnitt an der vorderen Seite desselben getrennt erscheint (Varamus Bengalensis, Iguana tuberculata). ${ }^{* *}$ )

Bei Chamaeleo vulgaris habe ich nur ein Ganglion finden können (Taf. II, fig. 4, B). Aus der vorderen Fläche des Wurzelstammes geht ohne Bildung eines Ganglions der erste Ast hervor. An der hinteren Seite liegt das flache, halbkreisförmige Ganglion des zweiten und dritten Astes so angeheftet, dass die Convexität nach hinten gerichtet ist, und die vordere Fläche des Wurzelstammes, von der, wie eben gesagt, auch der erste Ast abgeht, ohne directe Theilnahme am Ganglion in den nach aussen gerichteten dritten Ast sich fortsetzt. Aus der höchsten, nach hinten gekehrten Krümmung des Ganglions geht der zweite Ast hervor, erst ebenfalls auf eine ganz kleine Strecke die Richtung nach hinten verfolgend, dann nach oben und mit rascher Biegung nach vorn über den dritten Ast forttretend und nun die Richtung nach aussen und vorn einhaltend.

*) M ̈̈lle r erwähnt einer besonderen Portio motoria des Trigeminus bei der Klapperschlange und bei Python tigris. (Vergl. Neurologie der Myxinoiden in den Abhandl. d. berlin. Akad. der Wissensch. 1839. pg. 229.)

*) Ein besonderes Ganglion des ersten Astes bildet Müller ab bei der Klapperschlange 1. 1. Taf. IV, fig. 4, 5'. 
Gewöhnlich ist das Ganglion des zweiten und dritten Astes in dem für den Austritt des Nerven bestimmten Loche selbst gelegen, und zwar so, dass es halb aus demselben nach aussen vorragt. Dies Loch wird von hinten, unten und oben von der Knochenmasse des Felsenbeins, von vorn aber von der häutigen Seitenwand des Schädels begrenzt. Das Loch für den ersten Ast liegt in der häutigen Seitenwand selbst, etwas vor und unter der Oeffnung für den zweiten und dritten Ast.

\section{Von den Zweigen des Trigeminus.}

Ausser den gewöhnlichen drei Aesten geht aus der Wurzel des Trigeminus oder der unteren Fläche des Ganglion Gasseri, - bei den Krokodilen aus der Portio minor - ein feiner Nerv hervor, der unter dem ersten Aste nach vom in die Orbita eintritt, und sich hier von unten her an den M. adductor maxillae superioris *) da anlegt, wo dieser am Gelenkfortsatz des Keilbeins sich befestigt. Eine kurze Strecke läuft dieser Nerv unter dem genannten Muskel nach vorn, und breitet sich dann in demselben mit mehreren feinen $\mathbf{Z}$ weigen aus.

Ich habe diesen Nerven bei allen untersuchten Eidechsen und Krokodilen gefunden, und zwar überall von derselben Form.

Bei den Krokodilen steigt die Zahl der aus der Wurzel des Trigeminus entspringenden Aeste noch um einen höher als bei den Sauriern, da der bei diesen aus dem zweiten Aste hervorgehende R. recurrens dort aus dem Ganglion selbst hervorgeht. (Taf. III, fig. 5, x.)

*) Was zunächst diesen Muskel betrifft, so ist es ohne Zweifel derselbe, den B o ian us bei Emys Europaea als $M$. palpebralis bezeichnet (Tab. XVIII, fig. 80, 12): „Palpebralis orbicularis musculi „palpebrarum loco; neque vero in orbem circumductus. - Ab inscriptione tendinea-oriundum, „ob pallorem tamen parum notabile stratum Inusculosum, juxta palpebrarum longitudinem por„rectum; in superiore palpebra vix aliquantum conspicuum, apertius inferiore, ibique bulbo „subductum. - Necdum tamen de universa huius musculi eiusque cum membranae nictitantis "illo intercedente forte reciproca ratione, mibi satis liquet etc. etc." - Auch mir ist nur der innere Anheftungspunkt dieses bei allen Sauriern und Krokodilen ausgebildeten Muskels deutlicb geworden. Er entspringt nämlich von dem vorderen Winkel, den der Gelenkfortsatz des Keilbeins mit dem Knorpelstiel des letzteren bildet, ferner in der Regel (uicht bei Varanus Bengalensis) von dem ganzen Innenrande des Knorpelstiels selbst, und endlich beständig mit einem ziemlich starken Bündel vom hinteren Rande des Vomer. Er geht von diesen Anbeftungspunkten mit queren Bündeln unter dem Bulbus nach Aussen, wird aber an der äusseren Fläche des Augapfels, den er von unten her innig umschliesst, so fein, dass es nicht möglich war, seinen äusseren Anbeftungspunkt aufzufinden. Dass er sich an den Inuenrand des Oberkieferbeins festsetze, wird aus der Bildung der Schlangen wahrscheinlicb, wo M ülle r (l. l.) einen Gaumenmuskel namhaft macht, der sich zwischen dem oberen Kieferapparat und der Basis cranii festheftet, und der, ganz wie unser Muskel, einen feinen Nerven aus der Portio motoria Trigemini bekommt. Ist dies Verhältniss dasselbe bei den Sauriern, so bat der Muskel den Zweck, den Oberkieferknochen (wegen dessen vorderen Befestigung in geringem Grade) nach innen zu biegen und ausserdem bei seiner Contraction den Angapfel nach oben zu drängen. Letzteres ist wohl die einzige Wirkung, die diesem Muskel bei den Krokodilen und Schildkröten übrig bleibt. Bei diesen hat, wie erst gesagt, Boianus, bei jenen habe ich ihn beobachtet. Boianus bezeichnet nicht näher, welcher Nerve denselben versorgt. 


\section{Vom ersten Aste des Trigeminus.}

Dieser ist immer der schwächste und in der Regel kaum halb so stark, wie jeder der beiden anderen. Gleich nach seinem Ursprunge aus seinem Ganglion theilt er sich gewöhnlich in 2 Aeste, einen R. frontalis und R. nasalis, von denen jener für die Haut der Stirngegend bestimmt ist, während dieser die Nasenschleimhaut versorgt, und ausserdem beständig einen Zweig ins Ganglion ciliare des Oculomotorius abgiebt.

Nur geringe Abweichungen finden in der Form dieses Nerven statt.

Bei Iguana tuberculata gehört, wie erst erwähnt, die vordere schwächere Hälfte des röthlichen Ganglion des Trigeminus dem ersten Aste an, der aus dem vorderen Theil desselben hervorgeht. Kaum aus der Schädelhöhle getreten, theilt er sich in seine beiden Aeste:

a) Der R. nasalis geht uach vorn, nachdem er gleich nach seinem Ursprunge seinen R. ciliaris in den vorderen Theil des Ganglion ciliare des Oculomotorius abgegeben hat, tritt, dem Patheticus dicht anliegend, über den Opticus und unter den M. obliquus superior fort nach vorn, und dringt durch den Kanal, der von den an der unteren Fläche der beiden Frontalia media befindlichen Leisten gebildet wird, in die Nasenhöhle, um sich auf der Schleimhaut derselben auszubreiten.

b) Der R. frontalis wendet sich sogleich nach oben längs der häutigen Seitenwand des Schädels, und theilt sich über dem Auge in mehrere Zweige. Einer derselben tritt unter den äusseren Rand des Os frontale medium nach innen, fast bis zur Mittellinie, wendet sich dann nach vorn und endigt in der Haut über dem vorderen inneren Theil des Bulbus. Ein anderer verbindet sich mit einem feinen Endzweige des zweiten Astes, der sich in der. Haut des oberen Augenlides ausbreitet. Auch die übrigen Endzweige verbreiten sich an der Haut der Stirn über dem Auge.

Bei Salvator Merianae hat der erste Ast keine besondere Oeffnung im Schädel, wohl aber ein eigenes längliches Ganglion, welches ausserhalb der Schädelhöhle liegt. Aus demselben gehen 3 Nerven hervor:

a) Der feinste derselben ist der Ramus ciliaris, der nach vorn und innen gehend, mit dem stärkeren $\mathbf{R}$. ciliaris des Oculomotorius zum Ganglion ciliare zusammentritt.

b) Der stärkste ist der R. nasalis, der sich ganz wie bei Iguana verhält.

c) An Stärke zwischen den beiden vorigen steht der R. frontalis. Er theilt sich bald nach seinem Ursprunge in mehrere $Z$ weige, welche hinter und innerhalb des Augapfels in die Höhe bis zur Stirnhaut hinter dem Auge aufsteigen, um in dieser sich auszubreiten. Ein Faden desselben gesellt sich zu dem R. recurrens des zweiten Astes.

Bei Salvator nigropunctatus ward von der Form der rerwandten Art keine Abweichung beobachtet. Auch bei Varanus Bengalensis dieselbe Theilung des ersten Astes in seine beiden Zweige (R. nasalis und R. frontalis) gleich nach seinem Austritt aus der ihm angehörigen, durch einen tiefen Einschnitt abgetheilten vorderen Hälfte des Ganglions. Der R. ciliaris tritt nicht gleichzeitig mit denselben aus dem letzteren aus, sondern ist, wie bei Iguana, Zweig des R. nasalis, und tritt, schwächer als der entsprechende Ast des Oculomotorius, seitwärts in die Mitte des ziemlich beträchtlichen Ganglion ciliare ein.

Ganz von derselben Form ist der erste Ast bei Lacerta ocellata.

Bei Chamaeleo, Euprepes, Platydactylus, Agama ward nur das Verhältniss des Augenastes zum Ganglion ciliare untersucht, die übrigen Verzweigungen nicht weiter verfolgt.

Die Krokodile zeigen insofern eine abweichende Bildung, als nicht alle zur Stirnhaut über dem Auge sich vertheilenden Fasern von einem einfachen R. frontalis ausgehen, sondern der erste 
Ast auch nach Absendung seines $R$. ciliaris noch wiederholt Fasern an die Stirnhaut sendet. Bei Crocodilus biporcatus trennt sich die Wurzel des ersten Astes, deren Ursprung vorher (pg. 6) dargestellt ist, unter rechtem Winkel von denjenigen des zweiten und dritten Astes, und geht nach vorn und unten, um durch ein eigenes Loch aus dem Schädel zu treten. Noch halb im Knochenkanal bildet sie ein sehr deutliches, ovales, plattes Ganglion (Taf. III, fig. 5, A), aus welchem 2 Zweige hervorgehen :

a) Der schwächere wendet sich sogleich nach aussen, schmiegt sich hinter dem M. rectus externus herum bis zum hinteren Augenwinkel, und breitet sich mit mehreren Zweigen in der Haut des unteren und oberen Augenlides aus. Von den das letztere versorgenden Nerven lassen sich einzelne Fäden bis zur Stirngegend verfolgen.

b) Der bei Weitem stärkere ist der eigentliche Hauptstamm. Er geht gerade aus nach vorn, giebt einen schwachen Zweig (Taf. III, fig. 5 c) in das benachbart liegende Ganglion ciliare (g c), tritt über den Opticus und den M. rectus internus fort, und läuft, an der Innenfläche des Augapfels dem Patheticus dicht anliegend, bis zur vorderen Ecke der Orbita. Hier tritt er unter dem M. obliquus superior fort nach vorn, und giebt mehrere Zweige nach aussen, die sich am vorderen Augenwinkel in der Haut des oberen und unteren Augenlides verbreiten, während der Hauptstamm selbst in die Nasenhöhle eindringt.

\section{Vom zweiten Aste des Trigeminus.}

Dass der zweite und dritte Ast des Trigeminus bei den Sauriern ein gemeinschaftliches Ganglion haben, das halb ausserhalb der Schädelhöhle liegt, ist erst (pg. 6) erwähnt. Bei den meisten tritt der zweite Ast aus der äusseren Spitze dieses Ganglions hervor, - nur beim Chamaeleon ward ein abweichender Austritt aus der hinteren Seite desselben erst (pg. 6) beschrieben.

Der zweite Ast ist bedeutend stärker, als der erste, aber meist um ein wenig schwächer, als der dritte. Muskeläste, wie Boianus einzelne bei Emys angiebt, werden bei den Sauriern und Krokodilen nie von ihm entsendet. Er ist dagegen beständig wichtig: 1) durch seine $Z_{w}$ eige an die Haut der Stirn und der Augenlider; 2) durch einen eigenthümlichen Drüsenast von ganz besonderer Form (an die Conjunctiva des Auges und an die Hardersche Drüse); 3) durch zwei sympathische Verbindungsschlingen, die eine an den Ramus palatinus, die andere (R. recurrens) an den hinteren Hauptstamm des Facialis selbst; 4) durch das Verhalten seiner vorderen Endigung als N. alveolaris superior, und 5) durch seine mit Gaumenästen des R. palatinus sich verbindenden Gaumenzweige.

Sein Verlauf bei den Sauriern, welcher von demjenigen der Krokodile in einigen wesentlichen Punkten abweicht, ist der Hauptform nach folgender:

Gewöhnlich tritt der Maxillaris superior ohne Zweige abzugeben durch die vordere und äussere Parthie der Kaumuskeln schräg nach vorn und aussen bis hinter das Auge, um hier Zweige für die Haut der Stirn, für das obere und untere Augenlid, und den Ramus recurrens ad Nervum facialem abzugeben, und ausserdem den erst erwähnten Drüsenast zu entsenden. Nach ihrer Abgabe durchbohrt die Fortsetzung des Nerven als eigentlicher Infraorbitalis von hinten her die äussere Parthie des M. adductor maxillae superioris, um zwischen diesem 
und dem äusseren Theil der unteren Fläche des Augapfels seinen Weg nach vorn fortzusetzen. Bei diesem Verlauf entsendet er seine hinteren Verbindungszweige an den N. palatinus (Ramus communicans posterior cum N. palatino), tritt dann wieder aus dem M. adductor maxillae superioris hervor, und wendet sich nach aussen an den Oberkieferknochen, um alsbald einen oder mehrere feine Zweige nach innen abzusenden, die mit den vorderen Verbindungszweigen des R. palatinus verschmolzen in der Mundhaut längs der Innenfläche des Zahnrandes des Oberkieferknochens sich verbreiten. Nach Abgabe dieser Zweige tritt der Maxillaris superior in den Kanal des Oberkiefers ein, und verläuft in ihm als eigentlicher Nervus alveolaris superior nach vorn bis zur Spitze des Zwischenkiefers, beständig Zweige an die Zähne und an die äussere Haut entsendend.

Dies der Verlauf bei den Sauriern. Besondere Abweichungen von dieser Form werden bei der Schilderung der einzelnen Parthieen angegeben werden. Der Maxillaris superior der Krokodile (Crocod. biporcatus) unterscheidet sich namentlich dadurch, dass der R. infraorbitalis (Taf. III. fig. $5, \lambda$ ) erst dann (in der Gegend des neunten Zahns) in den Knochenkanal eintritt, nachdem er zuvor schon einen Alveolaris posterior (fig. $5, \mu$ ) abgegeben, der in der Gegend des vierzehnten Zahns in seinen Kanal sich einsenkt, dessen letztes Ende er indessen selbst bei seinem Eintritt in den Knochen wieder aufnimmt. Dass übrigens bei den Krokodilen ein wirklicher Plexus sphenopalatinus stattfindet, der mit Zweigen des Ramus palatinus die gewöhnliche Schlinge bildet, dass auch hier ein Drüsenast, nur von etwas abweichender Form, vorhanden ist, so wie überhaupt manche andere specielle Abweichung von dem Typus der Saurier, wird bei den besonderen Formen der einzeluen Nervenzweige erwähnt werden.

a) Vom Ramus recurrens ad nervum facialem *).

Bei allen Sauriern ohne Ausnahme geht aus dem Maxillaris superior da, wo derselbe hinter dem Augapfel seine Zweige für die Haut der Stirn und der Augenlider entlässt, ein häufig durch Fäden des ersten Astes (R. frontalis) ver-

*) B endz (Bidrag til den sammenlignende. Anatomie af Nervus Glossopharyngeus, Vagus, Accessorius Willisii og Hypoglossus. Kjöbenharn 1843, pg. 5, Tab. I, 24.) entdeckte diesen Nerven zuerst bei Chelonia Mydas, wo er aus Fäden des ersten und zweiten Astes des Trigeminus gebildet wird, und nicht in den Facialis, sondern direct in den Halstheil des Sympathicus einmündet, und mit dem Ganglion petrosum in Verbindung steht. - Nach B on nsdorf (Descriptio anatomica Nervorum cerebralium Corvi Cornicis Linn. Actis Societ. Fenniae inserta. Helsingfors 1850. pg. 510) hat $\mathrm{Schlem} \mathrm{m}$ (Observatt. weurolog. Berol. 1834, pg. 18) bei Meleagris Gallopavo einen Nervus recurrens ans dem ersten Aste des Trigeminus an den Facialis zurücklaufend gesehen, von dem Stannius (Lehrbuch der vergleich. Anatomie pg. 283) ganz allgemein angiebt, dass er den Vögeln zukomme. Bonnsdorf versichert, diese Verbindung finde bei Corvus Cornix nicht statt. Der Nervus vidianus, mit welchem B. diesen Nerven vergleicht, entspringe hier aus dem zweiten Aste des Trigeminus. - Mit den Rami recurrentes bei den Fischen darf unser Nerv indessen theils wegen seines oberfächlichen Verlaufes, theils deshalb nicht verglichen werden, weil diese nach $\mathrm{S} t$ annius sich nie mit dem Glossopharyngeus, sondern stets nur mit Vagus und Hypoglossus verbindeu. 
stärkter Nerv von sehr eigenthümlicher Form hervor, der vielleicht nur den Reptilien eigen ist. Löst man nämlich vorsichtig die Knochenleiste ab, die sich bei vielen von ihnen vom Scheitelbein zum Querfortsatz des Hinterhauptsbeines erstreckt, so findet man an ihrer inneren Seite neben einem ziemlich starken Gefässstamm (Arteria temporomuscularis Boianus) einen äusserst feinen Nervenfaden, der aus dem zweiten Aste des 'Trigeminus an der genannten Theilungsstelle entsprungen, sich rückwärts über den Kopf wendet, neben jener Arterie dicht unter der Stirnhaut (oder, wie bei Lacerta, unter den dem Hautskelett angehörigen Deckknochen der Stirn) nach hinten läuft, hinter dem Querfortsatz des Hinterhauptsbeines abwärts steigt, und sich in den hinteren Hauptstamm des Facialis gewöhnlich da einsenkt, wo dieser seinen äusseren Verbindungsast zum Glossopharyngeus (R. communicans externus cum Glossopharyngeo) und die Chorda tympani entlässt. Diesen Nerven habe ich mit Bestimmtheit beobachtet bei Iguana tuberculata, Istiurus Amboinensis, Varanus Bengalensis, Salvator nigropunctatus, Salv. Merianae, Euprepes Sebae, Lacerta ocellata, Chamaeleo vulgaris, Platydactylus guttatus. Auch bei den Krokodilen ist er als viel stärkerer Nerv vorhanden, entspringt hier aber schon aus dem Ganglion des Trigeminus selbst, um nicht, wie bei den Eidechsen, in einem grossen Bogen über den Kopf nach hinten zu laufen, sondern um, dem Schädel nahe anliegend, in dem vorderen Theil der äusseren Gehörkapsel nach hinten zu gehen, und dort, gerade wie bei den Eidechsen, mit dem hinteren Hauptstamm des Facialis zu verschmelzen. (Taf. III, fig. 5, x.)

Die speciellen Formen dieses Nerven sind folgende:

Bei Varanus Bengalensis theilt sich der Maxillaris superior hinter und unter dem Auge in 3 Aeste : der stärkste ist der eigentliche Infraorbitalis; der zweite, viel schwächere, ist ein Nerv, der bald nach seinem Ursprung in den Drüsenzweig und die Augenlideräste sich theilt. Der dritte, schwächste endlich entlässt mehrere feine, in der Stirnhaut hinter dem Auge sich verbreitende Fäden und ausserdem unsern R. recurrens zum Facialis. Dieser läuft wie gewöhnlich als äusserst feiner Nervenfaden an der inneren Seite der vom Scheitelbein zum Querfortsatz des Hinterhauptsbeins sich erstreckenden Knochenleiste nach hinten, tritt an der Grenze zwischen Quadratbein und Querfortsatz nach unten, und senkt sich in den hinteren Hauptstamm des Facialis ein.

Bei Iguana tuberculata giebt ebenfalls der Maxillaris superior hinter dem Augapfel 2 Nerven ab, von denen der eine die für die Haut der Augenlider, die Conjunctiva und die Hardersche Drüse bestimmten Fäden enthält, während der zweite, für die Haut der Stirn bestimmte, unsern R. recurrens abgiebt. Dieser tritt ober- und ausserhalb der Kaumuskeln in Begleitung der Arteria temporomuscularis nach hinten unter dem Os frontale posterius fort, da wo dieser Knochen sich mit dem $O$ s quadrato-jugale verbindet, tritt dann mit dem genannten Gefäss unter die Knochenleiste, die vom Scheitelbein sich schräg nach hinten und aussen bis zum Querfortsatz des Occipitale laterale erstreckt, läuft dann unter dieser Leiste nach hinten, und tritt hinter dem Querfortsatz nach unten, um in den Theil des Facialis einzumünden, der die Chorda tympani, den Muskelzweig und den äusseren Verbindungsast zum Glossopharyngeus abgiebt. (Taf. II. fig. 3, x.) 
Bei Istiurus Amboinensis entlässt der Maxillaris superior 3 Nerven. Der erste und dritte sind für die Haut der beiden Augenlider bestimmt. Der mittlere giebt einzelne Fäden an die Stirnhaut ab, und wendet sich dann auf demselben Wege, wie bei den übrigen Eidechsen, als R. recurrens rückwärts, und verschmilat hinter dem Kopfe mit dem hinteren Hauptstamm des Facialis, da, wo dieser sich in seine Endäste theilt. (Taf. III. fig. 1, x.)

Bei Salvator Merianae tritt der zweite Ast des Trigeminus ebenfalls durch die Kaumuskeln hindurch schräg nach vorn und aussen. Hinter dem Augapfel giebt er den R. recurrens ab, um erst etwas später den Drüsenzweig und die Aeste für die Augenlider zu entlassen. Der R. recurrens enthält hier die für die Stirnhaut bestimmten Fasern, nach deren Abgabe er wie gewöhnlich, an der Innenseite der besprochenen Knochenleiste in Begleitung der Arteria temporomuscularis nach hinten läuft, um sich endlich mit dem Facialis zu verbinden.

Salvator nigropunctatus wiederholt ganz die Form von Salv. Merianae.

Von den übrigen Eidechsen weicht Euprepes Sebae, nur dadurch ab, dass unser Nerv nicht in den hinteren Hauptstamm des Facialis vor dessen Theilung in seine Endäste, sondern in den vorderen der Chorda tympani analogen $Z$ weig desselben einmündet. Gerade an seiner Einsenkungsstelle in denselben steht dieser jedoch durch eine schmale Nervenbrücke mit der andern, den sympathischen Verbindungszweig zum Glossopharyngeus entsendenden Hälfte (Muskelast) des hinteren Hauptstammes des Facialis in Verbindung.

Bei Chamaeleo vulgaris entspringt der R. recurrens ganz wie bei den übrigen Sauriern, läuft aber nicht hart unter der erwähnten Knochenleiste, sondern höher und weiter einwärts mitten durch die hintere Parthie der starken Kaumuskeln zwischen der mittleren, nach hinten verlängerten und der äusseren Schädelleiste (immer in Begleitung der Arteria temporomuscularis) und senkt sich nahe der Theilungsstelle des hinteren Hauptstammes des Facialis in denselben ein.

Auch bei den Krokodilen existirt ein Verbindungsnerv vom Trigeminus an den hinteren Hauptstamm des siebenten Paares. Derselbe gehört hier (Crocodilus biporcatus Taf. III. fig. 5, $x$ ) aber nicht zu den peripherischen Endigungen des zweiten Astes, sondern geht schon aus dem gemeinschaftlichen Ganglion des zweiten und dritten Astes hervor, läuft deshalb auch nicht über den Kopf nach hinten, sondern tritt dicht vor der knöchernen Gehörkapsel schräg nech aussen und hinten, und trifft mit dem ebenfalls fast dieselbe Richtung verfolgenden hinteren Hauptstamm des Facialis unter spitzem Winkel zusammen. Aus dieser Vereinigung gehen zwei Nerven hervor: der hintere Hauptstamm des Facialis selbst, und der Ramus communicans externus nervi Facialis cum Glossopharyngeo. Von beiden wird später die Rede sein.

b) Von den Zweigen an die Stirnhaut.

Mit dem eben beschriebenen $R$. recurrens zugleich gehen hinter dem Augapfel aus dem zweiten Aste des Trigeminus einzelne Fäden hervor, die hinter dem Bulbus in die Höhe steigen, und sich in der Haut der Stirn ausbreiten. Diese Fäden sind von besonderer Feinheit, - vielleicht ist das der Grund, weshalb ich sie nur bei den grösseren der mir zu Gebote stehenden Formen mit Deutlichkeit sah.

Bei Varanus Bengalensis entspringen sie in der eben angegebenen Weise mit dem $\mathbf{R}$. recurrens zugleich als getrennte Fäden. Ebenso gehen auch bei Iguana tuberculata zugleich mit dem R. recurrens Fäden aus dem zweiten Aste des Trigeminus hervor, die sich zugleich mit Zweigen vom R. frontalis des ersten Astes in der Haut der Stirn ausbreiten (pag. 8). Aehnliche Zweige wurden endlich noch bei Salvator Merianae und Salv. nigropunctatus beobachtet. 


\section{c) Von den Zweigen fïr die Haut der Augenlider.}

Derselbe Punkt, wo mit dem R. recurrens die eben erwähnten Zweige für die Stirnhaut aus dem Maxillaris superior entspringen, ist, anscheinend beständig, auch die Ursprungsstelle mehrerer feiner Nerven für das obere und untere Augenlid.

Ihr Abgang und ibre Form ist bei denjenigen Eidechsen, von denen mir grössere Exemplare zu Gebote standen, folgende:

Bei Varanus Bengalensis, wo, wie erst erwähnt, der Maxillaris superior sich hinter dem Auge in 3 Aeste theilt, ist es der zweite, der diese Augenlidernerven entlässt. (Der erste dieser drei Nerven ist, wie erwähnt, der eigentliche Infraorbitalis, der dritte entsendet den $R$. recurrens und die Stirnnerven.) Derselbe theilt sich da, wo der Maxillaris superior unter den Augapfel tritt, in zwei Zweige, deren schwächerer der gleich zu beschreibende Drüsenast ist. Der stärkere dagegen tritt unter die Haut hinter dem Ange, um sich sogleich wieder in mehrere Zweige zu theilen. Von diesen tritt einer unter die Haut des oberen Augenlides, und lässt sich unter derselben bis zum vorderen Winkel des Auges verfolgen; ein anderer läuft unter der Haut des unteren Augenlides nach vorn, gerade zwischen der Haut und dem den vorderen Theil der Augenhöhle von unten her begrenzenden Theil des Oberkiefers; ein dritter endlich, etwas stärker als dieser, läuft, dem Bulbus dicht anliegend, mehr nach innen zu, ebenfalls beständig Zweige in die Haut des unteren Augenlides sendend.

Bei Iguana tuberculata tritt wie immer der Maxillaris superior nach vorn und aussen zwischen den Kaumuskeln hindurch bis zum hinteren Augenwinkel. Auf diesem Wege giebt er zwei Aeste, $a$ und $b$ ab.

a) tritt hinter dem Auge an der vorderen Grenze der Kaumuskelmasse nach oben. Am oberen Augenlid angelangt entsendet er den vorhin abgehandelten $R$. recurrens, und verbindet sich alsdann mit einem von innen und unten längs der häutigen Seitenwand des Hirnschädels aufsteigenden Endzweige des R. frontalis vom ersten Aste. Aus dieser Verbindung gehen zwei feine Nerven hervor:

$\alpha$ geht unter dem oberen Augenlide bis zum vorderen Augenwinkel und löst sich mit zahlreichen Fäden in der Haut desselben auf;

$\beta$ geht ebenfalls unter dem oberen Augenlide nach vorn, aber etwas weiter nach innen $\mathrm{zu}$, um ebenso wie $\alpha$ in der Haut desselben sich zu verzweigen.

b) tritt hinter das untere Augenlid und theilt sich in zwei Aeste:

$\alpha$ läuft unter dem vorderen Augenlide nach vorn, und giebt zahlreiche Fäden in die Haut desselben $a b$, um selbst in dessen vorderen Winkel zu endigen;

$\beta$ ist der gleich zu beschreibende Drüsenzweig.

Bei Salvator nigropunctatus (Taf. I, fig. 1, $\beta$ ) und Istiurus Amboinensis wurden ebenfalls mit Deutlichkeit Zweige beobachtet, die am hinteren Augenwinkel aus dem zweiten Aste des Trigeminus hervorgehend, die beiden Augenlider und die den Oberkieferknochen bedeckende Haut mit Nerven versorgen.

\section{d) Vom Drïsenzweig des zweiten Astes.}

So möchte ich einen sehr beständigen, aber äusserst feinen Nerven nennen (dargestellt Taf. I, fig. 1, $\gamma$ ), der, wenigstens zuweilen, eine deutlich gangliöse Natur hat, und immer die Conjunctiva und die Hardersche Drüse mit Fäden versorgt. Derselbe steht mit den Verbindungszweigen zum Ramus palatinus paris septimi (mit dem Plexus sphenopalatinus) durchaus in keiner weiteren Verbindung, als dass er ebenfalls aus dem zweiten Aste des Trigeminus 
entspringt, und ist eben wegen seiner Aehnlichkeit mit der Form von Nervenzweigen, die man einem selbstständigen sympathischen System zuzuschreiben gewohnt ist, bei seinem Mangel an allen Verbindungsfäden zum sympathischen Kopftheil, höchst merkwürdig.

Die speciellen Formen dieses Nerven sind folgende:

Sein Ursprung aus dem zweiten Aste bei Varanus Bengalensis ist vorhin (bei Gelegenheit des R. recurrens und der Augenliderzweige) angegeben. Er tritt hier mit dem Infraorbitalis unter den Bulbus, durchbohrt mit demselben den M. adductor maxillae superioris, und läuft zwischen diesem und dem Augapfel an der Aussenseite des zweiten Astes des Trigeminus, dem letzteren sehr nahe, nach vorn. Auf seinem ganzen Verlauf empfängt er beständig zahlreiche feine Fäden aus dem benachbarten Infraorbitalis und bildet mit denselben kleine Geflechte, aus denen feine nach aussen gehende Zweige entspringen, welche an der Conjunctiva sich zu verbreiten scheinen. Der durch diese austretenden Fäden entstehende Verlust wird immer wieder durch neue Fäden aus dem Maxillaris superior ersetzt. An dem vorderen Theil des Bulbus, da wo der zweite Ast des Trigeminus sich nach aussen wendet, um in seinen Kanal einzutreten, tritt unser Nerv nach innen über den Maxillaris superior fort, und theilt sich in mehrere Zweige. Von diesen wendet sich einer nach innen, und geht in die Hardersche Drüse. Ein anderer Endfaden schlingt sich vorn um den Augapfel nach oben und endigt an der vorderen Oberfläche desselben in der Bindehaut.

Auch von Iguana tuberculata ward vorhin der Ursprung dieses Nerven schon nähér bezeichnet. Er verbindet sich mit einem feinen Faden des für die Augenlider bestimmten Nerven, und geht wie bei Varanus neben und aussen vom Maxillaris superior unter dem äusseren Theil des Augapfels nach vorn. Auch hier giebt er auf diesem Wege zahlreiche Fäden ab, die sich geflechtartig unter einander verbinden und in die Bindehaut des Auges gehen. (Ganglienartige Anschwellungen, wie bei Salvator, wurden eben so wenig wie bei Varanus bemerkt.) Dieser Abgang von Nervenfäden wird auch hier beständig wieder ersetzt durch zahlreiche auf seinem ganzen Wege in ihn eintretende Fäden des benachbarten Infraorbitalis. Ob der Nerv hier in der Harderschen Drüse endigt, wie bei Varanus, liess sich nicht ermitteln.

Nachdem der Maxillaris superior bei Salvator Merianae kaum unter den Augapfel getreten ist, giebt er den Drüsenzweig ab, der als äusserst feiner Nerv etwas ausserhałb vom Infraorbitalis und mit diesem parallel nach vorn verläuft. Er ist hier besonders ausgezeichnet durch seine gangliöse Natur, indem er aus einer grossen Zahl zwar äusserst kleiner, aber schon durch eine starke Loupe wahrnehmbarer Ganglien besteht, welche von hinten nach vorn einander in grader Linie folgend, durch feine Fäden mit einander verbunden sind, und sich fast wie eine Schnur Perlen ausnehmen. In jedes dieser Ganglien treten Fäden aus dem naheliegenden Infraorbitalis ein, aus jedem derselben treten andere, wie es scheint, an die Conjunctiva, aus. Unter dem vorderen Drittheil des Augapfels angelangt, empfängt dieser gangliöse Nerv einen stärkeren Verbindungszweig vom zweiten Aste des Trigeminus, und legt sich dann hart unter die Hardersche Drüse, um ihr verhältnissmässig beträchtliche Nervenfasern zu geben. Er selbst schmiegt sich vorn um den Augapfel in die Höhe und scheint in der Conjunctiva zu endigen.

Eben so deutlich ist dieser Drüsenzweig bei Salvator nigropunctatus (Taf. I, fig. 1, $\gamma$ ), der ganz die Form von Salv. Merianae wiederholt, nur dass keine Ganglien ip der Bahn desselben beobachtet wurden. Uebrigens dieselbe Abgabe von Zweigen an die Conjunctiva, dieselbe Aufnahme neuer Fäden (vgl. die rechte Seite der Abbildung) aus dem Infraorbitalis ( $\lambda$ ).

Auch bei den Krokodilen habe ich diesen Nerven, wenn auch in etwas anderer Form, wiedergefunden. Bei Crocodilus biporcatus tritt der zweite Ast des Trigeminus (Taf, III, fig. 5, n) von hinten und innen nach vorn und aussen bis hinter den Augapfel, tritt hier ïber die hinterste 
dickste Schicht des M. adductor maxillae superioris, und giebt, über derselben liegend, einen starken Zweig, den später zu beschreibenden Alveolaris posterior $(\mu)$, ab. Gleich nach seiner Abgabe entsendet er einen sehr feinen Nerven (Taf. III, fig. 5, $\gamma$ ), der mit ihm selbst parallel, und sogar in der Mitte des Bulbus wieder auf eine kurze Strecke mit ihm verschmelzend, nach vorn verläuft. Er löst sich im vorderen Theile der Orbita in mehrere feine Fäden auf, die sich geflechtartig auf der Conjunctiva ausbreiten. Einer derselben lässt sich eine Strecke nach vorn und oben um den Augapfel herum verfolgen. - Es fehlen hier also die bei den Eidechsen schon während seines ganzen Verlaufes aus dem Drüsenzweig austretenden Nervenfäden für die Conjunctiva, und statt der Ersatzfäden, die derselbe dort beständig aus dem Infraorbitalis erhält, findet bald nach seinem Austritt wieder eine Verschmelzung mit dem letzteren statt, bei welcher Gelegenheit vielleicht eine Aufnahme neuer Fäden erfolgt.

e) Von den Verbindungszweigen des zweiten Astes des Trigeminus zum N. palatinus.

(Dargestellt Taf. I, fig. 1, $\delta, \delta^{\prime}$. )

Es ward bei Gelegenheit der eben beschriebenen Zweige des Maxillaris superior wiederholt erwähnt, dass der letztere bei allen Sauriern und Krokodilen von hinten nach vorn tretend bald nach ihrer Entsendung den M. adductor maxillae superioris (Taf. I, fig. 1, K) durchbohrt, um zwischen diesem und dem darüber liegenden Augapfel nach vorn zu verlaufen. Erst in dem vorderen Theil der Augenhöhle tritt er wieder aus diesem Muskel heraus, nun bald den Charakter eines $\mathbf{N}$. alveolaris superior annehmend.

Auf diesem Wege gehen beständig nicht ganz unbeträchtlicheNervenzweige aus ihm hervor (sie sind immer viel stärker, als der Drüsenzweig, der R. recurrens und die Augenliderzweige), die nach innen und unten tretend, den $M$. adductor maxillae superioris durchbohren, um entweder direct zu eigenthümlichen Schlingen mit dem R. palatinus zusammen zu treten, oder mit Zweigen des letzteren einen kurzen Nervenstamm zu bilden, der, sowie jene Schlingen, mit dem Plexus sphenopalatinus verglichen werden muss. Der Antheil des R.palatinus an diesen Schlingen wird bei Gelegenheit des Facialis besprochen werden, sowie auch einer späteren Erörterung vorbehalten bleiben muss, welche aus dem R. palatinus austretenden Nervenzüge diesen aus dem Trigeminus in denselben übergehenden Nervenfasern entsprechen. Hier möge nur die Bemerkung Stelle finden, dass nur der R. communicans posterior nervi palatini cum nervo maxillari superiore an diesem Analogon des Sphenoidalgeflechtes Antheil nimmt.

Bei Iguana tuberculata treten bei dem eben erwähnten Verlaufe des Infraorbitalis nach einander drei stärkere Zweige aus ihm hervor, die den $M$. adductor maxillae superioris durchbohren, um sich mit Zweigen des R. palatinus in einer später zu erörternden Weise zu verbinden.

Auch bei Salvator Merianae verfolgt der Infraorbitalis nach Abgabe seines Drüsenzweiges den Weg zwischen Bulbus und M. adductor maxillae superioris nach vorn, und giebt nach einander drei nicht unbeträchtliche Nerven $a b$, welche den genannten Muskel nach unten zu durchbohren, um sich nach einander mit Zweigen des R. palatinus des Facialis zu einem kurzen Stamme zu verbinden. Ueber Letzteren vergl. die Beschreibung des R. palatinus. 
Bei Salvator nigropunctatus schickt der zweite Ast des Trigeminus (Taf. I, fig. 1, n, $\lambda$ ), denselben Weg, wie bei den übrigen Eidechsen verfolgend, nach Abgabe des Drüsenastes $(\gamma)$ einen ziemlich starken Ast (fig. 1, $\delta$ ) nach innen, der in zwei Zweige ( $\delta^{\prime}$ und $\left.\delta^{\prime}\right)$ gespalten, an zwei verschiedenen Punkten den $M$. adductor maxillae superioris durchbohrt, um unterhalb dieses Muskels, dem Os pterygoideum aufliegend, mit zwei Aesten ( $g$ und $g$ ) des R. palatinus (p) zu einem kurzen, unter der Mitte des Bulbus liegenden, feinen Nervenstamm $(\varepsilon)$ sich zu verbinden; aus dessen vorderem Theil gehen zwei Zweige hervor, von denen einer ((') wieder an den $\mathbf{R}$. palatinus sich anlegt, um mit ihm zu verschmelzen, während der andere (३) nach aussen läuft, den M. adductor maxillae superioris durchbohrend nach oben tritt, und sich wieder an den Infraorbitalis anlegt, mit dem er eine kurze Strecke parallel nach vorn geht, und dann unter sehr spitzem Winkel mit ihm verschmilzt. Zweige an die Gaumenhaut, die aus diesem gemischten Nervenstamm des Facialis und Trigeminus hervorgingen, wurden nicht beobachtet.

Bei Varanus Bengalensis entlässt an derselben Stelle, wie bei den übrigen Eidechsen, der Maxillaris superior einen ziemlich starken Nervenzweig, der den M. adductor maxillae superioris durchbohrend nach innen tritt, um mit dem Ramus communicans posterior nervi palatini cum maxillari superiore zn einer Schlinge zu verschmelzen. Es wird hier also nicht, wie bei Iguana und Salvator ein kurzer, aus $Z$ weigen des Trigeminus und des $\mathbf{R}$. palatinus gebildeter Nervenstamm zusammengesetzt, sondern das ganze Sphenoidalgeflecht ist auf eine einfache Schlinge reducirt. Ueber den Antheil des Facialis an dieser Schlinge vgl. die Beschreibung des R. palatinus.

Viel stärker ausgebildet ist das Sphenoidalgeflecht bei den Krokodilen. Bei Crocodilus biporcatus giebt, wie schon erst erwähnt, der Infraorbitalis, nachdem er über den M. adductor maxillae superioris getreten, einen starken Nervenzweig nach aussen ab (Taf. HI, fig. $5, \mu$ ), den R. alveolaris posterior, während er selbst erst viel später den Charakter eines Alveolaris anterior annimmt. Jener, der R. alveolaris posterior, giebt bald nach seinem Ursprunge $2-3$ deutliche starke $Z$ weige nach aussen ab (fig. $5, \delta, \delta^{\prime}$ ), zu denen sich noch ein fünfter $(\varepsilon)$, vom Infraorbitalis selbst herrührender, gesellt. Alle diese Zweige vereinen sich in der äusseren Ecke der Orbita, dem OberKieferknochen dicht anliegend, zu einem sehr ausgebildeten, netzartigen Geflecht (pl.) mit kleinen viereckigen Maschen. Aus diesem Geflecht, das in ähnlicher Ausbildung bei keiner Eidechse gefunden wurde, gehen nach allen Seiten Nerven von ziemlicher Stärke hervor. Einige schlagen sich nach aussen, zwischen Haut und Oberkieferknochen in die Höhe, und breiten sich in der Haut der Wangengegend aus. Andere laufen zurück bis zum Mundwinkel, um hier zu endigen. Noch andere (zwei bis drei, fig. $5, \zeta$ ) biegen nach innen um, laufen quer unter dem Augapfel an den R. palatinus des siebenten Paares heran, um mit einem Zweige desselben (fig. 5, g) eine Schlinge zu bilden, aus welcher keine $Z$ weige hervorgehen.

\section{f) Von den Gaumenhautzweigen. (Dargestellt Taf. I, fig. 1,9.)}

Nach Abgabe der eben abgehandelten Verbindungszweige mit dem Ramus communicans posterior nervi palatini cum maxillari superiore verfolgt der Infraorbitalis seinen Weg unter dem Augapfel, zwischen diesem und dem von unten her denselben überziehenden $M$, adductor maxillae superiolis nach vorn verlaufend. Fast an der Vorderfläche des Bulbus angelangt, durchbohrt er zum zweiten Male diesen Muskel, um wieder aus demselben hervor-, und an den Oberkieferknochen heranzutreten. Dieser Verlauf ist sänmtlichen untersuchten Eidechsen und Krokodilen eigen. 
Vor dem Eintritt in den Canalis alveolaris superior, und demselben schon sehr nahe, entlässt er sehr beständig einen feinen Ast nach innen, der mit dem Ramus communicans anterior nervi palatini cum maxillari superiore $\left(\vartheta^{\prime}\right)$ zu einer Schlinge zusammentritt (Taf. I, fig. 1,ף). Aus dieser Schlinge geht immer ein Nerv hervor $\left(\vartheta^{\prime \prime}\right)$, der längs der Innenfläche des Zahnrandes des Ober- und später des Zwischenkiefers zwischen Knochen und innerer Mundhaut nach vorn läuft, und in der letzteren mit zahlreichen $\mathrm{Z}$ weigen sich ausbreitet.

Die besonderen Verhältnisse dieses aus Fasern des Trigeminus und Facialis gebildeten Gaumennerveu werden bei Gelegenheit des R. palatinus erörtert werden. Sie wurden genau ermittelt bei Varanus Bengalensis, Iguana tuberculata, Salvator Merianae und Salvator nigropunctatus. Ueber Crocodilus biporcatus vergl. Taf. III, fig. 5. Hier ist 9 der in Rede stehende Zweig des Trigeminus, 9 ' der R. communicans anterior nervi palatini, $9 "$ der aus ihrer Verbindung hervorgehende Zweig für die innere Mundhaut.

\section{g) Von dem Zweig für die Haut des Oberkiefers. (Dargestellt Taf. I, fig. 1, भ.)}

In der Regel, vielleicht beständig, wird vom Maxillaris superior zugleich mit dem vorigen Nerven auch nach aussen ein feiner $Z_{w e i g}$ abgesandt, der längs der Aussenfläche des Zahnrandes des Oberkieferknochens, zwischen diesem und der ihn von aussen bekleidenden Haut, eine kurze Strecke nach vorn läuft, und sich in der letzteren ausbreitet. Bei allen grösseren Eidechsen und bei den Krokodilen ward dieser $\mathbf{Z}$ weig beobachtet, vielleicht also, dass er bei den kleineren Formen nur wegen seiner Feinheit nicht aufgefunden wurde.

\section{h) Vom Nervus alveolaris superior. (Taf. I, fig. 1, $\mu$.)}

Die letzte Endigung des zweiten Astes des Trigeminus ist constant dieselbe. Nachdem er als N. infraorbitalis ('Taf. I, fig. 1, $\lambda$ ) unter dem Augapfel nach vorn getreten ist, hier wieder den M. adductor maxillae superioris (K) durchbohrt, und sowohl den Zweig für die Haut des Oberkiefers, als den mit Endzweigen des R. palatinus sich verbindenden Ast für die innere Mundhaut abgegeben hat, nähert er sich von innen her dem Oberkieferknochen, tritt in den Canalis alveolaris desselben ein, und verläuft nach vorn bis zur Spitze des Zwischenkiefers. Auf diesem ganzen Wege gehen zweierlei Zweige aus ihm hervor: 1) Rami dentales, bei den Sauriern ausserordentlich fein, stärker bei den Krokodilen (Taf. III, fig. 5, d), von oben her an die Wurzel jedes Zahns herantretend; 2) Rami cutanei, bei den Krokodilen feiner, bei den Sauriern viel stärker als jene, in kleinen Absätzen durch feine Löcher des Knochens nach aussen tretend, und sich in der den Oberkiefer bekleidenden Haut ausbreitend.

Dies die Form des Nerven bei allen untersuchten Eidechsen. Wesentlich von ihr verschieden ist, wie schon oben bemerkt, diejenige der Krokodile. Hier (Crocodilus biporcatus) existirt nämlich ausser dem als $N$. alveolaris anterior endigenden Hauptstamm des Infraorbitalis (Taf. III, $\lambda, \mu^{\prime}$ ) noch ein R. alveolaris posterior $(\mu)$ von ansehnlicher Stärke. Dieser wird schon nach aussen 
abgegeben, sobald der Infraorbitalis den M. adductor maxillae superioris durchbohrt hat, um unter dem Augapfel nach vorn zu verlaufen. Dieser Alveolaris posterior entlässt, wie oben bemerkt, die meisten der das Sphenoidalgeflecht bildenden Zweige $\left(\delta, \delta^{\prime}\right)$, läuft dann nach aussen, um in der Gegend des vierzehnten Zahns in den für ihu bestimmten Kanal des Oberkiefers einzutreten. (Die eigentliche Fortsetzung des Infraorbitalis tritt als N. alveolaris anterior erst in der Gegend des neunten Zahns in den Oberkieferkanal ein.) Bei seinem Eintritt in denselben entlässt der $\mathbf{R}$. alveolaris posterior zuerst einen Zweig nach hinten, um auch die hinteren Zähne mit Zweigen zu versorgen, und läuft dann im Knochen bis zum zehnten Zahn nach vorn, in jeden der auf seinem Wege liegenden Zähne einen sehr starken Zweig entsendend (d). Durch diesen Abgang bedeutender Aeste wird seine Stärke rasch so verringert, dass in der Gegend des neunten Zahns nur ein sehr schwacher Rest desselben sich mit dem nun in den Kanal eintretenden und seine Stelle einnehmenden Alveolaris anterior $\left(\mu^{\prime}\right)$ verbinden kann. Der neunte Zahn wird noch vom Alveolaris posterior versorgt. - Der Alveolaris anterior, die Fortsetzung des eigentlichen Infraorbitalis, nimmt bei seinem Eintritt in den Kanal das letzte Ende des Alveolaris posterior auf, und läuft, wie erst bemerkt, im Knochen bis zur Spitze des Zwischenkiefers nach vorn, ebenfalls an die Wurzel jedes auf seinem Wege liegenden Zahns einen starken Zweig, und ausserdem schwächere Aeste an die den Oberkiefer bedeckende Haut abgebend.

\section{Vom dritten Aste des Trigeminus.}

Ueber den Ursprung des dritten Astes zugleich mit dem zweiten Aste aus dem Ganglion Gasseri ist oben (pag. 6 und 7) gehandelt worden. Nur bei den Krokodilen glückte es, den Uebergang der Portio minor der Trigeminus-Wurzel in diesen dritten Ast zu verfolgen. An Stärke übertrifft dieser beständig alle übrigen Hirnnerven mit Ausnahme des Opticus. Namentlich bei den Krokodilen, auch bei ganz kleinen Exemplaren, ist er von bedeutender Dicke, so wie auch seine Aeste zwar wegen der benachbarten Lage der von ihnen versorgten Organe die kürzesten, zugleich aber auch die stärksten sind.

Vor der Schilderung seines Verlaufes im Allgemeinen muss nochmals hingewiesen werden auf den schon früher (pag. 7) abgehandelten Nerven für den M. adductor maxillae superioris, der bei den Krokodilen (und Schlangen nach Müller) deutlich aus der Portio motoria entspringt, bei den Sauriern bald aus dem Ganglion, bald aus dem dritten Aste hervorgeht. - Ein zweiter Nerv, von gleicher Feinheit wie der vorige, der aber den Eidechsen völlig zu fehlen scheint, ward bei Crocodilus biporcatus aus der Portio minor ausgehend gefunden (Taf. III, fig. 5, r). Dieser wendet sich, noch bevor der ganze dritte Ast über das Ganglion hinausgekommen ist, auf dem unteren Boden der Orbita über der Gaumenhaut nach vorn, läuft bis zum vorderen Rande der vom Oberkiefer, vom Gaumenbein (Os palatinum Cuv.) und vom Os pterygoideum externum Cuv. begrenzten Grube, um hier mit vielen feinen Zweigen in der unteren und inneren Parthie des M. pterygoideus zu endigen, der mit seinen von vorn nach hinten sich erstreckenden Fasern die erwähnte Grube von unten her ganz begrenzt. 
Bei den Eidechsen erstrecken sich die Fasern des genannten Muskels nicht so weit nach vorn, - dies der einfache Grund, weshalb auch der diesen Theil desselben versorgende Nerv minder ausgebildet, vielleicht nicht vorhanden ist.

Der dritte Ast des Trigeminus hat, obgleich mit dem zweiten, wie erst erwähnt, aus einem gemeinschaftlichen Ganglion entspringend, doch bisweilen eine besondere Oeffnung im Schädel, in dem Falle nämlich, wenn das Ganglion nicht theilweise aus dem Knochen hervorragt. Dann liegt die Oeffnung für den dritten Ast etwas hinter und unter derjenigen für den zweiten Ast, allseitig vom Felsenbein begrenzt. Dies ist z. B. der Fall bei Istiurus Amboinensis. In den meisten Fällen ist, wie oben angegeben, beiden Aesten eine Oeffnung gemeinschaftlich. -

Von seinem Austritte an ist er sogleich schräg nach aussen und unten gerichtet, vor dem Quadratbein abwärts bis zum Unterkieferknochen verlaufend, Auf diesem Wege entsendet er einen Zweig nach vorn und aussen an die Haut der Wangengegend, bisweilen auch an den M. levator anguli oris, und seine Kaumuskelzweige. Am Unterkiefer angelangt, tritt er in den Canalis alveolaris inferios ein, um selbst als N. alveolaris inferior nach vorn zu verlaufen. Auf diesem Wege verbindet er sich mit einem Zweige vom hinteren Hauptstamm des Facialis, der Chorda tympani, entsendet zahlreiche Zweige aus dem Knochen nach aussen an die den Unterkiefer bedeckende Haut, und schickt endlich regelmässig einen nicht unbeträchtlichen Ast nach innen, der sich theils in der Haut des Unterkiefers, theils im M. mylohyoideus, theils endlich (als Ramus lingualis) zugleich mit Endzweigen des Hypoglossus in der Zunge verbreitet.

a) Vom Zweig für die Haut der Wange und den M. levator anguli oris.

Gewöhnlich unmittelbar nach seinem Austritt aus dem Schädel entsendet der dritte Ast des Trigeminus einen Nervenzweig, den man den R. subcutaneus malae nennen könnte, wenn nicht dieser Name beim Menschen zur Bezeichnung eines bekannten Hautzweiges des zweiten Astes diente. Auch dieser Nerv der Saurier scheint bei oberflächlicher Betrachtung aus dem zweiten Aste zu stammen, da ex demselben an seiner unteren Seite dicht anliegt, und ganz dieselbe Richtung: verfolgt, wie jener. Verfolgt man seinen Weg aber in centripetaler Richtung, so hält es nicht schwer, sich von seinem Ursprunge aus dem Anfange des dritten Astes zu überzeugen *).

Schon gleich nach seinem Ursprunge legt sich dieser Nerv dicht an die untere Seite des zweiten Astes an, und tritt mit demselben durch die vordere

) Auch Vog t heschreibt bei Python einen feinen Ast des Ramus tertius, der parallel dem ersten Zweige des Ramus secundus nach vorn und aussen läuft, und sich in der äusseren Hant des Mundwinkels, zum Theil auch in der Mundschleimhaut in der Ecke des Mundes veribeilt. Mii 11 ers Arch. 1839 , pg. 46 . 
und äussere Parthie der Kaumuskeln hindurch schräg nach vorn und aussen, wendet sich, an der Haut über dem Mundwinkel angelangt, um die vordere Grenze der Kaumuskeln herum nach aussen und eine kurze Strecke nach hinten, und breitet sich in der Haut über und hinter dem Mundwinkel aus. Von dieser Form ward der Nerv gefunden bei Lacerta ocellata, Varanus Bengalensis, Iguana tuberculata. Bei Salvator Merianae und Salvator nigropunctatus dringen seine Fasern nur theilweise in die Haut des Mundwinkels ein: seine hauptsächliche Verbreitung erfolgt hier in dem ausnahmsweise bei Salvator vorhandenen M. levator anguli oris (vom äusseren Rande des Os frontale posterius schräg nach unten und vorn an die Haut des Mundwinkels). -

b) Nerven für die Hebemuskeln des Unterkiefers.

Ausser dem eben erwähnten Nerven, der nur bisweilen an Muskeln sich verbreitet, gehen beständig noch drei Muskelnerven aus dem Stamme des dritten Astes hervor:

a) an die hinteren Hebemuskeln des Unterkiefers,

b) an die äusseren Hebemuskeln

und etwas später, als $a$ und $b$ tritt von der inneren Seite des Stammes ein Nerv hervor

c) der, stärker, als die beiden vorigen, die inneren Hebemuskeln des Unterkiefers (Mm. pterygoidei) mit Zweigen versorgt.

Bei allen darauf untersuchten Sauriern wurden diese Nerven in der angegebenen Form gefunden.

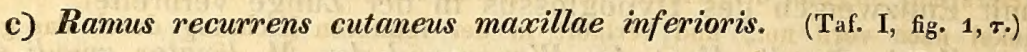

Bei allen Sauriern und Krokodilen tritt der dritte Ast des Trigeminus nach Entsendung aller Muskelzweige nach aussen und unten an den Oberkieferknochen heran. Bevor er in seinen Kanal tritt, entspringt aus ihm ein Nerv von sehr eigenthümlicher Form. Während der Stamm selbst nämlich nach vorn umbiegt, wendet sich dieser, an seiner hinteren Seite entspringend, nach hinten, und tritt vor dem Gelenk des Quadratbeins in einen eigenen Kanal des Unterkiefers ein, um in demselben, unter diesem Gelenk durch, nach hinten zu verlaufen.

Gefunden habe ich diesen Nerven bei allen darauf untersuchten Formen, nämlich: Iguana tuberculata, Istiurus Amboinensis, Varanus Bengalensis und Niloticus, Lacerta ocellata, Euprepes Sebae, Chamaeleo vulgaris, Crocodilus acutus, Crocodilus biporcatus und Alligator punctulatus. Seine Stärke ist indessen so gering, und der Knochen an dieser Stelle so fest, dass es mir nur bei einer Eidechse (Salvutor nigropunctatus), und bei den Krokodilen gelang, seine Endigung in der den Unterkiefer bedeckenden Haut zu ermitteln.

Bei Salvator nigropunctatus tritt unser Nerv, wie überall, vor dem Gelenk des Quadratbeines in einen eigenen Kanal des Unterkiefers, der sich nahe der Aussenfläche des Knochens befindet. 
Dieser Kanal mündet nit einer feinen Oeffnung an der Aussenseite des Unterkiefers, unter und etwas vor dem Trommelfell nach aussen, - und durch diese Oeffnung tritt der genannte Nerv wieder hervor. Gleich nach seinem Hervortritt theilt sich derselbe in mehrere feine $Z$ weige, von denen die meisten und stärkeren sich in der das Unterkiefergelenk bedeckenden Haut ausbreiten. Ein Faden lässt sich bis zum vorderen Rand des Trommelfells verfolgen, und dürfte vielleicht als R. auricularis zu deuten sein.

Bei den übrigen Sauriern scheint dieser Nerv einen abweichenden Verlauf zu haben. Ich konnte nirgends an der Aussenfläche des Unterkieferknochens eine Oeffnung seines Kanals finden, es gelang vielmehr öfter, den Letzteren unter dem Gelenk des Quadratbeins nach hinten zu verfolgen. - Uebrigens ist zu bemerken, dass an dieser Stelle (unter dem Gelenk des Quadratbeins) zwei Knochenkanäle sich kreuzen, ohne sich jedoch zu berühren; einer, der Aussenseite des Knochens nahe gelegen, in welchem unser Ramus recurrens cutaneus nach hinten verläuft, - der andere, mehr an der Innenseite des Knochens, führt die Chorda tympani von hinten nach vorn.

Auch bei den Krokodilen gehen an der Biegungsstelle des Maxillaris inferior Nerven aus demselben hervor, die diesem rücklaufenden Aste der Saurier analog zu sein scheinen, obgleich es mir nicht gelang, jenen bei Salvator bis zum Gehörgang verlaufenden Faden aufzufinden. Crocodilus acutus zeigt folgende Form: An der Stelle, wo der dritte Ast des Trigeminus nach vorn umbiegt, um in seinen Knochenkanal einzutreten, entsendet er aus seiner hinteren Fläche zwei Nerven :

a) Der vordere derselben läuft vertical abwärts, die bisherige Richtung des Hauptstammes einhaltend, tritt in ein feines, vor dem Gelenk des Unterkiefers gelegenes Loch des letzteren ein, verlässt jedoch gleich darauf wieder den Knochen durch eine an der innern Seite desselben gelegene Oeffnung, verfolgt seinen Weg nach unten, und breitet sich in der den Unterkiefer an dieser Stelle von unten her bedeckenden Haut aus.

b) Der hintere Nerv ist nur halb so stark, als a; er wendet sich etwas rückwärts, und theilt sich in zwei Aeste:

a) Der vordere, stärkere dringt hinter $a$ von oben her in einen für ihn bestimmten Kanal des Unterkiefers ein, biegt in demselben, dem unteren Rande des Knochens ziemlich nahe, unter rechtem Winkel nach-vorn um, und verläuft in der letzteren Richtung durch das ganze letzte Drittheil des Unterkieferknochens. Dann endlich theilt dieser Nerv sich in zwei feine Fäden, die aus dem Kanal nach unten heraustreten, und sich in der den Unterkiefer von unten her bedeckenden Haut ausbreiten.

ß) Der hintere, schwächere, dringt noch weiter nach hinten als $\alpha$ in den Knochen ein, durchbohrt denselben in vertikaler Richtung, und breitet sich ebenfalls in der Haut aus, die den Unterkiefer an dieser Stelle bedeckt.

\section{d) Vom Nervus alveolaris inferior und dessen Zneigen.}

Nach Abgabe des eben abgehandelten $R$. recurrens cutaneus schlägt der bisher schräg nach aussen und unten verlaufende Maxillaris inferior die Richtung nach vorn ein, tritt in den Canalis alveolaris maxillae inferioris, nimmt die von hinten her in einem feinen Kanal herangetretene Chorda tympani auf (vergl. über letztere den hinteren Hauptstamm des Facialis), und verläuft als Nervus alveolaris inferior bis zur Spitze des Unterkiefers. Auf diesem Wege giebt derselbe ausser zahlreichen Fäden nach oben an die Wurzeln der Zähne und ausser stärkeren Zweigen nach aussen an die Haut des Unterkiefers einen Nerven ab, den man gleichzeitig als $\boldsymbol{R}$. lingualis und $\boldsymbol{R}$. mylohyoideus betrachten könnte. 
Die speciellen Formen dieses Zweiges sind folgende:

Bei Varanus Bengalensis flndet sich am Anfang des zweiten Drittheils des Unterkiefers an dessen unteren Seite ein rauher Vorsprung, als Ansatzpunkt des M. hyomaxillaris. Hier dringt der genannte Zweig des Alveolaris inferior aus dem Knochen hervor, und theilt sich in mehrere Zweige. Einige derselben breiten sich an der Haut des Unterkiefers aus, zwei andere verzweigen sich am M. mylohyoideus, während der stärkste über die vorderen Zungenbeinmuskeln nach innen dringt, und sich mit einem Endzweige des Hypoglossus zu einer Schlinge verbindet, aus welcher mehrere feine Nerven hervorgehen, die von der Seite her in die Zunge eindringen.

Auch bei Iguana tuberculata tritt ein starker Zweig am Ende des vorderen Drittheils des Unterkiefers durch ein an dessen Innenfläche gelegenes Loch nach innen, und theilt sich, wie bei Varanus, in mehrere feine Zweige. Auch hier breiten sich einige in der Haut des Unterkiefers, andere im M. mylohyoideus aus, während der Hauptzweig diesen Muskel, dann auch den darüber liegenden M. genioglossus durchbohrt, und einige feine $Z$ weige abgiebt, welche deutliche Schlingen bilden mit einigen der letzten Endzweige des Hypoglossus. Zwischen diesen Endzweigen beider Nerven findet hart an der Aussenseite des M. lingualis ein feines Geflecht statt, von welchem sogar mehrere äusserst feine Zweige in ein sehr kleines, an der Aussenfläche des genannten Muskels liegendes Ganglion zusammenstrahlen. Der in Rede stehende Endzweig des Maxiltaris inferior tritt darauf an der Seite des starken Zungenmuskels in die Höhe, und dringt mit einigen der letzten Zweige des Hypoglossus von der Seite her in die Zunge ein.

Ganz dieselbe Form findet sich bei Salvator nigropunctatus, nur mit der Abweichung, dass keine Verbindung mit Endzweigen des Hypoglossus (wenigstens nicht ausserhalb der Zunge) stattfindet, und dass die Endzweige beider Nerven neben einander in die Zungenwurzel eindringen.

Bei Platydactylus guttatus wieder fast ganz die Form, wie bei Iguana. Der für die Zunge bestimmte Endzweig durchbohrt von unten her den hier vorliandenen unteren Bauch des M. geniohyoideus und verbindet sich geflechtartig mit mehreren feinen, ebenfalls durch den genaunten Muskel hindurch tretenden Endzweigen des Hypoglossus. Aus diesem Geflecht geht ein Hauptstamm und mehrere feinere Nerven hervor, die alle von der Seite her sich in die Zungenwurzel einsenken.

Agama spinosa zeigt denselben Ast des Alveolaris inferior von etwas ansehnlicherer Stärke, im Uebrigen aber von derselben Form, wie bei den anderen Eidechsen. Der für die Zunge bestimmte $Z$ weig tritt quer hinüber durch die unteren Zungenbeinmuskeln an die Zungenwurzel, legt sich hier dicht an einen der drei Endzweige des Hypoglossus (vergl. diesen), verlässt ihn aber sogleich wieder, um vollständig mit einem anderen (dem dritten) Endaste dieses Nerven zu verschmelzen. Die aus dieser Verbindung hervorgehenden zwei Nerven dringen beide von der Seite her in die Zungenwurzel ein.

Bei Istiurus Amboinensis theilt sich der aus seiner Oeffnung (diese bat dieselbe Lage wie bei Varanus) hervorgetretene Nerv ebenfalls sogleich in drei Zweige, von denen einer in die Haut des Unterkiefers, ein anderer in den M. mylohyoideus geht, während der dritte, stärkste, nach innen an den M. hyoglossus herantritt, und sich hier mit einem der Endzweige des Hypoglossus vereint. Durch ihre Verbindung wird ein feiner Nervenstamm gebildet, der, die bisherige Richtung dieses vom Hypoglossus, stammenden Nerven beibehaltend, nach vorn läuft. Auf seinem Wege giebt er nach einander drei Zweige aus, die von der Seite her in die Zunge eindringen, während die letzte Endigung dieses Nervenstammes, die ohne Zweifel dem Hypoglossus angehört, im M. genioglossus sich verbreitet.

Bei Chamaeleo vulyaris liegt das Loch für den Austritt unseres Nerven etwas weiter nach hinten, nämlich in der Mitte der Innenfläche des Unterkiefers. Gleich nach seinem Hervortritt theilt sich derselhe in zwei Aeste. Der erste tritt unter den. M. mylohyoideus, und breitet sich in: 
diesem, so wie in der ihn bedeckenden Haut aus. Der zweite durchbohrt diesen Muskel, und tritt über dem M. geniohyoideus von der Seite her an die Zungenwurzel heran, um in dieselbe einzudringen. Eine Verbindung mit Endzweigen des Hypoglossus findet ausserhalb der Zunge nicht statt.

Bei den Krokodilen liegt die Oeffnung für den Austritt dieses Nerven, der überhaupt eine etwas abweichende Form zeigt, noch weiter nach hinten. Gleich nachdem nämlich (bei Crocodilus acutus) der Maxillaris inferior in seinen Kanal eingetreten, um in ihm nach vorn zu verlaufen, entlässt er einen starken Nerven, der sich wieder in zwei Zweige theilt:

a) Einer derselben bleibt im Canalis alveolaris inferior, und läuft, in demselben unter dem Stamme des Maxillaris inferior liegend, nach vorn. In der Gegend des dreizehnten Zahns theilt er sich wieder in zwei Aeste. Der stärkere tritt hier aus dem Kanal hervor, und breitet sich in der inneren Haut des Mundes, nahe dem Zahnrande des Unterkiefers, aus. Der feinere läuft weiter nach vorn bis zur Gegend des neunten Zahns, verlässt hier ebenfalls den Kanal, und endet wie der vorige.

b) Der zweite Ast unseres Nerven tritt sogleich nach seinem Ursprung durch ein Joch an der Innenseite des Knochens hervor, und theilt sich in vier Zweige. Zwei davon breiten sich im Mylohyoideus und in der Haut des Mundwinkels aus; einer geht in die hier liegende Hautdrüse; einer endlich läuft längs des Innenrandes des Unterkiefers zwischen Haut und Mylohyoideus nach vorn, giebt feine Zweige an die Haut, und drei bis vier feine Nerven ab, die den M. mylohyoideus durchbohren, und sich auf dem muskulösen Boden der Mundhöhle ausbreiten. Dieser Nerv lässt sich bis zum ersten Drittheil des Unterkiefers verfolgen, wo er in der Haut endigt.

\section{Dritter Abschnitt. Vom Nervus Facialis.}

Die Wurzel des N. facialis (auf den Abbildungen mit 7 bezeichnet) ist immer ein einfacher, feiner, walzenförmiger Nervenstrang, hart vor der Wurzel des Acusticus von der Seitenfläche des verlängerten Markes entspringend, und immer durch einen eigenen feinen Knochenkanal des Felsenbeins aus dem Schädel tretend. Bei allen Sauriern und Krokodilen bleibt, im Gegensatz zu der Bildung: vieler Fische und nackter Amphibien, diese Wurzel von derjenigen des Trigeminus völlig getrennt, - nur in den letzten Endigungen beider Nerven werden oft eigenthümliche Schlingenbildungen beobachtet.

Eben aus dem Schädel getreten, bisweilen noch im Knochenkanale selbst, schwillt sie zu einem beständig vorhandenen, zwar nicht grossen, aber immer deutlichen Ganglion an (auf allen Abbildungen mit $C$ bezeichnet). Ich habe dies Ganglion bei allen untersuchten Arten, am grössten bei Iguana tuberculata, angetroffen.*) - Gewöhnlich hat dasselbe eine abgestumpft dreieckige Gestalt,

*) Bei den Vögeln scheint es nicht beständig zu sein; Bonnsdorf beobachtete indessen doch zuweilen ein Ganglion geniculum bei Corvus Cornix 1. 1. pg. 525. Bei den Amphibien ist es beständig vorhanden, nur bisweilen (bei den Ecaudata) mit dem Ganglion des Trigeminus verschmolzen. Vergl. meine frühere Abbandlung. Unter den Fischen besitzen es nach $S$ tan nius die Plagiostomen, wo der Ramus palatinus direct aus dem Facialis entspringt. 
und dann gehen aus zwei seiner Ecken die beiden Hauptstämme des Facialis hervor, während die dritte Ecke der Punkt ist, wo die Wurzel selbst in das Ganglion eintritt. Bei einigen, Iguana, (Taf. II, fig. 3, C) ist die Gestalt des Ganglions oval, - dann gehen ausser den beiden Hauptstämmen noch andere Nervenzweige aus ihm hervor.

Es werden nämlich constant zwei aus dem Ganglion des Facialis austretende Hauptstämme beobachtet, ein vorderer, der R. palatinus, und ein hinterer Hauptstamm. Unter sämmtlichen untersuchten Formen ist keine, wo einer dieser Hauptstämme fehlte, oder auch nur durch Verschmelzung mit anderen Hirnnerven seinen Ursprung vom Facialis aufgegeben hätte, - ausser ihnen gehen zuweilen aus dem Ganglion noch Verbindungszweige an das Ganglion petrosum des Glossopharyngeus hervor, die indessen in der Regel aus dem R. palatinus, nur ausnahmsweise aus dem Ganglion entspringen.

\section{A. Vom Ramus palatinus. (Dargestellt Taf. I, fig. 1, p, p.)}

Der Nervus palatinus scheint bei den kaltblütigen Wirbelthieren von besonderer Wichtigkeit zu sein. Bei den Fischen entsendet er nach $\mathbf{S}$ t a nnius feine Zweige zur Schleimhaut des Gaumens, seltener auch an Muskeln (z. B. den queren Gaumenmuskel bei Perca, Cottus u. A.), und steht anscheinend immer mit dem zweiten Aste des Trigeminus in Verbindung. *) Bei den Amphibien scheinen nur häutige Gebilde von ihm versorgt zu werden, doch fehlen auch hier nicht die Verbindungen mit dem zweiten Aste des Trigeminus. $\left.{ }^{* *}\right)$ Bei den Reptilien endlich, von denen ich freilich nur die Saurier und Krokodile untersuchen konnte, entlässt er nur Aeste an die Schleimhaut des Gaumens, bildet aber ausserdem beständig die Brücke, wodurch der zweite Ast des fünften Paares, und, wenn es vorhanden ist, das Sphenoidalgeflecht entweder direct, oder durch Vermittelung des Gangl. petrosum mit dem Halstheil des Sympathicus in Verbindung steht.

Immer hat bei den Sauriern und Krokodilen dieser Nerv die Form, die unter den Fischen schon bei Chimaera, Raia, Spinax und Carcharias vorkommt, und die sich bei allen nackten Amphibien, am deutlichsten bei den Salamandrinen wiederholt, sofern er nie, (wie bei Silums) als Ast des Trigeminus, oder gar (wie bei Lophius) als gesonderter Nerv erscheint, sondern beständig als Ast des mit einer gangliösen Anschwellung versehenen Facialis auftritt. Nach seinem Ursprunge aus dem Ganglion wendet er sich nach innen und unten, um dann nach vorn durch einen kurzen Kanal im Basilarstück des Keilbeins (Vgl. Taf. I, fig. 1, Canalis vidianus Auct.) zu laufen. Aus ihm hervorgetreten, läuft unser

*) Vgl. über die genaueren Verhältnisse: Stannius das peripher. Nervensystem der Fische, pg. $54 \mathrm{ff}$.

**) Besonders deutlich ist diese Verbindung bei Pelobates und Bombinator. Vergl. meine frühere Abhandlung pg. 22. 
Nerv über den Gelenkfortsatz des Keilbeins fort, und tritt über dem Os pterygoideum nach vorn, fast auf der Mitte des Bodens der Orbita seinen Weg verfolgend. Bei den Krokodilen (Taf. III, fig. 5, p), wo der R. palatinus dem vorderen Stiele des Keilbeins fest anliegend nach vorn verläuft, erinnert seine Form mehr an diejenige der Fische, wo er *) zwar auch durch einen kurzen Kanal des Os sphenoideum basilare, dann aber längs der Aussenseite des verschmälerten Abschnittes dieses Knochens nach vorn läuft. Auf seinem Wege nach vorn entspringen dreierlei Nerven von ihm: 1. Verbindungsäste zum N. infraorbitalis; 2. Verbindungsäste zum Glossopharyngeus; 3. Zweige an die Schleimhaut des Gaumens.

Was zunächst die ersteren dieser Nerven betrifft, so finden sich gewöhnlich zwei Verbindungsstellen zwischen $R$. palatinus und Maxillaris superior, die eine, bald nachdem der $R$. palatinus auf das Gaumengewölbe getreten, die zweite im vorderen Abschnitte der Orbita. Nur die erstere möchte als Analogon des Sphenoidalgeflechtes zu betrachten sein, während die zweite wohl nur eine Vermischung von Nervenfasern des fünften und siebenten Paares zur Versorgung der Gaumenhaut bewirkt. Zur besseren Unterscheidung wollen wir jene als hinteren, (R. communicans posterior), diese als vorderen Verbindungsast ( $R$. communicans anterior) bezeichnen.

\section{a) Vom R. communicans posterior rami palatini cum Maxillari superiore. (Dargestellt Taf. I, fig. 1, g, g.)}

Die hinteren Verbindungsäste zwischen R. palatinus und Maxillaris superior, über deren Verhältniss zum Kopftheil des Sympathicus später bei Gelegenheit des letzteren die Rede sein wird, erscheinen, wie früher pag. 15 schon dargethan ist, entweder als einfache brückenartige Verbindungsschlingen zwischen beiden Nerven, oder die aus den letzteren stammenden Elemente treten auf dem Boden der Orbita zu einem kurzen Stamme zusammen.

Das erste Verhalten ward früher (pg. 16) von Varanus Bengalensis geschildert, wo ein einfacher Nervenzweig aus dem Maxillaris superior quer hinübertritt an den R. palatinus. Hier möge nur erwähnt werden, dass, wenn man diesen ganzen Zweig als aus dem ersteren kommend, und in den letzteren einmündend betrachtet (nicht umgekehrt), die Form seiner Verschmelzung mit dem R. palatinus auf ein Rücklaufen einiger von seinen Fasern in der Bahn des letzteren schliessen lässt. Man sieht nämlich schon bei mässiger Vergrösserung an dieser Verbindungsstelle einen Theil seiner Fasern sich nach vorn mit dem R. palatinus wenden, um mit diesem verschmolzen, in centrifugaler Richtuug nach vorn zu verlaufen. Andere wenden sich unzweifelhaft nach hinten, verschmelzen ebenfalls mit dem R. palatinus, und gehen in centripetaler Richtung: (nach hinten) fort. Es leuchtet ein, dass diese letzteren auch als aus dem R. palatinus stammend und an den Maxillaris superior hinübergehend aufgefasst werden können.

*) Stan nius das peripher. Nervensystem der Fische, pg. 56. 
Bei Iguana tuberculata findet sich dagegen die zweite der erst angeführten Verbindungsweisen. Die Form, unter der diese sich darstellt, ist folgende: Nachdem der. R. palatinus seinen Kanal verlassen hat und auf das $O$ s pterygoideum getreten ist, um zwischen diesem und dem $M$. adductor maxillae superioris nach vorn zu verlaufen, giebt er gleich anfangs drei bis vier feine Fäden nach aussen, die sich geflechtartig unter einander, und dann mit einem von oben nach unten den genannten Muskel durchbohrenden Aste des Infraorbitalis zu einem feinen Nervenstamme verbinden, der, dem letztgenannten Nerven nahe liegend, aber durch den M. adductor maxillae superioris von ihm getrennt, von hinten nach vorn läuft. Dieser durch Elemente des R. palatinus und des Maxillaris superior zusammengesetzte Nerv empfängt bald darauf noch einen den M. adductor maxillae superioris durchbohrenden Zweig des letzteren, und theilt sich in zwei Aeste, von denen einer wieder zurïck geht an den R. palatinus, um mit diesem zu verschmelzen, während der andere sich mït einem neuen $Z$ weige des Maxillaris superior zu dem später abzuhandelnden $Z$ weig für die innere Mundhaut vereint.

Etwa in der Mitte der Orbita giebt der R. palatinus noch einen neuen Zweig ab, stärker als die vorigen, der sich schräg nach aussen und vorn wendet, und ebenfalls einen starken den M. adductor maxillae superioris durchbohrenden Verstärkungszweig aus dem Infraorbitalis empfängt, dann nach vorn und innen über die tellerförmige Ausbreitung der Gaumenhaut tritt, um hier sich zu verzweigen.

Bei Salvator nigropunctatus bilden ebenfalls Nerven, die aus dem R. palatinus und dem Maxillaris superior fast gleichzeitig ausgehen, einen schon früher (pg. 16) beschriebenen kurzen Nervenstamm (vgl. Taf. I, fig. $1, \varepsilon$ ).

Ganz ähnlich verhält sich Salvator Merianae. Nachdem der R. palatinus in gewöhnlicher Weise über den Gelenkfortsatz des Keilbeins fort nach aussen auf das Os pterygoideum getreten ist, an dessen innerem Rande er, dem Knochen fest anliegend, unter dem M. adductor maxillae superioris nach vorn verläuft, giebt er einen $Z$ weig nach aussen, der ebenfalls unter dem genannten Muskel nach vorn gehend, drei nach einander aus dem Infraorbitalis ansgetretene Nervenzweige aufnimmt, und so einen kurzen Nervenstamm bildet, aus welchem bei dieser Art keine an die Gaumenhaut gehenden Zweige beobachtet wurden. Das vordere Ende dieses Nervenstammes biegt wieder nach innen um, und mündet wieder in den $R$. palatinus ein.

Die Krokodile wiederholen dagegen die Form von Varanus Bengalensis. Nachdem bei Crocodilus biporcatus der R. palatinus, dem Felsenbein dicht anliegend, bis zur Basis des Keilbeins getreten, und bis zur hinteren Ecke der Orbita über die vordere flache Ausbreitung des M. pterygoideus gelangt ist, giebt er einen Zweig ab (Taf. II, fig. 5, g), der unter rechtem Winkel sich von der bisherigen Richtung ab und nach aussen wendet, um mit dem früher (pg. 16) beschriebenen aus dem Sphenoidalgeflecht hervorgehenden Aste des Trigeminus zu einer Schlinge $(g-\zeta)$ sich zu verbinden.

So bilden bei allen Sauriern und Krokodilen *) diese hinteren Verbindungsäste eine Brücke zwischen R. palatinus (Facialis) und Maxillaris superior (Trigeminus). Ob durch ihre Vermittelung Nervenfasern aus diesem in jenen, oder aus jenem in diesen übergefühit werden, ist schwer zy entscheiden. Ich möchte mich für die erste dieser Ansichten entscheiden, und glauben, dass

*) Vogt beschreibt diese hintere Verbindung zwischen R. palatinus und Maxillaris superior bei Python tigris als seinen ersten Plexus (Müll. Arch. 1839, pg. 48). Auch Müller in seinen Bemerkungen zu Vogts Arbeit erwähut dieser Verbindung (1. l. pg. 60), und bildet sie von Python tigris ab. (Vgl. Neurologie der Myxinoiden, Taf, IV, fig. 3, 5".) 
diese hinteren Verbindungsäste zwischen Trigeminus und Palatinus die erste der sympathischen Schlingen sind, die sich weiter unten am Rumpf in ähnlicher Weise wiederholen *). Diese Schlingenbildung setzt sich vom R. palatinus dann nach hinten durch einen in den Halstheil des Sympathicus gehenden Nerven fort (den später zu beschreibenden Ramus communicans internus rami palatini cum nervo glossopharyngeo).

Ueber den genaueren Zusammenhang unseres Verbindungszweiges mit den übrigen sympathischen Schlingen vergl. das Kapitel über den Kopftheil des Sympathicus.

b) Vom Ramus communicans anterior rami palatini cum Maxillari superiore. (Dargestellt Taf. I, fig. 1, y'.)

Nachdem der R. palatinus die hintere Verbindungsschlinge mit dem zweiten Aste des Trigeminus gebildet hat, tritt er meist ohne Abgabe weiterer Zweige mehr oder weniger nahe an den schmalen Knorpelstiel des Keilbeins heran, läuft auf dem Boden der Orbita nach vorn, und spaltet sich an der vorderen Grenze derselben in mehrere Zweige. Einige derselben breiten sich in der Schleimhaut des Gaumens auf der vorderen Decke der Mundhöhle aus, einer derselben, den wir mit dem Namen des vorderen Verbindungszweiges zwischen R. palatinus und Maxillaris superior bezeichnen wollen, tritt beständig nach aussen an den Oberkieferast des Trigeminus heran, um mit ihm eine neue Verbindung von eigenthümlicher Form einzugehen. Ueberall tritt dieser R. communicans anterior als wirklicher Ast des R. palatinus auf, und während wir es als wahrscheinlich ansehen mussten, dass durch den hinteren Verbindungsast Nervenfasern an den Facialis übergeführt werden, kann hier fast nur von solchen Fasern die Rede sein, die umgekehrt aus dem $\mathbf{R}$. palatinus an den Trigeminus hinübertreten. Denn meistens lässt sich dieser vordere Verbindungsast als besonderer Nerv, der nur vom Maxillaris superior Verstärkungsfasern erhält, bis zu seiner endlichen Ausbreitung àn der die innere Fläche des Zahnrandes des Oberkiefers bedeckenden Mundhaut verfolgen.

Bei Salvator nigropunctatus giebt der zweite Ast des Trigeminus vor seinem Eintritt in den Oberkieferkanal einen feinen Ast nach innen ab (Taf. I, fig. 1, 9 ), der sich mit unserem, im vorderen inneren Winkel der Orbita abgegebenen, R. communicans anterior (fig. I, $g^{\prime}$ ) des R. palatinus zu einer Schlinge verbindet. Aus dieser Schlinge geht ein Nerv hervor (fig. 1, 9"), der zwischen innerer Mundhaut und Zahnrand des Oberkieferknochens parallel mit dem im Kanal des letzteren verlaufenden Alveolaris superior nach vorn tretend, sich an der den Knochen von innen her bedeckenden Mundhaut ausbreitet. Ich sah bei meinem Exemplar deutlich von beiden Seiten her Fasern in diesen Nerven übergehen, einen anderen Theil der in jener Schlinge enthaltenen Fäden

*) Namentlich $S t a n n i u s ~ b e b t ~ d i e ~ A e h n l i c h k e i t$ dieser Schlingenbildungen am Kopf mit den subvertebralen Schlingen am Rumpfe hervcr. (Das periph. Nervensystem der Fische, pg. 72.) 
jedoch nicht an der Bildung desselben Theil nehmen, sondern quer von der einen Seite nach der anderen hinübertreten. $\mathrm{Ob}$ diese letzteren vom Oberkieferast zum R. palatinus, oder umgekehrt von diesem zu jenem verlaufen, war unmöglich, zu entscheiden.

Bei Varanus Bengalensis tritt unser Nerv in der vorderen Grenze der Orbita als einer der drei Endzweige des N. palatinus (die beiden anderen breiten sich in der Schleimbaut des Gaumens aus) an den Maxillaris superior da heran, wo dieser im Begriff ist, als $\mathbf{N}$. alveolaris superior in seinen Knochenkanal einzutreten, legt sich hier dicht an diesen Nerven an, und verschmilzt mit ihm, um bei dieser Verbindung sich durch Fasern aus dem Trigeminus zu verstärken. Sogleich darauf trennt er sich wieder vom Maxillaris superior, und während dieser in den Oberkieferkanal eindringt, verläuft er selbst an der, der Mundhöhle zugewandten, Fläche des Knochens, zwischen diesem und der Mundhaut. Vorn, an der Grenze des Zwischenkiefers, zerfällt er in mehrere Zweige, die sich an der, den Knochen von innen her bedeckenden, Mundhaut ausbreiten.

Bei Iguana tuberculata verbinden sich, wie schon vorhin erwähnt, die hinteren VerbindungsAeste in der Form mehrerer feiner Nerven unter einander und mit einem von oben her den $\mathbf{M}$. adductor maxillae superioris durchbohrenden $Z_{\text {weig }}$ des Infraorbitalis zu einem kurzen Nervenstamm. Dieser empfängt auf dem vorderen Theil des Bodens der Augenhöhle noch einen ferneren Zweig des Maxillaris superior, und wird nun selbst zum Theil zu dem in Rede stehenden vorderen Verbindungszweig, ohne jedoch dass, wie bei Varanus Bengalensis, eine wirkliche Verschmelzung mit dem zweiten Aste des Trigeminus stattfände. Nachdem er nämlich hart an den OberkieferKnochen herangetreten, empfängt er, ganz wie bei Salvator nigropunctatus, einen kurzen Verstärkungsast aus dem ganz benachbart liegenden Maxillaris superior, und einen anderen von innen her aus dem R. palatinus, und legt sich alsdann an die Innenseite des Zahnrandes des Oberkieferknochens fest an, um auf dieselbe Weise, wie bei Varanus und Iguana zu verlaufen und sich auszubreiten.

Salvator Merianue wiederholt in Bezug auf diesen Nerven ganz die Bildung von S. nigropunctatus.

Von diesen Formen der Eidechsen zeigen die Krokodile nur geringe Abweichungen. Bei Crocodilus biporcatus läuft der R. palatinus (Taf. III, fig. $5, p$ ), nach der Bildung der hinteren Verbindungsschlinge $(\mathrm{g})$, gerade aus nach vorn, dem vorderen Knochenstiel des Keilbeinkörpers dicht anliegend. In der vorderen inneren Ecke der Orbita endigt er in mehreren feinen $Z$ weigen. Einige derselben breiten sich in der Gaumenhaut ans (Taf. III, fig. 5, p'), ein anderer tritt nach aussen ( $(9)$ nahe an den Oberkieferknochen heran, und verbindet sich mit einem in der Gegend des zwölften Zahns vom zweiten Aste des Trigeminus entsendeten Zweig (Э) zu einem Nerren, der sich gleich darauf in zwei Theile spaltet. Der schwächere breitet sich sogleich in der Gaumenhaut aus; der stärkere ( $\left.{ }^{\prime \prime}\right)$ lässt sich auf der letzteren, der er an der inneren und unteren Seite des Oberkieferknochiens dicht anliegt, bis etwa in die Gegend des achten Zahns verfolgen, wo er sehr fein in der den inneren Rand des Knochens bedeckenden Mundhaut sich verliert. ${ }^{*}$ )

*) Aehnliche Verbindungen der letzten Endzweige des R. palatinus mit Aesten des Trigeminus sind auch bei auderen Wirbelthieren beobachtet worden. Unter den Fischen erwähnt $\mathbf{S} t a n-$ nius (das peripher. Nervens. d. Fische, pg. 42) bei Cyclopterus, Pleuronectes, Salmo, Corregonus, Esox, Cyprinus, Anguilla Zweige des Maxillaris superior, welche mit Endzweigen des R. palatinus Verbindungen, of in der Form von Schlingen, eingehen, und "die Schleimhaut der Mundhöhle arn Eingang der letzteren" mit Fäden versorgen. Bei Collitis fossilis wird sogar der ganze N. palatinus zu dieser Verbindung mit der ganzen Fortsetzung des Maxillar. super. verwandt. - Bei Emys Europaea beschreibt B o ia u us (Tab. XXVI, fig. 130, $\beta^{\circ}$ ), als aus dem Maxillaris super. hervorgehend, einen R. palatinus posterior und R. palatinus anterior, welche sich anf der Schleimhaut des Gaumens ausbreiten. Letzterer bildet in der vorderen Ecke der Augenböhle mit dem Ramulus posterior ex infraorbitali eine Schlinge. - Auch bei Python tigris erwähnen Vogt und Müll e r ähnlicher Nerven. (M üll. Arch. 1839, pg.49 und pg.61.) 


\section{c) Zweige an die Gaumenhaut.}

Auf dem ganzen Wege des R. palatinus bis zum vorderen Winkel der Orbita habe ich nie Zweige an die Gaumenhaut aus ihm hervorgehen sehen, möchte jedoch auf deren Anwesenheit auch im hinteren Abschnitte der Augenhöhle daraus schliessen, dass bei der Fortnahme des Os pterygoideum von unten her der darauf liegende $\mathbf{R}$. palatinus dem Knochen dicht anhaftet, und nur mit einiger Mühe von ihm zu trennen ist. Vielleicht, dass dieses Anhaften eben durch feine Nervenfasern bewirkt wird, die hier natürlich den Knochen nach unten durchdringen müssen, um zur Gaumenhaut zu gelangen.

Deutliche Gaumenzweige treten erst in der vorderen inneren Ecke der Augenhöhle auf, und zwar scheint sich immer der ganze Rest des R. palatinus in diese $\mathbf{Z w e i g e ~ a u f z u l o ̈ s e n . ~}$

An demselben Punkte, wo bei Varanus Bengalensis der eben beschriebene R. communicans anterior aus dem R. palatinus hervorgeht, theilt sich dieser in noch zwei andere Zweige :

a) Der äussere derselben läuft gerade aus nach vorn an der inneren Seite der vorderen Gaumengrube, tritt bis zum Zahnrand des Zwischenkiefers und breitet sich hier in dem vorderen Theil der Schleimhaut des Mundes aus.

b) Der zweite, innere Endast des R. palatinus, etwa halb so schwach wie der vorige, läuft nach innen und vorn auf der Haut des Gaumens, verschmilzt in der Mittellinie mit dem entsprechenden Nerven der anderen Seite, und endigt in der Schleimhaut des Gaumens.

Bei Iguana tuberculata tritt der $\mathbf{R}$. palatinus nach Abgabe der vorhin beschriebenen hinteren und vorderen Verbindungszweige ziemlich nahe an die Mittellinie heran, um endich an der vorderen Grenze der Orbita in mehrere Aeste sich aufzulösen, die sich in der vorderen Haut des Gaumens ausbreiten. Eine Verbindung eines dieser Endzweige mit einem entsprechenden $Z$ weige von der anderen Seite ward nicht beobachtet.

Bei Salvator Merianae und Salv. nigropunctatus treten gleichzeitig mit dem $\mathbf{R}$. communicans anterior mehrere Zweige hervor, die sich ('Taf. I, fig. 1, p') auf der Gaumenhaut, besonders auf der tellerförmigen Platte derselben ausbreiten. Bei Chamaeleo, Euprepes, Lacerta, Agama und Istiurus wurden diese Gaumenzweige ebenfalls beobachtet, ihre Feinheit war jedoch zu gross, um eine klare Vorstellung über ihre Ausbreitung zu gewinnen.

Bei Crocodilus biporcatus wurden dieselben genau verfolgt. Sie gehen auch hier als letzte Endzweige des R. palatinus da aus demselben hervor, wo dieser den vorderen Verbindungsast zum Trigeminus entsendet (Taf.III, fig. 5, p'). Ihre Ausbreitung ist ganz diejenige von Iguana und Salvator.

\section{B. Von den Verbindungszweigen zwischen Facialis und Glossopharyngeus.}

Der Facialis steht mit dem Glossopharyngeus beständig durch zwei Nerven in Verbindung, die sich in Bezug auf ihre Einmündung in den letzteren ziemlich gleich verhalten, sofern sie beide entweder in das Gangl. petrosum sich einsenken, oder sich mit dem Stamm des Glossopharyngeus selbst verbinden. In ihrem Urprunge sind beide sehr verschieden, - der eine, innere, entspringt beständig aus dem R. palatinus, höchstens aus dem Ganglion des Facialis selbst; der andere, äussere, geht immer aus dem hinteren Hauptstamme des 
Facialis hervor. Den ersteren (auf allen Figuren mit $i$ bezeichnet) wollen wir mit dem Namen des R. communicans internus rami palatini cum Glossopharyngeo belegen, - der letztere (überall mit $e$ bezeichnet) wird sich von ihm als R. communicans externus nervi Facialis cum Glossopharyngeo unterscheiden lassen.

a) Vom Ramus communicans internus rami palatini cum Glossopharyngeo. (Taf. I, fig. 1, i, i.)

Dieser Nerv gehört zu den feinsten Nerven der Saurier, - nur mit grosser Vorsicht und Mühe gelingt es, ihn vom Glossopharyngeus aus bis zu seinem Ursprunge aus dem R.palatinus oder, der seltenere Fall, aus dem Ganglion des Facialis zu verfolgen. Zugleich gehört er aber auch zu den beständigsten Nerven und scheint ganz allgemein zum Plane des Nervensystems der Saurier zu gehören.

Aus dem R. palatinus oder dem Ganglion des Facialis entspringt er gewöhnlich mit zwei bis drei feinen Fäden, die sich, sogleich nach hinten laufend, bald zu einem feinen Stamme verbinden. Dieser legt sich nahe an den eben aus seiner Schädelöffnung hervorgetretenen Glossopharyngeus an, um mit ihm selbst zu verschmelzen, oder an derselben Stelle wie dieser in das Ganglion petrosum einzumünden. In einigen Fällen glückt es, ihn unter dem letzteren hindurch in den Halsstamm des Sympathicus zu verfolgen, - ein Umstand, aus welchem sich seine Natur als einer der Hauptschlingen des letzteren beweisen lässt. Vergl. hierüber den Abschnitt vom Kopftheil des Sympathicus.

Als vom R. palatinus entspringend, ist unser Nerv bei Chamaeleo vulgaris am deutlichsten. Da, wo dieser, auf dem Gaumengewölbe nach vorn laufend, unter den Bulbus tritt, entsendet er zwei feine Zweige nach hinten (Taf. II, fig. 4, i), die sich gleich darauf zu einem Nerven verbinden. Dieser verläuft, dem Keilbeinkörper dicht anliegend, tief unter dem Ganglion des Facialis durch rückwärts bis zum Ganglion petrosum (D), passirt dasselbe sogar eine ganz kurze Strecke, biegt dann kurz hinter demselben knieförmig nach innen und vorn um, und mündet so in das Ganglion petrosum ein, dass er wie ein aus demselben ausgesandter, erst nach hinten gehender, dann sogleich nach vorn umbiegender Nerv erscheint. - Diese Form der Einmündung in das Ganglion petrosum ward indessen bei keiner anderen Eidechse beobachtet. -

Bei Varanus Bengalensis wird unser Nerv (Taf. II, fig. 2, i) aus drei Fäden gebildet, die nach einander aus dem R. palatinus, der letzte aus dem Ganglion des Facialis, entspringen. Er läuft, dem Keilbeinkörper anliegend, nach hinten, tritt an den Stamm des Glossopharyngeus heran (Taf II, fig. 2,9), und verschmilzt mit demselben, jedoch so, dass er ihm nur wie angeklebt erscheint, und sich deutlich unter demselben durch in den Halstheil des Sympathicus verfolgen lässt (Taf. II, fig. '2, s').

Ganz ähnlich ist das Verhalten bei Salvator nigropunctatus. Auch hier entspringen aus dem R. palatinus kurz nach dessen Ursprunge zwei feine Nerven, die, der Basis cranii fest anliegend (Taf. I, fig. 1, i i), sich bald vereinigen, und nun in der Form eines feinen einfachen Nervenstammes (i) rückwärts bis zum Ganglion petrosum (D) verlaufen. In das letztere tritt dieser nicht vollständig ein, sondern legt sich der unteren Fläche desselben fest an, und verwächst mit ihm, 
jedoch so, dass er sich deutlich in den vereinigten Stamm (F) von Vagus und Hypoglossus verfolgen lässt.

Bei Istiurus Amboinensis entlässt der R. palatinus, kurz, nachdem er aus dem Ganglion ge treten, zwei feine Fäden, die sich unmittelbar nach ihrem Ursprunge zu einem Faden vereinen (Taf. 1II, fig. 1, i). Dieser geht eine kurze Strecke parallel mit dem hinteren Hauptstamm des Façialis schräg nach aussen und hinten, und tritt mit dem etwas stärkeren $R$. communicans externus (e) und mit der feinen Wurzel des Glossopharyngeus (9) selbst von innen und vorn her in das Ganglion petrosum (D) ein.

Aehnlich bei Platydactylus guttatus, wo ich es indessen unentschieden lassen muss, ob unser Verbindungsast (Taf. III, fig. 3, i) nur aus dem R. palatinus entspringt, oder auch aus dem Ganglion des Facialis eine Verstärkung erhält. Er tritt mit dem feinen Stamme des Glossopharingeus (9) von innen und hinten her in das schwache Ganglion petrosum (D) ein. Von vorn her tritt der R. communicans externus (e) erst an den aus dem Ganglios hervorgehenden Stamm.

Etwas abweichend ist die Form von Agama spinosa. Hier treten der R. communicans internus (Taf. III, fig. 2, i) und externus (e) schon vor ihrer Einmündung in den Glossopharyngeus zu einem kurzen Nervenstamm (a) zusammen. Dieser verbindet sich mit dem feinen Stamm des neunten Paares (9), ohne dass sich eine Spur einer Anschwellung fände. Aus dem verbundenen Stamme geht einerseits die Fortsetzung des Glossopharyngeus (99) in den Hypoglossus, andererseits der mit dem Vagus verschmelzende Halstheil des Sympathicus hervor (s).

Durch Vergleichung dieser eben geschilderten Formen lassen sich leicht auch bei den übrigen Sauriern die, diesem R. communicans externus entsprechenden, Elemente auffinden. Bei Iguana tuberculata (Taf. Il, fig. 3, i i) entspringen die beiden ihn repräsentirenden Nerven nicht aus dem R. palatinus, sondern schon aus dem Ganglion des Facialis (C) selbst. Beide gehen, ohne sich zu vereinigen, an der Basis cranii nach hinten, und treten von innen und vorn zugleich mit dem Glossopharyngeus (9) und dem $R$ : communicans externus (e) in das Ganglion petrosum (D) ein.

Bei Lacerta ocellata lässt sich noch besser, als bei Varanus, dieser Nerv in den Halstheil des Sympathicus verfolgen. Er geht hier nämlich (Taf. 1I, fig. 1, i) ganz bei dem Ganglion petrosum (D) vorbei, und mündet erst jenseits desselben mit den übrigen, den Halstheil des Sympathicus bildenden, Nervenstämmen zusammen (e e und s"). *)

4) Ob der von Vogt (Beitx. z. Neurologie der Reptilien) beschriebene ,vordere Kopfstamm" (Chelonia Mydas, Monitor Niloticus, Varanus spec., Lacerta ocellata) unserem Nerven analog sei, ist mir wahrscheinlicb, lässt sich aber nicht mit Sicherheit entscheiden, da Vogt denselben immer aus dem Sphenoidalgeflecht entstehen lässt. Ich habe diesen Ursprung bei unserem Nerven nie nachweisen können, sondern inmer gesehen; dass er entweder aus dem R.palatinus, oder aus dem Ganglion des Facialis entsteht. Allerdings steht, wie oben dargethan, der $R$. palatinus immer mit dem Sphenoidalgeflecht des zweiten Astes des Trigeminus in Verbindung, und hiedurch konnte es kommen, dass Vogt, der vom Verlauf des R. palatinus keine klare Vorstellung hatte, sondern denselben vielleicht als einen vom Trigeminus entspringenden Nerven des Sphenoidalgeflechtes ansab, den aus dem R. palatinus entspringenden Nerven als vom Sphenoidalgeflechte abgehend schilderte. - Das zweite, was mir bei Vogts Darstellung zu erinnern bleibt, ist, dass dieser Forscher bei mehreren Eidechsen eine Verbindung des in Rede stehenden Nerven mit einem Ast des Abducens angiebt. Es ist mir trotz aller gerade anf diesen Punkt gerichteten Aufmerksamkeit nie gelungen, diesen Verbindungsast aufzufinden. Bei Chamaeleo sali ich allerdings einen Nerveufaden aus dem Abducens in der Richtung nach unserem Nerven abgehen, er war aber zu fein, um ihn selbst mit Hülfe einer sehr scharfen Loupe bis ans Ende verfolgen zu können. - Uebrigens hat M üller (vergl. Neurologie der Myxinoiden Taf. IV, fig. 3 und fig. 4) nnsern Nerven bei Python tigris und Crotalus horridus abgebildet. Bei jenem (fig. 3,8 ) entspringt derselbe aus dem $R$. palatinus ( 7 *) und geht rückwărts ins Ganglion petrosum (von $\mathbf{M}$ üller als Ganglion cervicale supremum bezeichnet). Bei Crotalus entspringt er vom Facialis (fig. VII), da wo dieser den R. palatinus (66) entlässt, und 


\section{b) Vom Ramus communicans externus nervi facialis cum Glosso-} pharyngeo. (Auf allen Figuren mit $e$ bezeichnet.)

Der zweite der Aeste, wodurch der Facialis mit dem Glossopharyngeus oder dem Ganglion petrosum in Verbindung steht, ist wo möglich noch beständiger, als der erst beschriebene. Er ist von mir bei allen untersuchten Formen aufgefunden worden, und geht beständig vom hinteren Hauptstamm des Facialis ab, meist da, wo dieser zugleich die Chorda tympani und den Muskelast entlässt. Seine Einmündung ist nicht bei allen dieselbe: meist senkt er sich mit dem R. communicans internus und dem Glossopharyngeus von innen her ins Ganglion petrosum ein, bisweilen aber verbindet er sich ohne Anschwellung mit dem Glossopharyngeus; in noch anderen aber selteneren Fällen umgeht er den Glossopharyngeus und das Ganglion petrosum gänzlich, steht mit letzterem nur durch feine Fäden in Verbindung, und setzt sich direct in den Halstheil des Sympathicus fort.

Bei Varanus Bengalensis (Taf. II, fig. 2, e) besteht unser Nerv aus zwei neben einander entspringenden und verlaufenden Zweigen. Der hintere Hauptstamm (fig. 2, f) entsendet dieselben, nachdem er die Chorda tympani $(t)$ entlassen und den $R$. recurrens aus dem Trigeminus ( $x$ ) aufgenommen, so dass nach Abgang unserer beiden Nerven nur der Muskelast (m) übrig bleibt. Beide Nerven senken sich in den Stamm des Glossopharyngeus da ein, wo diesèr die beiden Verbindungsäste $(1,1)$ vom anfänglich vereinten Vagus und Hypoglossus aufnimmt, und wo auch der R. communicans internus (i) an ihn herantritt.

Beim Leguan entspringt dieser Nerv gerade da aus dem hinteren Hauptstamm des Facialis (Taf. II, fig. 3, e), wo dieser ( $f$ ) von vorn und oben her den $R$. recurrens Trigemini ( $x^{\prime}$ ) erhält, während der Facialis selbst nach aussen geht, um sich in Chorda tympani ( $t$ ) und Muskelast (m) zu theilen. Die Verbindung des Nerven mit dem Ganglion petrosum erfolgt entweder direct, indem er (linke Seite meines Exemplars) zugleich mit den beiden inneren Verbindungszweigen (i i) und mit dem Glossopharyngeus selbst (9) von innen her in's Ganglion petrosum (D) einmündet, oder indem er (rechte Seite) mit einem der beiden Zweige (i) verschmilzt, ehe diese sich in's Ganglion einsenken.

Bei Istiurus Amboinensis geht dieser Nerv ebenfalls an der Theilungsstelle des hinteren Hauptstammes des Facialis aus demselben hervor, und mündet, wie bei Iguana, mit dem feinen Stamme des Glossopharyngeus (Taf. IIl, fig. 1, 9) und dem R. communicans internus (i) in's Ganglion petrosum (D) ein. Aus letzterem geht ausser dem Stamm des Glossopharyngeus (9) nur der Halsstamm des Sympathicus (s) hervor.

Bei Salvator nigropunctatus theilt sich ebenfalls der hintere Hauptstamm des Facialis nach Aufnahme des $\mathbf{R}$. recurrens (Taf. I, fig. 1, x) vom Trigeminus und nach Abgabe der Chorda tympani ( $t$ ) in den Muskelast (m) und den in Rede stehenden Nerven, der, nach hinten verlaufend, da in's Ganglion petrosum (D) einmündet, wo auch der Glossopharyngeus selbst (9) in dasselbe eingeht.

Bei Salvator Merianae entspringt unser Nerv (Taf. II, fig. 4, e) an derselben Stelle aus dem hinteren Hauptstamm des Facialis, wo dieser sich nach Aufnahme des R. recurrens (x) in Muskel-

geht (99) mit dem Glossopharyngeus (IX) zusammen in den vereinigten Stamm der hinteren Hirnnerven ein. M ïller vergleicht diesen Nerven mit der Jakobsonschen Anastomose, - eine Ansicht, der wir, trotz unserer abweichenden Meinung über den N. vidianus (unsern R. palatinus), nur beipflichten können. 
Ast (m) und Chorda tympani ( $\mathrm{t}$ ) theilt. Ein merkwürdiger Unterschied von der Bildung des Salvator nigropunctatus besteht jedoch darin, dass bei dem Mangel eines Ganglion petrosum unser Nerv (e) den feinen Stamm des Glossopharyngeus (9) aufnimmt, ohne eine Spur einer gangliösen Anschwellung zu zeigen; bald darauf nimmt der so entstandene feine Stamm noch einen Faden (1) aus dem vereinigten Stamm von Vagus und Hypoglossus auf, und mündet alsdann in den letzteren da ein, wo der (dem Hypoglossus angehörige) Verbindungszweig des ersten Halsnerven sich in denselben einsenkt. Hiedurch entsteht ein kurzer Nervenstamm (F), der Glossopharyngeus, Vagus, Hypoglossus, Accessorius und Sympathicus enthält,

Bei Chamaeleo vulgaris ist unser Nerv (Taf. II, fig. 4, e) der am weitesten nach innen liegende der vier Endzweige, in die sich der hintere Hauptstamm des Facialis (f) theilt. Er läuft in einem nach hinten convexen Bogen nach innen, und tritt von aussen und hinten dicht neben dem $\mathbf{R}$. communicans internus (i) so in das Ganglion petrosum (D) ein, dass er (gerade wie der Ast i) wie ein von diesem ausgehender Nerv erscheint.

Bei Euprepes Sebae entspringt der in Rede stehende Verbindungsast gerade da aus dem hinteren Hauptstamm des Facialis, wo von oben und vorn her der $R$. recurrens Trigemini in diesen einmündet. Sein Ursprung und Verlauf bei dieser Eidechse ist aus mehreren Gründen interessant. Erstens lässt sich nämlich mit ziemlicher Deutlichkeit der Uebergang des R. recurrens Trigemini in unseren Nerven verfolgen, so dass letzterer deutlich als die, durch Fasern des Facialis verstärkte Fortsetzung des ersteren erscheint. Jener (der R. recurrens) mündet zwar in diejenige Hälfte des hinteren Hauptstammes des Facialis ein, die sich später als Chorda tympani verhält, während dieser aus der zweiten Hälfte entspringt, die sich gleich darauf als Muskelast verzweigt, aber beide Hälften des hinteren Hauptstammes sind gerade da, wo der eine den R. recurrens aufnimmt, der andere den $R$. communicans externus abgiebt, durch eine schmale Nervenbrücke mit einander verbunden, so dass man den letzteren als die, allerdings verstärkte, Fortsetzung des $R$. recurrens erkennt. Ferner aber ist das auffallend an der Bildung von Euprepes, dass unser äusserer Verbindungsast mit dem Glossopharyngeus zwar sich verbindet, denselben aber (als Halsstamm des Sympathicus) eher wieder verlässt, ehe dieser sein Ganglion petrosum gebildet.

Platydactylus guttalus erinnert in mancher Beziehung an die Form von Euprepes, sofern auch hier unser R. communicans externus (Taf. III, fig. 3, e) sich direct in den Halsstamm des Sympathicus (s) verfolgen lässt. Nur mündet er nicht mit Glossopharyngeus (9) und innerem Verbindungsast (i) zusammen von hinten her in's Ganglion petrosum (D) ein, sondern kreuzt erst den aus diesem hervorgehenden Stamm (gl), an der Kreuzungsstelle mit dem letzteren fest verwachsend.

Schon aus diesen Formen von Euprepes und Platydactylus geht deutlich hervor, dass auch dieser zweite Verbindungsast zwischen Facialis und Glossopharyngeus als eine der sympathischen Schlingen zwischen zwei verschiedenen Nerven zu betrachten sei. Noch deutlicher folgt dies aus der Bildung von Lacerta ocellata.

Während er hier nämlich auf der linken Seite meines Exemplars, wie bei Iguana und Salvator nigropunctatus, in's Ganglion petrosum selbst einmündet (vgl. die Abbildung Taf. II, fig. 1, e') steht er auf der rechten Seite nur durch einige Nervenfäden $(\alpha, \alpha)$ mit demselben in Verbindung, geht aber (ähnlich wie der R. communicans internus) selbst an dem Ganglion vorbei, um sich in einen der geflechtartig mit einander verbundenen Halsstämme des Sympathicus (e e) fortzusetzen.

Auch bei den Krokodilen findet sich dieser Verbindungsast, und zwar von ansehnlicher Stärke. Auch hier (Crocodilus biporcatus, Taf. III, fig. 5, e) entspringt er aus dem hinteren Hauptstamm des Facialis gerade da, wo dieser den R. recurrens ( $x$ ) aus dem Ganglion des Trigeminus aufgenommen hat. Nur verschmilat er nicht mit dem Glossopharyngeus, sondern verläuft in einem. 
eigenen Knochenkanal nach hinten bis zum gemeinschaftlichen Ganglion (D) der hinteren Hirnnerven, in dessen vordere kleinere Hälfte er zugleich mit den Wurzeln des Vagus, Glossopharyngeus und Accessorius eintritt.

So findet sich also, wie aus den eben gegebenen Specialbeschreibungen hervorgeht, bei den Sauriern und Krokodilen allgemein dieser $\mathbf{R}$. communicans externus nervi Facialis cum Glossopharyngeo. Bald mündet er direct ins Ganglion petrosum ein (Iguana tuberculata, Salvator nigropunctatus, Chamaeleo vilgaris, Istiurus Amboinensis); bald liegt dieses Ganglion ganz ausserhalb der Verbindung unseres Nerven mit dem Glossopharyngeus (Euprepes Sebae, Platydactylus guttatus); bei einigen verbindet er sich mit dem Glossopharyngeus, um gleich darauf (ohne Ganglienbildung) in den vereinigten Stamm der hinteren Hirnnerven einzumünden (Salvator Merianae); bei anderen endlich (rechte Seite von Lacerta ocellata) steht er mur durch einzelne Fäden mit dem Ganglion petrosum in Verbindung und lässt sich deutlich als einer der den Halstheil des Sympathicus bildenden Hauptstämme erkennen.

Dass dieser ganze $Z_{w e i g}$, wie namentlich aus der letzten Bildung sich ergiebt, ein Theil von einer der beiden grossen sympathischen Schlingen zwischen Trigeminus und hinteren Hirnnerven sei, wird später, in dem Abschnitte über den Sympathicus, gezeigt werden.

\section{Vom hinteren Hauptstamm des Facialis.}

( $A$ uf allen Figuren mit $\boldsymbol{f}$ bezeichnet.)

Des besseren Zusammenhanges wegen waren wir genöthigt, auf den vorigen Seiten schon einen Nerven (den R. communicans externus nervi Facialis cum Glossopharyngeo) zu betrachten, der vom hinteren Hauptstamm des Facialis ausgeht, ehe der Verlauf des letzteren im Allgemeinen und seine übrigen Verzweigungen genauer auseinandergesetzt wurden. Jetzt; nach Abzug aller derjenigen in den Facialis einmündenden oder von $\mathrm{ihm}$ ausgehenden Zweige, die als Verbindungsschlingen des Sympathicus anzusehen sind, nämlich der Rami communicantes internus et externus cum Glossopharyngeo, wird es leicht sein, die übrigen Zweige des Facialis kennen zu lernen, die als der eigentliche Verbreitungsbezirk des Antlitznerven zu betrachten sind.

Aus dem Ganglion des Facialis geht ausser dem R. palatinus und einigen unbeständigen Aesten (bei Iguana dem R. communicans internus cum Glossopharyngeo) noch der hintere Hauptstamm des siebenten Paares hervor, an Stärke den R. palatinus meist um ein Geringes übertreffend, der eine dem letzteren entgegengesetzte Richtung einschlägt. (Vergl. namentlich $f$ auf der linken Seite von Taf. I, fig. 1). Er wendet sich nämlich sogleich nach hinten, anfangs der Seite des Schädels dicht anliegend, tritt über das lange Gehörknöchelchen fort, und theilt sich gleich darauf in seine drei Endäste. Vor der Theilung oder an 
der Theilungsstelle selbst, seltener etwas später, empfängt er den ober- und ausserhalb des Schädels in einem grossen Bogen nach hinten verlaufenden Ramus recurrens aus dem Trigeminus (vergl. über diesen pag. $10 \mathrm{ff}$ ). Dass letzterer als eine der beiden Hauptparthien zu betrachten sei, mit denen der Kopftheil des Sympathicus bei den Sauriern (überhaupt den Reptilien?) beginnt, wird später bei näherer Erörterung der sympathischen Schlingen dargethan werden. Als seine Fortsetzung ist der dritte der aus dem hinteren Hauptstamm des Facialis hervorgehenden Aeste zu betrachten, nämlich der vorhin abgehandelte R. communicans externus cum Glossopharyngeo. Zieht man diese Verbindungszweige, wodurch der Facialis einerseits mit dem Glossopharyngeus und dem sympathischen Halstheil, andererseits mit dem Trigeminus (R. recurrens) verbunden ist, ab, so bleiben, als dem eigentlichen Verbreitungsbezirk desselben angehörig, nur zwei Nerven übrig, die Chorda tympani und der Muskelast.

a) Von der Chorda tympani.

(In den Figuren mit $t$ bezeichnet.)

Einen als Chorda tympani sich verhaltenden Nerven, der aus dem hinteren Hauptstamme des Facialis hervorgehend sich längs der hinteren Fläche des Quadratbeins nach unten schmiegt, in ein Loch des Unterkieferknochens hinter dem Gelenk des Quadratbeins eindringt, und dann im Knochen nach vorn umbiegt, um in einem eigenen Kanal nach vorn zu verlaufen und sich bald darauf mit dem Alveolartheile des dritten Astes des Trigeminus zu verbinden, habe ich mit Bestimmtheit gefunden bei Lacerta ocellata, Varanus Bengalensis, Varanus Niloticus, Euprepes Sebae, Platydactylus guttatus, Agama spinosa, Salvator nigropunctatus, Salvator Merianae, Iguana tuberculata, Istiurus Amboinensis. Bei Chamaeleo vulgaris und den Krokodilen habe ich mich von seinem Dasein nicht überzeugen können.*) Da sich, wie oben auseinander gesetzt (pag. 21 und 22) ein

*) Es ist dies ohne Zweifel derselbe Nerv, den Vog $\iota$ bei Monitor Niloticus, Varanus spec., Lucerta ocellata, Platydactylus guttatus, Chamaeleo Africanus als Paukenast beschreibt, ihm eine Verbreitung im Paukenfelle zuschreibend. Bei aller auf diesen Punkt gerichteten Aufmerksamkeit habe ich nie das kleinste Fädchen aus diesem Nerven ans Trommelfell gehen sehen, ihn dagegen ohne Ausnahme bei allen oben genannten Eidechsen bis in sein Loch im Unterkiefer verfolgen können. Ist dies derselbe, von Vogt nur nicht bis zu Ende verfolgte Ast, so wäre die Chorda tympani nach der Notiz dieses Forschers anch bei Chamaeleo zu statuiren. Bei den Krokodilen hat auch Vog t seinen Pankenast vermisst. - Dass die Chorda auch den Schlangen eigen sei, wird aus Müllers Darstellung (vergl. Neurologie der Myxinoiden in d. Abhandl. der Berl. Akad. d. Wissenscb. 1838, pag. 230) mehr als wahrscheinlich. Hier tritt aus dem Ganglion cervicale supremum (unserem Ganglion petrosum), in welches vorher mehrere Zweige aus dem Facialis eingetreten sind, ein Zweig ( $T$ af. IV, fig. 3, 9') ,zum hinteren Winkel „,des Unterkiefers, und tritt hier in eine sehr kleine Oeffnung, er verbindet sich wahrscheinlich "im Innern des Unterkiefers mit dem N. alveolaris inferior." - Nachdem Platner bekanntlich die Chorda bei den Vögeln und ibren Uebergang in den R. maxillaris inferior aufgefunden (bei der Krähe), ist es bemerkenswerth, dass Bonnsdorf (Act. Fenn. 1850, pag. 553) diesen Nerven gerade bei Corvus Cornix vermisste, ihn jedoch bei Grus cinerea mit ziemlicher Bestimmtheit auffand. 
Ast des Alveolaris inferior Trigemini beständig im M. mylohyoideus und als Ramus lingualis in der Zunge verbreitet, muss bei dem eben geschilderten Verlauf des in Rede stehenden Nerven wenigstens die Möglichkeit zugegeben werden, dass Fasern des Facialis an dieser Ausbreitung. Theil nehmen. Da es ferner mehr als wahrscheinlich ist, dass es sympathische Fasern sind, die durch unsern R. recurrens vom zweiten Ast des Trigeminus (vergl. oben pg. 10 und weiter unten die Abhandlung über den Kopftheil des Sympathicus) an den hinteren Hauptstamm des Facialis übergeführt werden, und da dieser R. recurrens von dem letzteren meist vor Abgang der Chorda, zuweilen sogar (Euprepes Sebae, Iguana tuberculata) von der Chorda selbst aufgenommen wird, so muss zweitens wenigstens die Möglichkeit zugegeben werden, dass auf diesem Wege auch sympathische Fasern, aus dem zweiten Aste des Trigeminus stammend, in die Zunge gelangen.

Bei allen erst genannten Formen ward der Ursprung der Chorda tympani und ihr Verlauf bis zur Oeffnung im hinteren Vorsprung des Unterkiefers verfolgt, bei einigen (Varanus Bengalensis, Salvator nigropunctatus) ward ihr weiterer Verlauf im Knochenkanal bis zur Verbindung mit dem Maxillaris inferior beobachtet.

Nachdem bei Varanus Bengalensis der hintere Hauptstamm des Facialis (Taf. II, fig. 2, f) in seiner Richtung nach hinten und aussen über die Columella fortgetreten, entlässt er einen Zweig $(\alpha)$ nach aussen, der sich sogleich wieder in zwei feinere Nerven theilt.

a) Der eine (fig. $2, \beta$ ) schlägt sich wieder nach innen und vorn, um sich wieder mit dem Hauptstamm des Facialis an der Stelle zu vereinen, wo der $\mathbf{R}$. recurrens aus dem Trigeminus in diesen einmündet.

ß) Der zweite (fig. 2, t) ist die Chorda tympani, welche über der Columella zurück an das Quadratbein herantritt, sich, der hinteren Fläche desselben anliegend, nach unten schlingt, und dicht hinter dem Gelenk dieses Knochens in ein besonderes Loch im hinteren Fortsatz des Unterkiefers einsenkt, um in einem eigenen, an der Innenseite des letzteren gelegenen, Kanal nach vorn zu gehen, und sich mit dem Maxillaris inferior Trigemini zu vereinen.

Bei Iguana tuberculata spaltet sich der hintere Hauptstamm des Facialis (Taf. II, fig. 3, f), schon bevor er über die Columella nach aussen und hinten getreten ist, in zwei anfangs eng mit einander verbundene $Z$ weige.

a) Der hintere (fig. 3, m), den R. communicans externus cum Glossopharyngeo (e) entlassend, giebt sich als der weiter unten zu beschreibende Muskelast zu erkennen.

ß) Der vordere nimmt den $R$. recurrens (x) ex Trigemino auf, schmiegt sich dann in einem Bogen an der hinteren Fläche des Quadratbeins nach unten, um als Chorda tympani durch ein feines Loch hinter dem Gelenk des Quadratbeins in den für ihn bestimmten Kanal des Unterkiefers einzutreten.

Auch bei Salvator Merianae tritt der hintere Hauptstamm über das Gehörknöchelchen fort nach hinten. Etwas hinter dem letzteren wendet er sich schräg nach aussen, um sich alsbald in gleicher Höhe mit der Austrittsstelle des Vagus in drei Aeste zu spalten. An dieser Theilungsstelle empfängt er den über den Schädel nach hinten getretenen R. recurrens Trigemini (Taf. III, fig. 4, $x$ ), so, dass es scheint, als ginge dieser allein in den ersten dieser drei Zweige über. 
Dieser erste Zweig, die Chorda tympani (fig. 4, t), von gleicher Stärke mit dem Muskelast (m), und dem Verbindungsast zum Glossopharyngeus (e), legt sich an den hinteren und inneren Rand des Quadratbeins an, um, ganz wie bei den übrigen Sauriern, längs desselben bis zu seinem Eintritt in den Unterkiefer zu verlaufen.

Salvator nigropunctatus (Taf. I, fig. 1, t) wiederholt ganz die Form von Salvator Merianae. Die Chorda ward auch hier, wie bei Varanus Bengalensis, in einem an der Innenseite des Unterkieferknochens gelegenen Kanal, bis zur Verschmelzung mit dem dritten Aste des Trigeminus, verfolgt.

Bei Lacerta ocellata theilt sich der hintere Hauptstamm des Facialis nach Aufnahme des $R$. recurrens aus dem Trigeminus (Taf. II, fig. 1, x), und nach Abgabe des R. communicans externus (e) in den Muskelast (m) und die Chorda tympani (t). Letztere zeigt bis zum Eintritt in ihr feines Loch im Unterkiefer ganz denselben Verlauf, wie bei den übrigen Eidechsen.

Dass die Chorda tympani bei Euprepes Sebae den R. recurrens aus dem Trigeminus aufnimmt, an der Verbindungsstelle aber durch eine feine Nervènbrücke mit dem, den Verbindungsast zum Glossopharyngeus entsendenden, Muskelast des Facialis in Verbindung steht, ward oben (pag. 33) erwähnt. Die Chorda geht hierauf wieder zurück über die Columella, legt sich an die hintere und innere Kante des Quadratbeins an, und läuft, demselben dicht anliegend, um, wie gewöhnlich, in ihr Loch hinter dem Gelenk des Quadratbeins einzutreten.

Bei Istiurus Amboinensis, Agama spinosa, Platydactylus guttatus wurden keine wesentliche Abweichungen beobachtet.

Bei Chamaeleo vulgaris verläuft der hintere Hauptstamm des Facialis (Taf. II, fig. 4, f) über den inneren Anheftungspunkt der Columella fort schräg nach hinten und aussen, um ziemlich nahe dem Ganglion petrosum den $R$. recurrens aus dem Trigeminus aufzunehmen, und unmittelbar darauf sich in vier $Z$ weige zu spalten.

Der vorderste von ihnen (fig. $4, t$ ) wendet sich schräg nach aussen und vorn, tritt wieder über die Columella zurück, und schlägt die Richtung nach dem Unterkiefergelenk ein. Es glückte nicht, ihn bis an's Ende zu verfolgen.

Bei Crocodilus biporcatus tritt der hintere Hauptstamm des Facialis (Taf. III, fig. 5, f) schräg nach unten, hinten und aussen, und verbindet sich hinter der knöchernen Gehörkapsel mit dem starken R. recurrens (x) aus dem Ganglion Trigemini unter spitzem Winkel, aus dessen Scheitelpunkt nicht nur der oben beschriebene starke R. communicans externus cum Glossopharyngeo (e), sondern noch ein zweiter Ast hervorgeht, der ganz die Richtung des vorherigen hinteren Hauptstammes verfolgt. Von diesem letzteren, hauptsächlich im M. digastricus sich verbreitenden Zweige, geht ein feiner Ast hervor, der zwar auch, wie bei Chamaeleo, die Richtung nach dem Unterkiefergelenk einschlägt, den es aber eben so wenig glïckte, bis an's Ende zu verfolgen.

\section{b) Vom Muskelaste des Facialis. \\ (Auf allen Figuren mit $m$ hezeichnet.)}

Ganz allgemein ist dies der zweite der beiden Endzweige, in die sich nach Aufnahme des R. recurrens und nach Abgabe des R. communicans externus cum Glossopharyngeo der hintere Hauptstamm des Facialis spaltet. Sein Ursprung aus dem letzteren ist bei den Specialbeschreibungen der Chorda tympani schon mit angegeben worden. Sein Verlauf, schräg nach aussen und hinten an den M. digastricus maxillae inferioris, sowie seine Verbreitung in diesem, und in dem M. longissimus colli Boianus (hintere, von den Dornfortsätzen der ersten Halswirbel entspringende Parthie des Mylohyoideus), ist so beständig bei allen 
Arten dieselbe, dass eine specielle Darlegung der einzelnen Formen vollkommen überflüssig erscheint. Dass der Facialis durch seine Ausbreitung an diesen beiden Muskeln wiederum seine Function als Nerv der Athemmuskeln bekundet, ist einleuchtend.

\section{Vierter Abschnitt. \\ Vom Nervus glossopharyngeus.}

Der Ursprung des Glossopharyngeus ist bei allen Sauriern von dem des Vagus getrennt*). Seine feine Wurzel entspringt von der Seitenfläche des verlängerten Markes (auf allen Figuren mit 9 bezeichnet) ziemlich nahe hinter dem Ursprung des Acusticus. Beständig tritt ferner dieselbe durch ein eigenes feines, vor dem des Vagus gelegenes Loch im Occipitale laterale aus dem Schädel.

Während indessen alle untersuchten Saurier diesen getrennten Ursprung und Austritt des Glossopharyngeus zeigten, konnte ich denselben bei Crocodilus biporcatus, Crocodilus acutus, und Alligator punctulatus nicht finden **). Man könnte die vorderste der fächerförmig zusammenstrahlenden Wurzeln des Vagus (vergl. von Crocodilus biporcatus, Taf. III, fig. 5, 10), wie Vogt es thut, als Wurzel des Glossopharyngeus deuten, ohne jedoch im Stande zu sein, einen directen Beweis für diese Ansicht zu liefern, da diese Wurzel keine getrennte Schädelöffnung hat, und sich ganz verhält wie die übrigen Vagus-Wurzeln.

Auch bei den Sauriern indessen, wo ein getrennter Ursprung des Glossopharyngeus sich nachweisen lässt, bleibt dieser in seinem Verlaufe nur selten frei. Bisweilen verschmilzt er früher oder später mit dem Stamme des Нypoglossus, um dann als dessen Ast aufzutreten, ***) oft erhält er Verstärkungszweige vom Vagus, die dann wieder aus seinem Stamme als eigenthümliche Zweige hervorgehen, - überall endlich finden sich die schon oben abgehandelten

*) Bendz giebt (I. l. pg. 15) bei Chamaeleo Africanus eine Verschmelzung von Glossopharyngens, Vagus und Hypoglossus an, die ich bei dem von mir untersuchten Exemplare nicht finde. Ebenso wenig kann ich Vogt beistimmen, der von Iguana und Platydactylus eine ähnliche Verschmelzung berichtet. - So scheint der Glossopharyngeus auch bei den übrigen Ordnungen einen getrennten Ursprung und Austritt aus dem Schädel zu haben. Unter den Schildhröten bei Emys Europaea nach Boianus, bei Testudo graeca und Chelonia mydas nach Bendz. Von den Schlangen bildet Müller einen getrennten Ursprung des neunten Paares ab von Python tigris und Crotalus horridus. (Vergl. Neurologie der Myxinoiden Taf. IV, fig. 3 u. 4.)

**) Nach Bendz ist dev Glossoph. bei Alligator lucius vollständig vom Vagus getrennt. Nach Vogt hat er bei Champza und Crocodilus zwar eine eigene Wurzel, tritt aber nicht aus einem besonderen Kaval aus, sondern mündet in die Oeffnung des Vagus ein, in dessen Ganglion er sich einsenkt.

***) Als Ast des Vagus, wie bei den meisten der nackten Amphibien, habe ich ibn nie auftreten seben, und muss auch hier dem Ausspruche von Bendz in Bezug auf Chamaeleo, so wie von Vogt in Bezug auf Platydactylus, Iguana und Draco widersprechen. 
Verbindungszweige vom Facialis (R. communicans internus rami palatini und R. communicans externus nervi Facialis). - Alle diese fremden Beimengungen machen es oft schwierig zu entscheiden, welche der austretenden Zweige dem Glossopharyngeus selbst, und welche den benachbarten Hirnnerven angehören.

\section{a. Vom Ganglion petrosum.}

(Auf den Figuren mit $D$ bezeichnet.)

Bevor wir diese fremden Verstärkungszweige weiter berïhren, von denen übrigens nach dem oben Gesagten die Verbindungsäste des Facialis keiner weiteren Erörterung bedürfen, ist es nöthig, eines Ganglions zu erwähnen, durch dessen Vermittelung meist die Vereinigung des Glossopharyngeus mit jenen Verbindungszweigen aus dem Facialis, oft auch mit denjenigen aus dem Vagus erfolgt. Wir bezeichnen dasselbe vorläufig nach Bendz' Vorgange als Ganglion petrosum, und behalten uns vor, die Gründe für diese Bezeichnung später, im Abschnitte über den Sympathicus näher auseinander zu setzen. Dasselbe liegt, wenn es überhaupt vorhanden ist, in der Bahn des Glossopharyngeus, meist kurz nach dessen Austritt aus dem Schädel, nimmt den von hinten kommenden Glossopharyngeus, die Verbindungszweige aus dem Facialis, meist auch diejenigen aus dem Vagus auf, und entlässt auf der anderen Seite ausser dem Stamm des Glossopharyngeus noch den Halsstamm des Sympathicus oder einen Theil desselben.

Sehr deutlich ist das röthliche elliptische Ganglion petrosum bei Iguana tuberculata (Taf. II, fig. 3, D). Ausser der eigentlichen Wurzel des Glossopharyngeus (9) treten hier drei Zweige aus dem Facialis (i i und e) in dasselbe ein, von denen oben ausführlich die Rede gewesen ist. Gleich aus dem hinteren Theil dieses Ganglions tritt ein feiner Nervenfaden $(\alpha)$, der mit einem Zweige des Vagus zusammen $(\beta)$ einen der drei sympathischen Halsstämme ( $s^{\prime \prime}$ ) bildet. Aus dem anderen Ende des Ganglions entstehen drei Nerven : der feinste $(\gamma)$ verbindet sich mit dem eben erwähnten sympathischen Stamm. Der zweite, stärkere ( $\left.s^{\prime}\right)$, bildet für sich den zweiten der Hauptstämme des Sympathicus am Halse. Der dritte endlich ( $\mathrm{gl}$ ) giebt sich in seinem Verlauf als eigentlicher Glossopharyngeus zu erkennen.

Bei Istiurus Amboinensis liegt das starke Ganglion petrosum (Taf. III, fig. 1, D), nicht nahe am Schädel, sondern noch etwas ausserhalb des Ganglion radicis nervi Vagi (E), von dem es noch um das Doppelte an Stärke übertroffen wird. In dasselbe treten ein: die Wurzel des neunten Paares (9) und die beiden Verbindungsäste vom Facialis ( $i$ und e). Austreten : der Halsstamm des Sympathicus (s) und der anfangs mit diesem verbundene Stamm des Glossopharyngeus ( $\mathrm{gl}$ ). Letzterer erhält gleich darauf einen Verstärkungszweig vom Vagus (1), und verschmilzt dann mit dem Hypoglossus.

Bei Salvator nigropunctatus (Taf. I, fig. 1, D) münden in das spindelförmige Ganglion petrosum ausser dem eigentlichen Glossopharyngeus (9) noch die beiden Verbindungszweige vom Facialis (der innere derselben [i] lässt sich als feiner weisser Streif unter dem Ganglion fort in den vereinigten Stamm von Vagus und Hypoglossus verfolgen), und zwei Zweige (1) aus dem vereinigten Stamm. 
Bei Salvator Merianae existirt dagegen bestimmt kein gesondertes Ganglion petrosum, sondern die Wurzel des neunten Paares tritt bald nach ihrem Austritt aus dem Schädel (Taf. III, fig. 4,9) in den gemeinschaftlichen Stamm der hinteren Hirnnerven ein (F), der weder hier, noch sonst, eine gangliöse Anschwellung zeigt.

Ob die Vereinigung von Nerven ein Ganglion zu nennen sei, blieb mir zweifelhaft bei Varanus Bengalensis, wo sechs verschiedene Wurzeln zu einem Stamme zusammentreten (drei Verbindungszweige aus dem Facialis [Taf. II, fig. 2, i und e e], zwei Verstärkungsäste aus dem Vagus $[1,1]$, und die Wurzel des Glossopharyngeus selbst [9]). Dieser Stamm erscheint gleichförmig dick, und nicht stärker, als die ein- und austretenden Nerven ihn erwarten lassen. Bei Varanus Niloticus ist dagegen das Ganglion sehr deutlich und gross; ausser den von hinten her in dasselbe einmündenden Verbindungszweigen vom Facialis und ausser dem Glossopharyngeus selbst, tritt noch ein kurzer Verstärkungsast aus dem Vagus in dasselbe ein. Ein einfacher Stamm geht daraus hervor, der sich bald in Vagus und Halsstamm des Sympathicus theilt.

Platydactylus guttatus zeigt ebenfalls eine schwache aber deutliche Anschwellung, die dem Ganglion petrosum verglichen werden muss (Taf. III, fig. 3, D). Der Glossopharyngeus verbindet sich ausserhalb des Schädels mit dem R. communicans internus (i), und schwillt nun zu einem schwachen länglichen Ganglion an. An den aus diesem Ganglion hervorgehenden einfachen Stamm tritt von vorn her unter rechtem Winkel der äussere Verbindungszweig des Facialis (e) heran, und lässt sich, an der Kreuzungsstelle mit ihm verschmelzend, in den Halsstamm des Sympathicus verfolgen. Ich kann $\mathrm{V}$ og t durchaus nicht beipflichten, nach welchem bei Platydactylus alle hinteren Hirnnervenwurzeln sich in einen grossen Stamm vereinen, aus dem Glossopharyngeus, Hypoglossus, Vagus und Sympathicus austreten sollen.

Bei Agama spinosa ist an der gewöhnlichen Stelle kein Ganglion vorhanden. Die beiden Verbindungszweige vom Facialis (Taf. III, fig. 2, i und e) verschmelzen mit einander zu einem kurzen Stamm, der gleich darauf in den Glossopharyngeus sich einsenkt, ohne dass dieser hier eine Spur einer Anschwellung zeigte. Der so entstandene Stamm ( $\mathrm{g} \mathrm{s}$ ) theilt sich bald wieder in den mit dem Vagus verschmelzenden sympathischen Halstheil ( $s$, und in den mit dem Hypoglossus sich verbindenden Glossopharyngeus (g l). Letzterer, in der Form eines kurzen Verbindungszweiges erscheinend, zeigt allerdings eine schwache längliche Anschwellung, die aber sehwerlich als Ganglion petrosum zu deuten sein möchte.

Bei Chamaeleo africanus wird weder von Bendz (1.1.pg. 15), noch von Vogt (1.1.pg. 26) ein Ganglion petrosum erwähnt. Beide schildern hier die Wurzeln des Vagus, Glossopharyngeus und Hypoglossus in einen einzigen starken Stamm (Ganglion nach Vogt) zusammentretend. Ich finde bei meinem Exemplar ein von diesen Darstellungen ganz verschiedenes Verhalten: Der. Glossopharyngeus tritt als feiner, aber deutlich zn unterscheidender Nerv (Taf. II, fig. 4, 9) durch ein etwas vor dem des Vagus gelegenes Loch aus dem Schädel, legt sich sogleich eng an den vereinigten Stamm von Vagus und Hypoglossus an, und erhält von diesem einen bedeutenden Verstärkungsast (I). Hiedurch erscheint der Nerv zwar stärker, als vorher, anfangs aber noch gleichförmig dick, schwillt jedoch gleich zu einem kleinen, aber deutlichen, dem vereinigten Stamme von Vagus und Hypoglossus sehr dicht anliegenden, Ganglion an (D). Aus diesem gehen fünf Nerven hervor: Die beiden Verbindungszweige vom Facialis (i und $e$, von uns als in's Ganglion einmündend angesehen), der Schlundzweig des Glossopharyngeus (g), ein starker, bisweilen aber anch vom Schlundzweige ausgehender, Verstärkungsdst an den Hypoglossus (o), und der Halsstamm des Sympathicus (s).

Euprepes Sebae besitzt ein Ganglion in dem Stamm des Glossopharyngeus, das aber nicht, wie sonst gewöhnlich, nahe der Austrittsstelle des letzteren liegt, und ausserdem weder mit dem Facialis noch mit dem Vagus in Verbindung steht. Der sehr feine Glossopharyngeus läuft, nachdem 
er dicht vor dem Vagus aus dem Schädel getreten, schräg nach hinten und aussen bis etwa in die Gegend des Unterkieferfortsatzes, verbindet sich hier mit dem gewöhnlichen R. communicans externus nervi Facialis, und bildet mit ihm einen kurzen Stamm, in den noch ein feiner Faden aus dem Vagus einmündet, der aber durchaus keine Spur einer gangliösen Anschwellung zeigt. Dieser kurze aber gleichförmig dicke Stamm theilt sich bald in zwei Nervenstämme : a) Der eine verfolgt seine Richtung nach hinten, nimmt noch einen Faden aus dem Vagus auf, und giebt sich durch seinen späteren Verlauf als Halsstamm des Sympathicus zu erkennen. - b) Der zweite ist der eigentliche Glossopharyngeus, der sich schräge nach hinten und aussen schlägt, noch einen Faden aus dem Vagus aufnimmt, und nun erst zu einem kleinen halbkugelförmigen Ganglion anschwillt, in das weiter kein Zweig vom Sympathicus, Vagus und Facialis einmündet.

So liegt auch bei Lacerta ocellata (wenigstens auf der rechten Seite meines Exemplars) das Ganglion petrosum (Taf. II, fig. 1, D) nur in der Bahn des Glossopharyngeus, ohne dass die Verbindungszweige aus dem Facialis in dasselbe einmündeten (i und e). Beide gehen vielmehr an dem Ganglion vorbei, und nur der äussere derselben (e) ist durch zwei Fäden $(\alpha, \alpha)$ mit ihm verbunden. Auf der linken Seite (rechte Seite der Figur) mündete dagegen bei dem von mir untersuchten Exemplar der äussere Verbindungsast (e') in das Ganglion (Dd) ein, während der innere (i) auch hier dasselbe umgeht. ${ }^{*}$ )

Was die Krokodile betrifft, so schreibt Bendz bei Alligator lucius dem Glossopharyngeus, dessen Wurzel mit der des Vagus durch eine gemeinschaftliche Oeffnung aus dem Schädel gehe, ein kleines ovales Ganglion petrosum zu**), das dicht vor dem Ganglion cervicale supremum liege, und mit diesem durch Zellgewebe verbunden sei. (Ein nach vorn gehender Verbindungszweig, unser R. communicans externus nervi Facalis cum Glossopharyngeo, ward nicht weiter verfolgt). Der Glossopharyngeus ist nach Bendz hier vollständig getrennt vom Vagus, und nur durch einen feinen Nervenfaden ist das Ganglion radicis nervi Vagi mit dem Ganglion petrosum verknüpft. Nach dieser Schilderung sind bei Alligator lucius drei sehr benachbarte Ganglien vorhanden, Ganglion cervicale supremum, Ganglion radicis nervi Vagi und Ganglion petrosum, - eine Bildungsweise, die ich bei keiner Eidechse und keinem Krokodil aufgefunden habe. Bei Alligator punctulatus, den ich zu untersuchen Gelegenheit hatte, fand ich eben so, wie bei Crocodilus biporcatus und Crocodilus acutus, dass die Wurzeln des Glossopharyngeus, Vagus, Accessorius und theilweise auch die des Hypoglossus in ein grosses, hart am Schädel gelegenes Ganglion zusammenmünden; das also nach der Bildung von Alligatov lucius als aus jenen drei Ganglien verschmolzen anzusehen sein würde. (Von Crocodilus biporcatus dargestellt Taf. III, fig. 5, D).

\section{b. Von den Verstärkungszweigen des Vagus an den Glossopharyngeus.}

(Auf den Figureu mit $l$ bezeichnet.)

Bei vielen Sauriern, jedoch keineswegs bei allen, werden Verstärkungszweige vom Vagus an den Glossopharyngeus abgegeben. Es ist wichtig, ihr

*) In Vogts flüchtigen Darstellungen ist bei keincr Eidechse ein Ganglion erwähnt, das dem Ganglion petrosum verglichen werden könnte. B e ndz erwähnt dasselbe dagegen überall, wo er einen getrennten Verlauf des Glossopharyngeus beschreibt (Lacerta agilis, Amphisbaena); nnter den Schildkröten findet es sich nach B o ia nus bei Emys Europaea, und nach Be nd z bei Chelonia Mydas, Testudo, Bei den Schlangen scheint dies Ganglion vorzukommen. M üll e r bildet dasselbe als Ganglion cervicale supremum von Python tigris ab (1. 1. Taf. IV, fig. 3), erwähnt seiner jedoch nicht bei der Klapperschlange. Auch bei Tropidonotus natrix ist es von B endz (1. 1. pg. 19) nicht aufgefunden.

**) Bidrag til den sammenlignende Anatomie af N. Glossopharyng. Vagus og Hypoglossus. Kiöbenhavn 1843, pg. 10 . 
Verhältniss bei den verschiedenen Formen genau zu ermitteln, weil dies der einzige anatomische $\mathrm{Weg}$ ist, durch den man zur Entscheidung über einzelne Nervenzweige gelangen kann, die, obgleich häufig als Aeste des Glossopharyngeus auftretend, dennoch nicht ihm angehören, sondern von Fasern des Vagus abzuleiten sind.

Diese Verbindungszweige sind immer sehr kurz, - häufig so kurz, dass es der grössten Vorsicht bedarf, um sie darzustellen. Die Schwierigkeit ihrer Behandlung wird dadurch erhöht, dass sie bald nach dem Austritt der hinteren Hirnnerven aus dem Schädel, wo diese noch sehr nahe bei einander verlaufen, abgegeben werden. Bei einigen erfolgt ihre Abgabe und respect. Aufnahme erst jenseits, bei vielen noch diesseits des Ganglion petrosum. Zuweilen fehlen sie, obgleich die ihnen entsprechenden Endzweige aus der Bahn des Glossopharyngeus hervorgehen, dann aber ist der letztere selbst vorher auf eine kurze Strecke mit den übrigen hinteren Hirnnerven zu einem gemeinschaftlichen Stamm verschmolzen, - eine Form, bei der ein Uebergang von Fasern des Vagus an den Glossopharyngeus noch einfacher bewirkt wird, als auf dem Wege wirklicher Verstärkungszweige.

Sehr nahe am Schädel werden diese Zweige vom Vagus an den Ǵlossopharyngeus abgegeben bei Varanus Bengalensis (Taf. II, fig. 2, 1). Es sind deren zwei, von ungleicher Stärke, gleichzeitig aus dem Vagus (v) da abgegeben, wo dieser sich gleich nach dem Austritt aus dem Schädel von dem ihm anfangs verbundenen Theil (der ersten Hirnwurzel [h']) des Hypoglossus trennt. Sie gehen schräg nach aussen, und münden gleichzeitig da in den Glossopharyngeus (9) ein, wo dieser die oben abgehandelten Verbindungszweige aus dem Facialis (e e und i) aufnimmt. So treten hier sechs Nerven (e, e, i, 9, 1, 1) zur Bildung eines Stammes zusammen, der sich durch diese Verstärkungen zwar ansehnlich verdickt zeigt, ohne dass man sich jedoch mit Bestimmtheit für das Dasein einer gángliösen Anschwellung entscheiden könnte.

Auch bei Varanus Niloticus, wo indessen ein sehr deutliches Ganglion petrosum in der Bahn des Glossopharyngeus vorhanden ist, geht ein feiner Verbindungszweig aus dem benachbarten Vagus von der Seite her in die Mitte desselben ein.

Bei Chamaeleo vulgaris (Taf. II, fig. 4) empfängt ebenfalls der feine Glossopharyngeus (9) gleich nach seinem Austritt aus dem Schädel einen kurzen aber starken Zweig (I) aus dem benachbarten Vagus (10), und schwillt sofort zu dem oben geschilderten Ganglion petrosum an (D).

Bei Salvator nigropunctatus (Taf. 1, fig. 1), wo der Glossopharyngeus vom Vagus getrennt bleibt, und ein deutliches Ganglion petrosum (D) zeigt, münden in die innere Fläche desselben zwei kurze Zweige $(1,1)$ aus dem Vagus ein.

Auch bei Salvator Merianae (Taf. III, fig. 4) existirt ein Verbigdungszweig (I) aus dem Vagus (10) an den Glossopharyngeus (9), welcher letztere sich aber kurz nach dessen Aufnahme und nach der Vereinigung mit dem äusseren Verbindungsast aus dem Facialis (e) wieder in den vereinigten Stamm (F) von Vagus und Hypoglossus einsenkt.

Erst jenseits des Ganglion petrosum empfängt der Glossopharyngeus diesen Verstärkungsast aus dem Vagus (Taf. II, fig. 3, I) bei Iguana tuberculata, obgleich zu bemerken ist, dass das Ganglion petrosum selbst durch eine geflechtartige Verbindung sympathischer Fäden mit Vagus und Hypoglossus in Verbindung steht. - 
Aehnlich bei Istiurus Amboinensis (Taf. III, fig. 1). Der Vagus giebt hier erst nach der Bildung seines grossen Ganglion radicis (E) einen starken Verbindungszweig (I) an den Glossopharyngeus $a b$, der in den letzteren ( $\mathrm{gl}$ ) erst jenseits des Ganglion petrosum (D) einmündet. Der Glossopharyngeus selbst verschmilzt bald nach seiner Aufnahme vollständig mit dem Hypoglossus (h). -

Bei Lacerta ocellata (Taf. II, fig. I) fehlen diese Verstärkungszweige des Vagus an den Glossopharyngeus gänzlich. Aus jenem gehen nur mehrere feine sympathische Fäden ( $\left.\beta, \beta^{\prime}, \beta^{\prime \prime}\right)$ hervor, die in das hier stark entwickelte Halsgeflecht eingehen, also nur auf indirecte Weise mit dem durch das Ganglion petrosum (D) damit verbundenen Glossopharyngeus $(9-\mathrm{gl})$ in Verbindung stehen.

Ebenso findet sich auch bei Euprepes Sebae kein eigentlicher Verstärkungsast des Vagus. Auch hier steht der letztere nur durch einzelne (drei) sehr feine sympathische Fäden mit dem Glossopharyngeus in Verbindung.

Bei Platydactylus guttatus tritt, wie bei Iguana und Istiurus, der nicht unbeträchtliche Verstärkungszweig aus dem Vagus (Taf. III, fig. 3,1 ) erst jenseits des Ganglion petrosum (D) in den Glossopharyngeus ( $\mathrm{g} \mathrm{l}$ ) ein.

Bei Agama spinosa ist das Verhältniss ziemlich verwickelt. Hier (Taf. III, fig. 2) verbindet sich der Vagus (10), nachdem er aus seinem Ganglion radicis (E) hervorgetreten, mit einem Theile (der ersten Hirnwurzel h') des Hypoglossus. Aus diesem vereinigten Stamme (hv) geht gleich darauf ein starker Verstärkungsast (I) an den Glossopharyngeus (99) ab, mit dem dieser zu einem kleinen Ganglion (petrosum? D) anschwillt. Unmittelbar nachher geht aus dem vereinigten Stanı ( $h v$ ) ein anderer Zweig (h) ab, der sich mit dem Rest des Hypoglossus (aus der zweiten Hirnwurzel, h", und dem ersten Halsnerven, 13, gebildet) vereinigt. Dieser letzte, wieder in den Hypoglossus eingehende Ast entspricht ohne Zweifel jener ersten Hirnwurzel des zwölften Paares. *)

\section{c. Verlauf des Glossopharyngeus im Allgemeinen.}

Nachdem der Glossopharyngeus ausserhalb des Schädels alle Verbindungszweige aús Facialis und Vagus (wenn solche vorhanden sind), aufgenommen hat, und nach seiner Trennung vom Halstheil des Sympathicus als selbstständiger Stamm entweder aus dem Ganglion peirosum oder aus einem gemeinschaftlichen Stamm der hinteren Hirnnerven hervorgetreten ist, verläuft er in der Regel folgendermassen :

Während der Vagus und der Halstheil des Sympathicus horizontal nach hinten laufen, schlägt sich der Glossopharyngeus, oft unter Abgabe von Schlundzweigen, nach aussen, um sich gewöhnlich dicht an den etwas mehr hinter-

*) Von Ameiva teguixin bildet Müll e r (vergl. Neurologie der Myxinoiden Taf. IV, fig. 5) einen deutlichen Verstärkungszweig des Vagus (X) an den Glossopharyngeus (IX) ab. - Beudz (Bidrag ete. pg. 13) erwähnt eines solchen bei Lacerta agilis, während Amphisbaena nach dieses Forschers Darstellung (pg. 17) seiner entbehrt. - Unter den Schlangen bildet Müller (1. 1. fig. 3) bei Python tigris einen Ast aus der Wurzel des Vagus in das Ganglion cervicale supremum (unser Ganglion petrosum) ab, während nach demselben Forscher bei der Klapperschlange (1. 1. fig. 4) eine gänzliche Verschmelzung der hinteren Hirnnerven, [wie bei Salvator Merianae] stautfindet. - Auch bei Tropidonotus natrix ist nach Bendz (l. L. pg. 18) Vagus und Glossopharyugens ganz verschmolzen. - Unter den Schildkröten fehlt der Verbindungsast aus dern Vagus an den Glossopharyngeus bei Emys Europaea (nach B oianus fig. 105), ist dagegen vorhanden bei Chelonia Mydas (nach Bendz, 1. 1. p:. 5). 
wärts entsprungenen Hypoglossus anzulegen, von diesem, abgesehen von seinem Ursprung und seiner Verbreitung, leicht durch seine bedeutendere Feinheit zu unterscheiden:). Beide treten, von aussen durch die $\mathrm{Mm}$. longissimus colli (Boianus) und Cucullaris bedeckt, um die hintere Spitze des grossen (hinteren) Zungenbeinhorns herum, wobei in der Regel der Glossopharyngeus an der vorderen Seite des Hypoglossus verläuft. Sie liegen auf diesem Wege einander sehr nahe, verschmelzen sogar bisweilen gänzlich mit einander. Beide biegen dann nach innen und vorn, und verlaufen parallel dem vorderen Rande des hinteren Zungenbeinhorns über dem $M$. geniohyoideus, (der selbst wieder vom M. mylohyoideus von unten her bedeckt wird) bis zur Aussenseite des hinteren Ansatzpunktes des M. hyoglossus (hinterer Rand des hinteren Zungenbeinhorns), um sich hier zu trennen. Der Hypoglossus tritt unter oder in den M. hyoglossus, der Glossopharyngeus dagegen bleibt über diesem Muskel, läuft unter dem M. hyoideus (vom hinteren Zungenbeinhorn an das vordere) nach vorn, und steigt da gegen die Mundhöhle in die Höhe, wo die beiden Zungenbeinhörner sich entweder mit einander, oder mit dem kurzen Körper des Zungenbeins unter spitzem Winkel verbinden, und endigt nahe dem Kehlkopf mit Schlund-, Kehlkopfsund Zungen - Zweigen.

Von diesem Verlauf, der sich bei Lacerta ocellata, Iguana tuberculata, Platydactylus guttatus, Salvator nigropunctatus, Varanus Bengalensis und Varanus Niloticus findet, zeigt Salvator Merianae insofern eine Abweichung, als der Glossopharyngeus, dessen selbstständige Wurzel (Taf. III, fig. 4,9), wie oben gesagt, mit dem vereinigten Stamm der hinteren Hirnnerven sich verbindet, später als Ast des aus diesem Stamm hervorgehenden Hypoglossus da erscheint, wo dieser um die hintere Spitze des hinteren Zungenbeinhorns über dem Geniohyoideus an den Hyoglossus hinanläuft.

Aehnlich bei Istiurus Amboinensis. Auch hier verschmilzt der Glossopharyngeus (Taf. III, fig. 1, gl) vollständig mit dem Hypoglossus (h), um später wieder als Ast des letzteren aufzutreten. Er trennt sich nämlich wieder von ihm da, wo dieser sich vor der hinteren Ecke des grossen Zungenbeinhorns zwischen die Bündel des M. geniohyoideus schlägt.

Dasselbe Verhältniss wiederholt sich bei Agama spinosa. Der Glossopharyngeus (Taf. III, fig. 2,9) nimmt den Kopftheil des Sympathicus (a) auf, tritt indessen bald wieder von dem, durch diese Verschmelzung entstandenen, Stamm ( $\mathrm{gs}$ ) wieder ab (99), um mit dem erst erwähnten Verstärkungszweig aus dem Vagus (I) zum Ganglion petrosum (D) anzuschwellen. Der hieraus hervorgehende einfache Stamm ( $\mathrm{gl}$ ) mündet ganz in den benachbarten Hypoglossus (hg) ein, aus dem er an derselben Stelle, wie bei Istiurus, wieder abgeht.

Bei Euprepes Sebae findet, abgesehen von der Verzweigung, in sofern eine geringe Abweichung von dem vorhin beschriebenen gewöhnlichen Verlaufe statt, als der äusserst feine Glossopharyngeus zwar auch hier in Begleitung des Hypoglossus den Bogen um das hintere Zungenbeinhorn macht,

*) Während der Hypoglossus der stärkste der hinteren Hirnnerven ist, erscheint der Glossopharyngeus immer als ein sehr feiner Stamm. Arn feinsten in Vergleich zu den übrigen erschien er mir bei Lacerta ocellata und Euprepes Sebae, - bier fehlen ihm nämlich die bei den übrigen seinen Stamm verstärkenden Elemente des Vagus. 
um später hinter dem Winkel des vorderen Hornes wieder in die Höhe zu treten, aber nicht an der vorderen, sondern an der hinteren, später inneren, Seite des Hypoglossus verlänft.

Was die Krokodile betrifft, so entsteht sowohl bei Crocodilus acutus und Crocodilus biporcatus, als auch bei Alligator punctulatus der Stamm des Glossopharyngeus aus dem vorderen Rande des dicht am Schädel liegenden grossen Ganglion der hinteren Hirnnerven. Bei Crocodilus biporcatus (Taf. UI, fig. 5, D) treten sechs Nerven aus diesem Ganglion aus: 1) Der Sympathicus impar (s); 2) ein Verbindungszweig zum ersten Halsnerven, nach unserer Ansicht dem R. externus des Accessorius entsprechend (v); 3) der R. laryngopharyngeus *) (Ip); 4) der Glossopharyngeus (gl); 5) der Vagus (v); 6) der Hypoglossus (h). - Von diesen entspringt der Glossopharyngeus (gl) am weitesten nach vorn aus dem Ganglion, so dass es scheint, als käme derselbe allein aus dem kleineren vorderen Abschnitt des Ganglions. Er ist indessen dem hinteren Abschnitt desselben fest verschmolzen, und lässt sich auf mechanischem Wege durchaus nicht isoliren. Er läuft schräg nach aussen und hinten, biegt dann hinter dem hinteren Horn des Zungenbeins nach vorn um, indem er über den Hypoglossus forttritt, und giebt hinter dem Zungenbeinhorn einen beträchtlichen Zweig (ל) nach innen an den aus dem N. laryngopharyngeus hervortretenden N. laryngeus superior (I s). Nach Abgabe dieses Zweiges tritt der. Glossopharyngeus in Begleitung des Hypoglossus an den M. hyomaxillaris **), unter welchem er sich in zwei Zweige theilt:

a) geht nach innen und oben, dringt in die Fasern des Hyomaxillaris ein, und breitet sich mit mehreren $Z$ weigen in demselben aus;

ß) tritt nahe an den benachbarten Hypoglossus heran, nimmt von ihm einen seiner eigenen Stärke gleichen Ast auf, und schlägt sich nach vorn und innen an den M. hyoglossus hinan. Der grösste Theil seiner Fasern dringt in diesen Muskel ein, und breitet sich in ihm und in dem muskulösen Boden der Mundhöhle aus. Ein Nervenbündel dagegen dringt weiter nach vorn, tritt vom Hyoglossus unter den mehr nach aussen gelegenen Genioglossus, um in ihm sich zu verbreiten.

Auffallend ist hier die Ausbreitung des Glossopharyngeus an so vielen Muskeln, wobei jedoch eines Theils die erwähnte Verschmelzung mit dem Hypoglossus, andererseits der benachbarte Ursprung mit dem letzteren aus dem gemeinschaftlichen Ganglion zu berücksichtigen ist. Wichtig

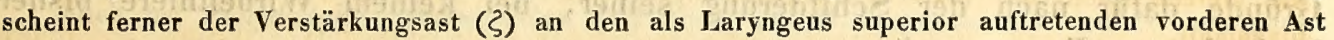
des Laryngopharyngeus ( $1 \mathrm{~s})$.

Auch bei Crocodilus acutus entspringt der Glossopharyngeus ganz wie bei Crocodilus biporcatus aus dem Ganglion. Auch hier giebt er einen beträchtlichen Verstärkungszweig an den aus dem N. laryngopharyngeus entspringenden N. laryngeus superior, tritt über den M. sternomaxillaris ***), giebt diesem und dem über demselben liegenden M. hyomaxillaris ansehnliche Zweige, und läuft an der inneren Seite des Hypoglossus nach vorn, um endlich im muskulösen Boden der Mundhöhle sich auszubreiten.

* Dass bei allen Krokodilen ein getrennter N. laryngopharyngeus aus dem Ganglion entspringt, der den R. laryngeus superior (Taf. III, fig. 5, $1 \mathrm{~s}$ ) und nebst den Rami recurrentes die Speiseröhrenzweige (Id) des Vagus enthält, von denen letztere als R. descendens glossopharyngei von S tannius beschrieben wurden, wird später dargethan. Hier möge nur erwäbnt werden, dass es mir bei der genauesten Untersuchung nicht möglich war, einen vom Vagus entspringenden, in diesen sogenannten $R$. descendens Glossopharyngei übergehenden $Z_{w e i g}$ anfzufinden, dessen Anwesenheit Stannius (Lehrb. pg. 191) behauptet.

**) Ueber die Zungenbeinmuskeln der Krokodile vgl. den Abschnitt von, der Ausbreitung des Hypoglossus.

***) Auch über diesen nur den Krokodilen eigenen Muskel verweisen wir anf den Abschnitt über den Hypoglossus. 
Ganz dieselbe Form zeigt Alligator punctulatus, nur dass hier der bei Crocodilus so beträchtliche Verstärkungszweig an den $\mathbf{N}$. laryngeus superior äusserst schwach ist, und ans zwei sehr feinen Fäden besteht. Ferner findet hier, nach Abgabe deutlicher Zweige an den M. hyomaxillaris, keine eigentliche Verschmelzung mit dem Hypoglossus statt, sondern der Glossopharyngeus steht mit dem letzteren nur durch feine Nervenschlingen in Verbindung.

\section{d. Von den Zweigen des Glossopharyngeus.}

Vom Stamme des Glossopharyngeus können auf dem in dem vorigen $\mathbf{A b -}$ schnitte angegebenen Wege nach seinem Hervorgang aus dem Ganglion petrosum und nach der Aufnahme der oben geschilderten Verbindungszweige aus dem Facialis und dem Vagus folgende Zweige abgegeben werden: 1) Schlundzweige; 2) Muskelzweige; 3) Kehlkopfszweige; 4) Zungenzweige. - Einzelne dieser Aeste fehlen hin und wieder, weil es Elemente anderer Nerven sind, die nicht bei allen Eidechsen in der Bahn des Glossopharyngeus verlaufen. Mögen hier zuerst diejenigen Zweige betrachtet werden, die nicht der eigentlichen Wurzel des letzteren selbst, sondern den Verstärkungszweigen anderer Hirnnerven entsprechen.

1) Vom Kehlkopfszweige. (N. laryngeus superior.)

a) Form desselben.

Bei vielen Sauriern entspringt aus der Bahn des Glossopharyngeus ein Nerv, der trotz seiner den Eidechsen und Krokodilen eigenthümlichen Form ohne Zweifel als ein Analogon des N. laryngeus superior nervi Vagi der höheren Thiere zu betrachten ist. Diese seine Abstammung aus dem Vagus sind wir auch für die Reptilien zu beweisen im Stande, und werden die anatomischen Gründe dafür nach der Schilderung seiner, bei keinem Wirbelthiere bisher beobachteten, Form angeben.

Nachdem der Glossopharyngeus die später zu behandelnden Schlund- und Muskel-Zweige abgegeben, tritt der Rest des Nerven, der nur noch den Kehlkopfs- und den Zungen-Zweig enthält, constant über den M. hyoglossus fort nach innen an die Luftröhre, an welcher er, nahe dem Kehlkopf, mit dem von hinten heraufsteigenden $R$. recurrens vagi zusammen tritt, verschmilzt bisweilen mit letzterem, und endigt nach Abgabe des Zungenzweiges immer in einer sehr auffallenden Form. Unter dem Kehlkopf nämlich tritt der Nerv der einen Seite constant nach der anderen hinüber, und verschmilzt mit dem entsprechenden Nerven der anderen Seite zu einer einfachen oder doppelten Schlinge.

Diese auffallende Schlingenbildung des N. laryngeus superior ward bei folgenden Eidechsen und Krokodilen gefunden: Lacerta ocellata, Varanus Bengalensis, Varanus Niloticus, Iguana tuber culata, Istiurus Amboinensis, Salvator Merianae, Salvator nigropunctatus, Platydactylus guttatus, Euprepes Sebae, Crocodilus biporcatus, Crocodilus acutus, Alligator punctulatus. Von allen darauf untersuchten Formen ward sie nur beim Chamaeleon nicht beobachtet. Der hier aus dem Ganglion petrosum entspringende und diesem Nerven entsprechende $\Lambda$ st (Taf. II, fig. 4, g) läuft unter Abgabe 
von Schlundfäden nach unten und innen, und scheint an der diesem Thier eigenthümlichen Kehlkopfsblase ohne Schlingenbildung zu endigen.

Ueberall liegt diese Schlinge unter dem hinteren Theil des Kehlkopfs, und stellt sich in der Form eines queren, namentlich in der Mitte abgeplatteten, bogenförmigen Nerven dar. Bei den Krakodilen ist die Schlinge besonders stark. Sie liegt hier über der schildförmigen Erweiterung des Zungenbeinkörpers, und wird erst nach ihrer Entfernung gesehen. Bei Crocodilus biporcatus ist sie doppelt, und die hintere derselben so stark, die aus ihr hervorgehenden Fäden so fein, dass man kaum eine peripherische Endigung aller zu ihrer Bildung ausammentretenden Nervenfäden annehmen kann, sondern fast zu der Annahme gedrängt wird, dass die Nervenfasern beider Seiten hier zusammentreten, um grösstentheils auf der anderen Seite centripetal zurück zu laufen. Bei Crocodilus acutus und Alligator punctulatus liegt eine solche Annahme viel ferner: auch hier ist die Schlinge sehr beträchtlich, allein die aus dem Ende des R. laryngeus superior hervortretenden Zweige für die Muskeln des Keblkopfes sind viel beträchtlicher.

B) Vom Verhältniss des Kehlkopfszmeiges zum $\boldsymbol{R}$. recurrens $\boldsymbol{N}$. vagi.

Immer tritt an das letzte Ende des Kehlkopfszweiges die letzte Endigung des $R$. recurrens Vagi heran, meist in der Gegend des dritten oder vierten Luftröhrenringes. Bald findet eine völlige Verschmelzung beider Nerven, bald eine blosse Verbindung durch Nervenzweige statt, während in einzelnen Fällen beide Nerven völlig getrennt bleiben. In letzterem Falle ist es der Kehlkopfszweig, der die Schlinge bildet.

Durchaus keine Verbindung beider Nerven zeigt Varanus Bengalensis. Unter dem hinteren Theil des Kehlkopfes communiciren die letzten Enden der Kehlkopfszweige der rechten und linken Seite mit einander und bilden mehrere dem Kehlkopf hart anliegende Schlingen mit einander. In gleicher Weise treten auch vom $R$. recurrens $N$. vagi, der übrigens getrennt verläuft, einzelne Fäden von der rechten Seite zur linken hinüber.

Auch bei Platydactylus guttatus keine Verbindung des R. recurrens mit dem N. laryngeus superior. Der Glossopharyngeus, der von aussen und hinten her hinter den Kehlkopf gelangt ist, theilt sich hier in vier Zweige. Zwei derselben dringen in die seitlichen und unteren starken Kehlkopfsmuskeln ein, der dritte geht als K. lingualis im M. hyoglossus zur Zunge, während der vierte allein hinter dem Kehlkopf die Querschlinge mit dem entsprechenden Nerven der anderen Seite bildet. Der $R$. recurrens vereint sich nicht mit dem Kehlkopfszweige, und nimmt an dessen Schlinge keinen Theil, sondern dringt frei von der Seite her in den Kehlkopf ein, um sich in dessen Schleimhäuten auszubreiten.

Mit einem Theil des R. recurrens ist der Kehlkopfszweig des Glossopharyngeus verbunden bei Iguana tuberculata und Salvator nigropunctatus. Aus dieser Verbindung geht auch hier eine deutliche Schlinge hinter und unter dem Kehlkopf nach dem entsprechenden Nerven der anderen Seite hinüber. Aus der Schlinge selbst gehen Fäden in die Muskeln des Kehlkopfs hervor. Der übrig gebliebene Theil des $R$. recurrens dringt von der Seite her in den Kehlkopf ein.

Bei Salvator Merianae findet dagegen die Verbindung des Kehlkopfszweiges mit dem Ende des R. recurrens erst statt, nachdem der erstere seine Schlinge gebildet hat. Diese entsteht in der Weise, dass der Nerv der linken Seite erst einen Verbindungszweig an denjenigen der rechten Seite absendet, um gleich darauf wieder von diesem Ersatzfäden zu erhalten. So findet in der Form einer doppelten Schlinge ein wirklicher Austausch von Fasern statt. An ein centripetales Zurücklaufen der Fäden eines Nerven auf der anderen Seite ist hier sicher nicht zu denken. 
Eine völlige Verschmelzung des $R$. recurrens Vagi mit dem Kehlkopfszweige findet statt bei Euprepes Sebae und Lacerla ocellata, welche beide ausserdem noch darin übereinstimmen, dass der letztere nicht als Ast des Glossopharyngeus, sondern als Zweig des Vagus erscheint. Bei Euprepes Sebae tritt der Kehlkopfszweig in der Gegend des vierten Luftröhrenringes an die Trachea heran, nimmt den von hinten längs der äusseren Seite der letzteren heraufsteigenden $R$. recurrens Vagi vollständig auf, schickt dann dicht hinter dem Kehlkopf eine stärkere, gleich darauf noch eine schwächere Schlinge nach der anderen Seite hinüber, und dringt dann selbst in die Muskeln des Kehlkopfes ein. Bei Lacerta ocellata steht der Kehlkopfszweig nahe am Kehlkopf nach aussen durch verhältnissmässig starke Nervenzweige mit dem eigentlichen Glossopharyngeus in Verbindung, während er nach innen entweder (rechte Seite meines Exemplars) mit dem R. recurrens ganz verschmilzt, oder ihm (linke Seite) eine beträchtliche Verstärkung zuschickt, so dass an dieser Stelle, nahe dem Kehlkopf, drei Nerven mit einander communiciren: der R. recurrens, der R. laryngeus superior und der Glossopharyngeus. Der so verstärkte $R$. recurrens theilt sich alsdann in zwei Theile, von denen der eine quer hinter dem Kehlkopfe die starke Schlinge bildet, während der andere in die starken Kehlkopfsmuskeln eindringt.

Bei den Krokodilen ist die Form dieses Kehlkopfszweiges vollkommen dieselbe, wie bei den Eidechsen, sein Ursprung aber ganz abweichend. Es existirt hier nämlich, wie schon vorhin (pg. 45) erwähnt, ein schon vom Ganglion der hinteren Hirnnerven an getrennter N. laryngopharyngeus (Taf. III, fig 5, l p), der alle den Kehlkopf, Speiseröhre, Luftröhre versorgenden Fäden des Vagus enthält. Dieser läuft parallel mit dem Glossopharyngeus, Hypoglossus und dem eigentlichen Stamm des Vagus nach aussen und unten, und theilt sich da, wo Glossopharyngeus und Hypoglossus nach vorn, Vagus nach hinten umbiegen, in zwei Aeste $\left.{ }^{*}\right)$. Der hintere ( $R$. descendens nervi laryngopharyngei [Taf. 3, fig. 5, ld], von Vogt als Sympathicus superficialis, von Stannius [Lehrbuch pg. 191] als R. descendens Glossopharyngei bezeichnet,) versorgt die Speiseröhre und entlässt die Rami recurrentes nervi Vagi. Der vordere (Is) verbindet sich beständig

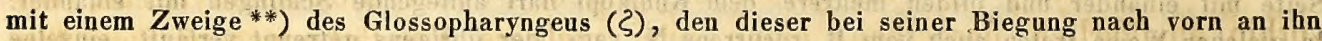
abgiebt. Nach dieser Verstärkung wird dieser vordere Ast des N. laryngopharyngeus zum eigentlichen Kehlkopfsnerven, der nach Abgabe einiger schwacher Schlundzweige das letzte Ende des R. recurrens aufnimmt, und entweder eine doppelte (Crocodilus biporcatus) oder einfache Schlinge (Crocodilus acutus) mit dem Nerven der anderen Seite unter dem hinteren Theil des Kehlkopfes bildet.

\section{y) Von der endlichen Verzweigung des Kehlkopfsnerven.}

Aus der Schlinge selbst gehen in der Regel keine Zweige hervor. Einzig: bei Crocodilus biporcatus ward aus der Mitte derselben ein in den Kehlkopf eindringender Faden beobachtet.

Das letzte Ende des diese Schlinge absendenden Kehlkopfszweiges dringt entweder verbunden mit Endzweigen des R. recurrens oder allein regelmässig: in die seitlichen und unteren Muskeln des Kehlkopfes ein. Andere Ausbreitungen der letzten Endigung desselben wurden nicht beobachtet. In den Fällen, wo der R. recurrens sich nicht mit jenem verbindet (Varanus Bengalensis, Platy-

*) Diese Theilung erfolgt bei Alligator punctulatus schon früher, nämlich bald nach dem Ursprung aus dem Ganglion.

*) Kurz und stark bei Crocodilus biporcatus, schwächer bei Crocodilus acutus. Zwei sehr schwache Verbindungszweige existiren bei Alligator punctulatus. 
dactyhis guttatus), geht dieser nicht in die Muskeln, sondern an die Schleimhäute des Kehlkopfes.

d) Ueber den Kehlkopfszweig als Ast des Vagus.

Es entsteht jetzt die Frage, ob der eben beschriebene Kehlkopfszweig wirklich dem eigentlichen Glossopharyngeus angehöre. Ein Zweifel hieran kann schon durch den Umstand entstehen, dass derselbe nicht immer aus dem Glossopharyngeus, sondern bisweilen aus dem Stamm des Vagus entspringt (Euprepes Sebae, Lacerta ocellata, und nach Bendz auch Amphisbaena), und dass gleichwohl der letztere vorher keine Verstärkungsfasern aus dem neunten Paare erhalten hat, von denen man diesen Kehlkopfsast ableiten könnte. Es lässt sich indessen auch anatomisch beweisen, dass dieser Nerv wirklich dem Vagus angehört, und nur hin und wieder in der Bahn des Glossopharyngeus verläuft, um als dessen Zweig aufzutreten. Diese Natur als eines Vagus-Astes ist diesem Nerven in der That auch bereits von Stannius zugesprochen*), der sein Auftreten als Ast des Glossopharyngeus mit Recht durch die Innigkeit der Verbindungen zwischen Glossopharyngeus und Vagus erklärt. Folgendes ist der aus unseren vorher geschilderten Beobachtungen sich ergebende directe Beweis für die Richtigkeit des Ausspruches dieses Forschers.

Alle Saurier, wo der R. laryngeus superior als Ast des Glossopharyngeus erscheint (Salvutor nigropunctatus, Iguana tuberculata, Platydactylus guttatus, Varanus Bengalensis)**), sind gerade diejenigen, wo der Glossopharyngeus, wie vorhin ausführlich dargethan, einen oder mehrere Verstärkungsäste aus dem Vagus erhält, oder gar völlig mit ihm und dem Hypoglossus zu einem gemeinschaftlichen Stamme der hinteren Hirnnerven verschmolzen ist (Salvator Merianae und unter den Schlangen Tropidonotus natrix nach Bend $\mathrm{z}^{* * *}$ ), Crotalus horridus nach Müller). Dahingegen, wo der Kehlkopfszweig als Ast des Glossopharyngeus fehlt, und als Zweig des Vagus auftritt (Euprepes Sebae und Lacerta ocellata)

*) Lehrbuch der vergl. Anat. pg. 191, Anmerk. 9.

**) Hieher auch Lacerta agilis. Nach B endz bekommt der Glossopharyngeus eineu Verstärkungszweig aus dem Vagus, und breitet sich später mit einem Zweige am Kehlkopf aus. - Dass auch bei Ameiva teguixin und von den Schlangen bei Python tigris, wo nach Müller, wie oben gesagt, Verstärkungszweige rom Vagus an den Glossopharyugeus stattfinden, der R. laryngeus superior aus dem letzteren hervorgeht, also jenem Verstärkungsaste des Vagus entspricht, folgt 2 war nicht aus einer speciellen Beschreibung des berühmten Anatomen, aber daraus, dass dieser den ganzen Glossopharyngeus als „vorderen Kehlkopfsnerven" bezeichnet. - Unter den Vögeln findet sich dasselbe Verhältniss nach B on s d o rf (1. 1. pg. 530, 555) bei Corvus Cornix. Hier erhält der Glossopharyngeus einen Verstärkungsast aus dem Ganglion radicis nervi Vagi, und entlässt dafür später den R. laryngeus superior. Ganz ebenso nach demselben Forscher (1. 1. pg. 605, 607) bei Grus cinereá.

***) Bei dieser Schlange entlässt nach B endz der vereinigte Stamm von Vagus und Glossopharyngeus einen sich am Kehlkopfe ausbreitenden $\mathrm{Zweig}$, den dieser Forscher für den N. laryngeus superior der höheren Thiere hält, weil der Mangel eines Ganglion petrosum ihn verhindert, denselben als Glossopharyngeus zu deuten (I. l. pg. 19). 
fehlen mit Bestimmtheit alle Verstärkungsfasern aus dem Vagus an den Glossopharyngeus *). Diese vorhin (pg. $41 \mathrm{ff}$.) abgehandelten Verstärkungszweige sind es also, die dem $\mathbf{N}$. laryngeus superior entsprechen, und letzterer ist mithin keinesweges, wie es bei der Mehrzahl der Saurier leicht scheinen könnte, als Ast des Glossopharyngeus, sondern als Zweig des Vagus zu betrachten.

Hieraus erklären sich denn auch einzelne Fälle, wo dieser Kehlkopfszweig sogar als Ast des Hypoglossus erscheint. Bei Agama spinosa, Istiurus Amboinensis und Salvator Merianae findet sich dies Verhältniss.

Bei Agama spinosa und Istiurus Amboinensis verbindet sich der Glossopharyngeus nach Aufnahme eines Verstärkungsastes aus dem Vagus (Taf. III, fig. 1, I und fig. 2, I) mit dem Hypoglossus, - natürlich also, dass nicht bloss der Geschmacksnerv selbst, sondern auch die mit ihm verschmolzenen fremden Elemente als Zweige desselben erscheinen. Bei Salvator Merianae geht der Glossopharyngeus (auch hier den Kehlkopfszweig enthaltend), mit dem Hypoglossus zu einem Stamm verbunden, aus dem vereinigten Stamm der hinteren Hirnnerven hervor, - ein Verhältniss, woraus sich leicht erklären lässt, wie die den Kehlkopfszweig bildenden Fasern des Vagus in die Bahn des Glossopharyngeus, und somit auch in die des Hypoglossus gelangten.

2) Von den Schlundzweigen des Glossopharyngeus.

Fast bei allen Sauriern gehen Schlundzweige aus der Bahn des Glossopharyngeus hervor. Bald erscheinen sie in der Form eines selbstständigen Astes (Euprepes, Iguana), bald sind die den Schlund versorgenden Fäden in dem Kehlkopfszweige enthalten, aus dem sie bei seiner Krümmung nach vorn und innen allmählich austreten. Letzteres Verhältniss namentlich scheint darauf hinzudeuten, dass auch sie, wie der Kehlkopfszweig selbst, vom Vagus abzuleiten sind. Nur lässt sich dagegen das Beispiel einiger Eidechsen, z. B. Euprepes Sebae, anführen, wo ein besonderer, stark ausgebildeter, vom N. laryngeus superior getrennter, Schlundzweig des Glossopharyngeus vorhanden ist, ohne dass dieser vorher Verstärkungszweige aus dem Vagus erhalten hätte.

\section{3) Von den Muskelzweigen des Glossopharyngeus.}

Zu den unzweifelhaft fremden in der Bahn des Glossopharyngeus verlaufenden Elementen gehören die bei den Krokodilen und einigen Eidechsen an einzelne Muskeln entsendeten Zweige. Häufig fehlen dieselben gänzlich, und wo sie vorhanden sind, erstrecken sie sich ausschliesslich an Muskeln des

* Bei Ampliisbaena alba wird von Bendz kein Kehlkopfszweig des Glossopharyngeus namhaft gemacht, dagegen ein mit 2 Aesten an der Luftröbre und dem Keblkopf sich ausbreitender Zweig des Vagus beschrieben. Diesem Verhältniss entspricht, dass derselbe Forscher hier keinen Verstärkungsast des Vagus an den Glossopharyngeus erwähnt. (1. 1. pg. 17 und 18.)

Unter den Schildkröten fehlen bei Emys Europaea nach Bo ianns (fig. 105), wie oben erwähnt, die Verstärkungszweige des Vagus an den Glossopharyngeus. Diesem entsprechend geht auch hier der Kehlkopfszweig nicht aus dem Glossopharyngeus, sondern aus dem Vagus hervor. Einer Schlinge unter dern Kehlkopf wird nicht erwähnt. Der Kehlkopfszweig breitet sicb auch hier in Muskeln, uämlich im M. dilatator und M. constrictor laryngis aus. (B o i a n us l. 1. fig. $107, \mathrm{e}^{*}$.) 
Zungenbeins. Schon aus diesem Umstande wird ihre Abstammung aus dem Hypoglossus wahrscheinlich. Dem letzteren liegt, wie oben gesagt, der Glossopharyngeus auf seinem Wege nach unten und vorn gewöhnlich so dicht an, dass es oft schwer hält, ihn von demselben zu trennen. Dazu kommt, dass oft Verbindungszweige des mit dem Vagus theilweise verschmolzenen Hypoglossus an den Glossopharyngeus vorkommen (Varanus, Bengalensis), ja, dass endlich zuweilen eine wirkliche Vereinigung von Vagus, Glossopharyngeus und Hypoglossus bald nach ihrem Austritte aus dem Schädel stattfindet (Salvator Merianae), - lauter Umstände, aus denen sich der Uebergang motorischer Fasern aus dem Hypoglossus an den Glossopharyngeus leicht erklären lässt. Dass indessen der schliessliche Beweis für die Richtigkeit dieser Ansicht sich erst aus Reizungsversuchen an lebenden Thieren ergeben würde, ist einleuchtend.

Uebrigens erklärt sich aus der Absendung einzelner Muskelzweige aus der Bahn des Glossopharyngeus dessen eigenthümlicher Verlauf bei vielen Eidechsen. Nur in seltenen Fällen, wo aber beständig diese Muskelzweige ihm fehlen, läuft derselbe, wie man es überall erwarten sollte, dem Schlunde dicht anliegend, nach aussen und unten, dann nach innen und vorn zur Zunge und zum Kehlkopf. In der Regel macht er in Begleitung des Hypoglossus einen viel grösseren Bogen um das hintere Zungenbeinhorn herum, ein Weg, der dadurch bedingt wird, dass er selbst noch oft einzelne Aeste an die Zungenbeinmuskeln abzugeben hat, bevor er seine Endigung an Kehlkopf und Zunge findet.

Alle Muskelzweige wurden gänzlich vermisst bei Chamaeleo vulgaris, Salvator nigropunctatus. Wenn dergleichen vorhanden sind, so ist am beständigsten ein Ast in den M. hyoideus (vom vorderen Rande des hinteren Zungenbeinhorns an den hinteren Rand des vorderen). Er wird vom Glossopharyngeus abgegeben, bald nachdem derselbe sich vom Hypoglossus getrennt, und unterhalb des M. hyoideus nach vorn zu dem Winkel verläuft, den das vordere Horn mit dem hinteren oder mit dem Zungenbeinkörper bildet. Dieser Muskelzweig ward beobachtet bei : Lacerta ocellata, Euprepes Sebae, Varanus Bengalensis, Iguana tuberculata. - Ausser diesem Aste ward einmal (bei Varanus Bengalensis) ein Zweig an den M. omohyoideus, und bei Platydactylus guttatus ein Ast an den M. hyoglossus beobachtet.

Bei den Krokodilen, wo freilich Glossopharyngeus und Hypoglossus gemeinschaftlich aus dem grossen Ganglion der hinteren Hirnnerven entspringen, ist, wie oben pg. 45 gesagt, die Zahl der Muskelzweige des ersteren viel stärker, als bei den Eidechsen. Immer wird hier der M. hyomaxillaris mit starken $Z$ weigen ron ihm versorgt. Unbeständig scheint der bei Crocodilus acutus beobachtete Zweig an den M. sternomaxillaris, und die Zweige an den M. hyoglossus und M. genioglossus (Crocodilus biporcatus) zu sein, welche letztere aus der kurz vor ihrer Abgabe stattfindenden erneuerten Verbindung mit dem Hypoglossus abzuleiten sind.

\section{4) Vom Zungenzweige des Glossopharyngeus.}

Nachdem in den vorhergehenden Abschnitten diejenigen Zweige des Glossopharyngeus abgehandelt wurden, welche als fremde Beimengungen anderer Nerven zu betrachten sein dürften, bleibt nur noch die Frage zu erledigen, wèlche 
peripherischen Endigungen seinen eigenen Wurzelfasern entsprechen. Diese Frage beantwortet sich leicht, wenn man die eintretenden Verstärkungszweige von anderen Nerven gegen die denselben entsprechenden austretenden Aeste in Rechnung bringt, - nach Abzug beider bleibt einerseits die Wurzel des Glossopharyngeus selbst nach, als deren Fortsetzung alsdann die auf der anderen Seite nachbleibenden $\mathrm{Zweige}$ zu betrachten sein werden.

Den Verbindungsästen aus dem Facialis entspricht, wie oben pg. 30 und 32 ff schon theilweise angedeutet ist, und weiter unten noch näher auseinandergesetzt werden wird, der einfache oder doppelte Halsstamm des Sympathicus, vom Ganglion petrosum des Glossopharyngeus aus in der Regel beginnend. Den Verstärkungszweigen aus dem Vagus entspricht der Kehlkopfszweig (vgl. pg. 49), vielleicht auch die Schlundzweige (pg. 50), während die hin und wieder aus der Bahn des Glossopharyngeus ausgegebenen Muskelzweige vom Hypoglossus abzuleiten sind. Es bleibt demnach von austretenden Aesten nur der Zungenzweig als derjenige Ast nach, der den Fasern des Glossopharyngeus selbst eigenthümlich ist.

Ein eigentlicher $\mathbf{R}$. lingualis des Glossopharyngeus wird bei allen denjenigen Formen vermisst, wo eine Verschmelzung des letzteren mit dem Hypoglossus stattfindet (Istiurus Amboinensis, Agama spinosa, Salvator Merianae, Chamaeleo vulgaris), - die Vermuthung liegt nahe, dass hier die Zungenfasern des Glossopharyngeus durch den Hypoglossus selbst bis zum Punkt ihrer Ausbreitung geführt werden. Bei den übrigen Sauriern ist derselbe vorhanden, gehört aber beständig zu den allerfeinsten und letzten Ausbreitungen des Stammes. Er wird beständig da abgegeben, wo der Glossopharyngeus in dem Winkel zwischen vorderen Zungenbeinhorn und Zungenbeinkörper in die Höhe tritt. Während hier der Kehlkopfszweig sich an den vordersten Theil der Luftröhre anlegt, um unter dem Kehlkopf die oben beschriebene Schlinge mit dem entsprechenden Zweige der anderen Seite zu bilden, tritt der andere Endzweig des Stammes als R. lingualis an den M. hyoglossus und verläuft in diesem, neben den Endzweigen des Hypoglossus, nach vorn bis zur Zunge.

\section{Fünfter Abschnitt. Vom Nervus Vagus. a. Von dem Ursprunge desselben.}

Der Vagus entspringt überall von der Seitenfläche des verlängerten Markes. In den meisten Fällen lassen sich seine Wurzeln (auf den Abbildungen mit 10 bezeichnet) nur sehr schwer von denen des Accessorius Willisii unterscheiden. 
Das erste, dem Vagus angehörige, Bündel liegt in der Regel der Grundfläche ziemlich nahe, eben hinter der Wurzel des Glossopharyngeus, während das letzte Wurzelbündel des Accessorius auf der Rückenfläche des verlängerten Markes selbst liegt, und bis hinter den ersten, bisweilen sogar bis hinter den zweiten Halsnerven hinabreicht. Zwischen diesen beiden äussersten Wurzeln liegt in schräger Linie eine Zahl von fünf bis acht Bündeln, dem Vagus und Accessorius gemeinschaftlich, wie es scheint, angehörig. Oft wird. ausserdem das Urtheil über den Ursprung des Vagus noch durch eine oder zwei von der Grundfläche des verlängerten Markes entspringende Wurzelbündel erschwert, so dass von drei verschiedenen Parthien des verlängerten Markes, Nervenbündel zu einem Stamme zusammenstrahlen, nämlich 1) von der Rückenseite; 2) von der Seitenfläche, 3) von der Grundfläche. Die dritte Parthie gehört, wie bald gezeigt werden wird, ausschliesslich dem Hypoglossus an, dessen Ursprünge bisweilen mit denen des Vagus sich vereinen; die erste und ein Theil der zweiten sind, wie dies namentlich die Bildung von Salvator nigropunctatus deutlich macht, als Wurzeln des Accessorius zu betrachten, so dass nach Abzug dieser Beiden nur die ersten Wurzeln der zweiten Parthie als eigentliche Wurzeln des Vagus nachbleiben.

Am freiesten zeigt sich der Ursprung des Vagus bei Salvator nigropunctatus (Taf. I, fig. I). Die feinen Wurzeln des Accessorius (II) sammeln sich zu einem dünnen Nervenstamm, der über (d. h. dem Rücken näher) der einfachen Wurzel des Vagus (10) durch dasselbe Loch austritt. Bei oberflächlicher Betrachtung scheinen beide nur einen, in der Richtung von vorn nach hinten schmalen, in der Richtung von unten nach oben breiten und platten Nervenstamm zu bilden. Bei vorsichtiger Behandlung sieht man jedoch, nachdem man die von unten her diesen Stamm bedeckende Wurzel des Hypoglossus (h') durchgeschnitten, und zur Seite gebogen hat, den Accessorius über dem Vagus nach aussen treten, und innerhalb des Kanals nur einen nicht unbeträchtlichen Verstärkungszweig an denselben abgeben. Eine Verbindung des Vagus mit Wurzeln des Hypoglossus findet innerhalb des Schädels nicht statt, sondern die erste Hirnwurzel des Jetzteren (h'), läuft durch einen besonderen Kanal nach aussen, um ausserhalb erst mit dem Vagus sich zu vereinen.

Bei Iguana tuberculata (Taf. II, fig. 3) scheint es unmöglich zu entscheiden, welche der fächerförmig in's Foramen lacerum zusammenstrahlenden Wurzeln dem Vagus, welche dem Accessorius angehören. Auch hier findet keine Verbindung der Vagus- (10) und Hypoglossus-Wurzeln (h' und h") statt, - ja letzterer bleibt auch ausserhalb des Schädels vollkommen frei.

Ganz ähnlich verhält sich Lacerta ocellata (Taf. II, fig. 1), Platydactylus guttatus (Taf. III, fig. 3) und Istiurus Amboinensis (Taf. III, fig. 1). Ueberall ein fächerförmiges Zusammenstrahlen der Wurzeln des Accessorius und Vagus (10 und 11), überall vollkommene Freibeit des Hypoglossus im Ursprung ( $h$ ' und $h$ ") und Verlauf $(h)$.

Bei Varanus Bengalensis (Taf. II, fig. 2) zeigen die Wurzelverhältnisse dieser drei Nerven eine viel complicirtere Form, die sich aber leicht durch Vergleichung mit den eben beschriebenen deuten lässt. Eine breite Nervenwurzel von der Grundfläche (erste Hirnwurzel des Hypoglossus h'), ein starker Nervenstrang von der Seitenfläche dicht hinter dem Glossopharyngeus (Vagus), und endlich mehrere feine Wurzeln von der Rückenseite des verlängerteu Markes entspringend (Accessorius), vereinen sich noch innerhalb des Schädels zu einem Stamme, der sich gleich ausserhalb desselben wieder in zwei Stämme, Vagus (v) und Hypoglossus (h) spaltet. 
Bei Agama spinosa (Taf. III, fig. 2) ist der Vagus (10) mit der ersten Hirnwurzel des Hypoglossus (h') innerhalb des Schädels nicht verschmolzen, verbindet sich aber mit ihr gleich nach der Bildung seines Ganglion radicis (E).

Was Chamaeleo vulgaris betrifft, so finde ich das von Bendz (1.1.pg. 15) beschriebene Zusammenstrahlen sämmtlicher Wurzeln der hinteren Hirnnerven innerhalb des Schädels in einen gemeinschaftlichen Stamm, den Vogt (I. I. pg. 26) als ein bedeutendes Ganglion schildert, bei meinem Exemplare nicht bestätigt (vgl. Taf. II, fig. 4). Hier ist zunächst die Wurzel des Glossopharyngeus (9), wie schon oben gesagt, vollkommen frei, geht durch eine besondere Oeffnung aus dem Schädel und schwillt nach Aufnahme eines kurzen aber starken Verstärkungszweiges (l) aus dem Vagus zum Ganglion petrosum (D) an. (Ueber die Bildung des letzteren vgl. pag. 40). Als eigentliche Wurzeln des Vagus möchten zwei, von der Seitenfläche des verlängerten Markes etwas weiter nach hinten als die des Glossopharyngeus entspringende stärkere Wurzelbündel (10) anzusehen sein, die durch einen besonderen Kanal im Occipitale laterale austreten, und in demselben sich zu einem kurzen Stamm verbinden. Eben ausserhalb des Schädels vereinigt sich mit demselben die ebenfalls durch eine besondere Oeffnung ausgetretene Hirnwurzel (h') des Hypoglossus.

Jenes, von Vogt für Chamaeleo beschriebene Verhältniss finde ich dagegen bei allen von mir untersuchten Krokodilen (Crocodilus biporcatus, Crocodilus acutus und Alligator punctulatus). Hier sammeln sich die Wurzeln sämmtlicher hinteren Hirnnerven in einem gemeinschaftlichen, dem Schädel dicht anliegenden grossen Ganglion, in welches ausserdem noch der oben beschriebene Verbindungsast vom Facialis einmündet. Von unten diese Wurzelverhältnisse untersuchend findet man bei Crocodilus biporcatus (Taf. III, fig. 5) sechs gesonderte Wurzeln in's Ganglion (D) eintretend: 1) Zwei Bündel von der Grundfäche des verlängerten Markes ( $h$ '), von unten her in die hintere grössere Hälfte des Ganglions einmündend, dem Hypoglossus angehörend; 2) vier Bündel in schräger Richtung von unten und vorn nach oben und hinten in den vorderen kleineren Theil des Ganglions eintretend, dem Vagus und Glossopharyngeus entsprechend (10); endlich tritt noch die aus sechs bis acht feinen Bündeln zusammengesetzte Wurzel des Accessorius hinzu, die nur von der Rückenseite aus sichtbar ist. *)

\section{b. Von dem Verhältniss des Vagus zu anderen Hirnnerven.}

Nur selten bleibt der Vagus in seinem ganzen Verlaufe vollständig frei (Euprepes Sebae, Lacerta ocellata). In der Regel findet früher oder später eine Verbindung mit dem Glossopharyngeus oder dem Hypoglossus, bisweilen auch mit beiden statt.

Was zunächst die Verbindung mit dem Glossopharyngeus betriff, so ist schon früher gesagt worden, dass eine vollständige Verschmelzung beider Nerven nur in dem einen Falle stattfindet, wenn überhaupt alle hinteren Hirnnerven sich zu einem gemeinschaftlichen Stamme vereinen. Dann theilt sich dieser letztere später in zwei Stämme, deren einer wiederum Glossopharyngeus und Hypoglossus zusammen, der andere Vagus und Halstheil des Sympathicus enthält. (Salvator

*) Nach Vogt (l. l. pg. 33) ist die Wurzel des Glossopharyngeus frei, und tritt durch einen eigenen Kanal aus. Nach Bendz (l. l. pg. 10) gebt sie bei Alligator lucius mit dem Vagus durch einen gemeinschaftlichen Kanal aus dem Schädel, bleibt aber in ihrem ganzen Verlaufe frei, ein eignes Ganglion petrosum bildend. Unser grosses Kopfoanglion scheint bei Alligator lucius nicht vorhanden zu sein. 
Merianae, Taf III, fig. 4.)*) - In den meisten Fällen erfolgt die Verbindung

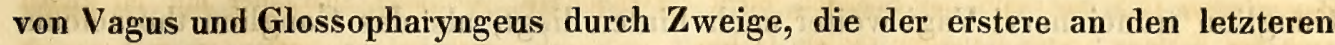
entsendet. Ueber diese Verstärkungszweige ist früher (pg. 41, 49, 50) ausführlich gehandelt, und gezeigt worden, dass sie dem N. laryngeus superior, vielleicht auch den Schlundzweigen des Glossopharyngeus entsprechen.

Mit dem Hypoglossus dagegen findet immer die erstere Art der Vereinigung

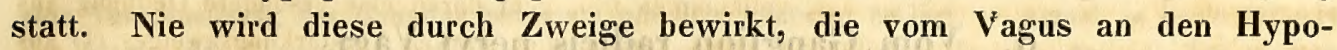
glossus, oder von diesem an jenen entsandt werden, sondern wo eine Verbindung beider Nerven beobachtet wird, erfolgt diese immer nur dadurch, dass der vordere Stamm des Hypoglossus, aus einer oder auch beiden Hirnwurzeln desselben gebildet, sich auf eine Strecke mit dem Vagus vereint. Diese Verhältnisse werden bei der Darstellung des Hypoglossus ihre Erledigung finden.

\section{c. Vom Verhältniss des Vagus zum Sympathicus.}

Der Vagus ist in der Regel mit dem Halstheil des Sympathicus nur durch feine Nervenschlingen verbunden. Nur selten verschmelzen die von vorn her kommenden sympathischen Elemente gänzlich mit ihm, um später von seinem Stamme sich wieder zu trennen. In diesem Falle fehlen erklärlicher Weise alle Verbindungszweige.

Völlige Vereinigung des Vagus mit dem Halstheil des Sympathicus findet sich bei Salvator nigropunctatus. Hier legen sich die aus dem R. palatinus nach hinten sich fortsetzenden Fasern des letzteren als $R$. communicans internus nervi palatini cum Glossopharyngeo (Taf. I, fig. I, i, i) an das Ganglion petrosum von unten her dicht an, lassen sich aber unter diesem durch in den vereinigten Stamm von Vagus und Hypoglossus verfolgen (F). Dieser theilt sich bald darauf in zwei Stämme. Der stärkere (h) wendet sich nach aussen, und ist in seinem Verlaufe als Hypoglossus zu erkennen. Der zweite ( $\mathrm{v} s$ ), etwas schwächer, verfolgt die Richtung nach hinten, und theilt sich bald nach seiner Trennung von jenem in zwei Zweige, den Halsstamm des Sympathicus, und den Vagus. Jeder der letzteren schwillt eben unter dem Brustgürtel zu einem starken ovalen Ganglion an. - Ganz ähnlich ist das Verhalten bei Salvator Merianae und nach Müllers Abbildung bei Ameiva teguixin.

In den meisten Fällen scheint übrigens der Halstheil des Sympathicus nur durch feine Fäden mit dem Vagus in Verbindung zu stehen. Diese Fäden, oft in der Form eines Geflechtes erscheinend (Lacerta ocellata, Iguana tuberculata), wurden wenigstens bei den grösseren Arten niemals vermisst.

Nach Abgabe dieser Fäden verläuft der Vagus in der Regel ohne weitere Verbindung mit dem Sympathicus bis zur Bildung seines Ganglion trunci. Wohl aber findet sich, anșcheinend beständig, eine starke von Vogt bei den Sauriern entdeckte Verbindungsschlinge zwischen diesem Ganglion und dem ersten oder zweiten Brustganglion des Sympathicus. Von dieser wird weiter unten die Rede

*) Nach Mülle r (vergl. Neurologie der Myxinoiden, Taf. IV, fig. 3) verschmelzen auch bei Crotalus horridus säımmtliche hinteren Hirnnerven zu einem Stamm. 
sein. Hier möge nur bemerkt werden, dass bei Varanus Bengalensis, wo das Ganglion trunci nervi Vagi weiter nach hinten liegt, als das Ganglion thoracicum primum, die aus dem letzteren austretenden Fäden nicht in das erwähnte Ganglion, sondern in den benachbarten Stamm des Vagus sich einsenken, und dass dieser an der Stelle ihrer Einmündung schon eine vordere, ganz kleine Anschwellung zeigt.

\section{d. Vom Ganglion radicis nervi Vagi.}

(Auf den Abbildungen mit $\boldsymbol{E}$ bezeichnet.)

Ein dem Vagus selbst angehöriges Wurzelganglion kommt nicht allen Sauriern $\mathrm{zu}$, und auch da, wo ein solches als unzweifelhaft vorhanden von den Autoren angegeben wird, findet häufig eine Verschmelzung mit dem Glossopharyngeus oder mit dem sympathischen Halstheil statt, so dass diese Anschwellung auch als Ganglion petrosum oder als Ganglion cervicale supremum gedeutet werden kann. Nur wenige Fälle sind mir bekannt, wo unzweifelhaft ein Ganglion radicis eben ausserhalb der Schädelhöhle in der Bahn des Vagus vorkommt.

Als vollkommen gleichförmiger Nervenstrang ohne Spur einer Verdickung erscheint der Vagus von seinem Ursprung innerhalb des Schädels bis zu seiner späteren Verzweigung bei Iguana tuberculata und Platydactylus guttatus. Hier nimmt der Vagus nur die Accessorius-Wurzel auf, und nicht einmal eine Verdickung des ursprünglichen Stammes findet durch Aufnahme von Verstärkungszweigen statt. (Taf. II, fig. $3, v$ und Taf. III, fig. 3, v.)

Bei Salvator nigropunctatus ist eher eine Täuschung möglich. Die einfache starke Wurzel des Vagus (Taf. I, fig. 1, 10) erhält innerhalb des Kanals einen Verstärkungszweig vom Accessorius, und nimmt, eben ausserhalb des Schädels, die durch einen besonderen Kanal austretende erste Hirnwurzel des Hypoglossus (h') auf." Bis hieher erscheint der Stamm gleichförmig dick. Etwas später, nach Abgabe zweier Verbindungszweige $(1,1)$ für das benachbarte Ganglion petrosum und eines Astes (u) für die Carotiden-Drüse zeigt sich freilich bei fast gleichzeitiger Aufnahme der Verstärkungszweige aus dem R. palatinus des Facialis (i) und der ferneren Elemente des Hypoglossus ( $h$ " und $k$, der zweiten Hirnwurzel und dem ersten Halsnerven angehörig) eine beträchtliche Verstärkung des Stammes (F), die aber nicht bedeutender ist, als dass sie nicht lediglich durch diese Verstärkungszweige erklärt würde. Der Stamm erscheint verstärkt, aber nicht ganglienartig angeschwollen.

Selbst bei Salvator Merianae (Taf. III, fig. 4), wo die Wurzel des Vagus mit einem Theil des Hypoglossus aus dem Schädel hervortritt, und dann auch den Glossopharyngeus (9) aufnimmt, wo man also mindestens eine dem Ganglion petrosum entsprechende Anschwellung erwarten sollte, findet sich ein einfacher, durch die Aufnahme so vieler Elemente ansehnlich verdickter, aber keineswegs ganglienartig angeschwollener Stamm (F).

Ebenso wenig finde ich ein Ganglion radicis bei Varanus Bengalensis (Taf. 1I, fig. 2). Die Wurzel des Vagus, diejenige des Accessorius, und die erste Hirnwurzel des Hypoglossus treten hier, wie oben bemerkt, schon inerhalb des Schädels zur Bildung eines gleichförmig dicken Stammes zusammen, der gleich ausserhalb des Foramen lacerum sich in die seinen Elementen entsprechenden Stämme theilt. 
Bei Chamaeleo vulgaris, wo von Vogt und Bendz ein deutliches Ganglion radicis angegeben wird, war auch ich zuerst in Zweifel. Bei sorgfältiger Behandlung der bei diesem Thier sehr feinen Nerven gelang es indessen, das dem Vagus sehr nahe anliegende Ganglion petrosum (Taf. II, fig. 4, D), mit welchem dieser durch Zellgewebe und einen sehr kurzen Verbindungszweig vereinigt ist, $\mathrm{zn}$ isoliren, worauf alsdann der vereinigte Stamm von Vagus und Hypoglossus gleichförmig dick erschien. Wenn also bei den von jenen beiden Forschern untersuchten Exemplaren ein Ganglion an der Austrittsstelle des Vagus sich fand, so ist diese Anschwellung leicht durch eine Verschmelzung des Ganglion petrosum mit dem letzteren erklärt, $\rightarrow$ zumal da beide Autoren den Stamm des Glossopharyngeus aus diesem Ganglion hervorgehen lassen, den ich bei meinem Exemplar aus dem getrennten Ganglion petrosum austreten sah.

Bei Lacerıa ocellata treten die fächerförmig zusammenstrahlenden Wurzeln des Vagus im Foramen lacerum zu einem Nerven zusammen, der sich auf den ersten Blick angeschwollen, oder vielmehr in der Richtung von unten nach oben verdickt darstellt. Diese Verdickung ist indessen so unbedeutend, dass es erst einer mikroskopischen Untersuchung an frischen Exemplaren bedürfen wird, um die ganglienartige Natur dieser Anschwellung zu erweisen.

Bei Istiurus Amboinensis ist dagegen bestimmt ein grosses Ganglion radicis nervi Vagi (Taf. III, fig. 1, E) gleich nach dem Austritt des letzteren aus der Schädelhöhle vorhanden. Aus demselben geht nach hinten und aussen der feine $R$. externus Accessorii (y), nach innen und hinten der starke Stamm des Vagus ( $v$ ) hervor.

Ebenso ist auch bei Agama spinosa ein sehr deutliches ovales Ganglion radicis vorhanden, aus welchem hier jedoch nur der gleich darauf mit der ersten Hirnwurzel des Hypoglossus verschmelzende Stamm des Vagus hervorgeht (Taf. III, fig. 2, D). ${ }^{*}$ )

Dass bei den Krokodilen (Crocodilus biporcatus, Crocodilus acutus und Alligator punctulatus) ein grosses Ganglion hart am Schädel vorhanden sei, in welches Glossopharyngeus, Vagus, Accessorius und Hypoglossus eintreten, und welches ausserdem noch den Kopftheil des Sympathicus aufnimmt, ist oben erwähnt. Dies Ganglion kann demnach als aus drei verschmolzenen Ganglien (Ganglion petrosum, Ganglion cervicale supremum und Ganglion radicis nervi Vagi) gebildet angesehen werden, um so mehr, als bei Alligator lucius nach $\mathbf{B}$ endz in der That diese drei Ganglien getrennt vorhanden sind.

\section{e. Vom Ganglion trunci nervi Vagi.}

Das von Vogt und Bendz gleichzeitig. entdeckte Ganglion trunci nervi Vagi, das der letztere auch bei den Schlangen, Schildkröten (Testudo) und

*) Von auderen Autoren erwähnt Vogt (1.l. pg. 15) kein Ganglion radicis bei Monitor Niloticus, ebenso wenig bei dem Varanus vom Senegal. - Von Ameiva teguixin bildet Müller (l. l. Taf. IV, fig. 5) kein Ganglion radicis nervi Vagi ab. - Bei Amplisbaena alba ist Be ndz (1. 1. pg. 17) über das Dasein eines Ganglion radicis in Zweifel. Vagus und Glossopharyngeus gehen hier durch eine gemeinschaftliche Oeffnung aus dem Schädel, und letzterer besitzt ein deutliches Ganglion petrosum. - Auch Vogt (l. l. pg. 30) beschreibt kein Ganglion radicis nervi Vagi bei Amphisbaena. Bei Lacerta agilis erwähnt Bendz (1. 1. pg. 13) desselben dagegen als unzweifelhaft vorbanden. - Unter den Schlangen fiudet es sich nach B e $\mathrm{ndz}$ bei Tropidonotus natrix (1. 1. pg. 19). Von Python tigris und Crotalus horridus hat Mülle r (1. 1.) kein Ganglion radicis nervi Vagi abgebildet. Die Vereinigung der hinteren Hirnnerven der letztgenannten Art schildert Vogt (1. 1. pg. 44) als ein grosses Ganglion, das in ähulicher Form auch bei Naja Haje vorhanden sein soll (1. l. pg. 47). Derselbe Forscher erwähnt dagegen keines Ganglions bei Coluber siculus (pg.49) und Vipera prester. Bei beiden sind die hinteren Hirnnerven zu einem gemeinschaftlichen Stamm vereint. - Von den Schildkröten giebt B e nd z (1. 1. pg. 6) bei Chelonia Mydas und bei Testudo (pg. 9) ein grosses Ganglion radicis nervi Vagi an. - Desselben erwähnt B oianus (fig. 107, X) bei Emys Europaea. 
Krokodilen auffand, ist insbesondere von Bendz sowohl seiner Lage und Form nach, als in Bezug auf die aus demselben hervorgehenden Zweige so gründich geschildert ${ }^{*}$ ), dass eine weitere Erörterung vollkommen überflüssig erscheint. Ich habe dasselbe von ansehnlicher Grösse bei allen untersuchten Sauriern und Krokodilen im Stamme des Vagus bei dessen Eintritt in die Brusthöhle, in der Nähe des Herzens, gefunden. Es ist oval, platt und meist von röthlicher Farbe; in der Regel steht es durch einen starken Zweig mit dem ersten Brustganglion des Sympathicus in Verbindung. Vor Bildung desselben gehen nur selten aus dem den Hals hinablaufenden Stamme des Vagus Zweige aus. Von diesen wird später gehandelt werden.

\section{f. Von den Aesten des Vagus.}

1) Vom N. laryngopharyngeus.

Von allen Zweigen des Vagus zeigen die den Kehlkopf und den Schlund versorgenden Aeste die grösste Neigung, sich von den übrigen Elementen desselben früh zu isoliren, - ohne Zweifel aus dem Grunde, weil sie Organe zu versorgen haben, die ziemlich weit nach vorn liegen, während der eigentliche Verbreitungsbezirk der übrigen Theile des Vagus erst von der Brusthöhle an beginnt. So ist schon oben (pg. $49 \mathrm{ff}$ ) ausführlich bewiesen worden, dass der R. laryngeus superior (der indessen, wie oben gesagt, zugleich auch meistens die Schlundfäden enthält, und deshalb eigentlich nach Bendz Vorgange als N. laryngopharyngeus aufgefasst werden muss) häufig in der Form eines Verstärkungsastes aus der Bahn des Vagus schon sehr früh in diejenige des Glossopharyngeus übertritt, um aus dem letzteren wieder in der Form eines seiner Aeste auszutreten, - und auch dieses Anlehnen an den Geschmacksnerven erklärt sich auf leichte Art aus dem Umstande, dass gerade dieser beständig an den von jenen Elementen versorgten Organen (Kehlkopf und Schlund) vorbei läuft. *)

Nur selten hält dieser Kehlkopf-Schlund-Nerv noch etwas länger mit den übrigen Fasern des Vagus zusammen, erst jenseits des Ganglion trunci austretend, - eine Form, die nur bei Euprepes Sebae und Lacerta ocellata beobachtet wurde, und die sich vielleicht daraus erklärt, dass diese Eidechsen einen verhältnissmässig kurzen Hals haben, mithin der Umweg in die Brusthöhle hinab und dann wieder zurück an Kehlkopf und Schlund bei ihnen nicht so gross ist, wie bei den übrigen Sauriern. Ebenso selten aber (nur bei den Krokodilen und

*) Bidrag etc. pg. 31 .

*) An ähnliche Verhältnisse bei den übrigen Ordnungen der Reptilien und bei den Vögeln ist oben (pg. 49 Anm.) erinnert. Bei den letzteren erklärt sich aus der Länge ihres Halses leicht bei diesem Nerven die Vermeidung des grossen Umweges durch die Brusthöhle. 
nach Bendz bei den Schildkröten) erscheint der $\mathbf{N}$. laryngopharyngeus als ein gleich vom Anfange an selbstständiger Nerv, enthält aber in diesem Falle auch noch diejenigen Fasern des Vagus, wodurch die am Halse selbst liegenden Eingeweide (Luftröhre und Speiseröhre) versorgt werden.

Bei Lacerta ocellata geht der R. laryngopharyngeus aus dem Ganglion trunci hervor, wendet sich sogleich nach innen und unten, dann, der Haut des Schlundes dicht anliegend, und ihr feine Zweige gebend, nach vorn, um sich dicht hinter dem Kehlkopf an die Trachea anzulegen, und communicirt hier sowohl nach aussen durch feine Verbindungszweige mit dem Glossopharyngeus, als nach innen mit dem längs der Luftröhre heraufsteigenden $R$. recurrens nervi Vagi. Einige Zweige desselben endigen hier in der Haut des Schlundes, ein anderer verbindet sich mit einem Endzweige des.R. recurrens, und bildet unter dem Kehlkopf die starke oben ausführlich erörterte Schlinge mit dem entsprechenden Nerven der anderen Seite. Die aus dieser Schlinge an beiden Seiten hervorgehenden Endzweige dringen in die Muskeln des Kehlkopfes ein.

Ganz ähnlich bei Euprepes Sebae. Auch hier entspringt unser Nerv aus dem Ganglion trunci nervi Vagi, schlägt sich um den Aortenbogen herum nach innen und vorn, hinter dem hinteren Zungenbeinhorn seinen Weg, dem Schlunde dicht anliegend, verfolgend. Am vierten Ringe der Luftröhre tritt er an diese heran, nimmt den von hinten längs derselben heraufsteigenden $\mathbf{R}$. recurrens vollständig auf, und schickt dicht hinter dem Kehlkopf zwei starke Schlingen nach der anderen Seite hinüber. Sein letztes Ende dringt auch hier in die Muskeln des Kehlkopfes ein.

Die eben berührte Form des $\mathbf{N}$. laryngopharyngeus bei den Krokodilen als selbstständig aus dem gemeinschaftlichen Ganglion der hinteren Hirnnerven entspringenden Nerven (von B endz 1. I. pg. 11 zuerst beschrieben) ward oben (pg. 48 dieser Schrift) ausführlich besprochen. Der vordere Ast desselben, durch Zweige des Glossopharyngeus verstärkt (Taf. III, fig. 5, Is), giebt sich als $R$. laryngeus superior zu erkennen, und ist durch die oben berührte Bildung seiner starken Schlingen nach der anderen Seite ausgezeichnet. Der hintere Ast ( $1 \mathrm{~d}, \mathbf{R}$. descendens) breitet sich bis tief unter den Brustgürtel mit zahlreichen Fäden geflechtartig auf der Speiseröhre aus, und entlässt nach einander mehrere längs der Trachea heraufsteigende Rami recurrentes. *)

\section{2) Vom Ramus recurrens nervi Vagi.}

$\uparrow$

Bei allen Sauriern finden sich Nervenzweige des Vagus, die von hinten her an der äusseren Seite der Luftröhre bis zum Kehlkopf heraufsteigen, und sich mit dem $R$. recurrens der Säugethiere und Vögel vergleichen lassen. Ihr Ursprung ist verschieden: bald gehen sie jenseits, bald diesseits des Ganglion trunci aus dem Vagus hervor, meist entspringen sie aus dem Stamme des letzteren selbst (Saurier), bisweilen aber aus dem vom Stamme des Vagus losgetrennten N. laryngopharyngeus (Krokodile). Auch ihre Zahl ist schwankend, - statt des in der Regel einfachen $\mathbf{R}$. recurrens kommen deren bei einzelnen Formen

*) Von ganz ähulicher Form, wie bei den Krokodilen ist nach B endz der N. laryngopharyngeus bei den Sehildkröten (Chelonia Mydas, Testudo). Er entspringt hier aus dem Ganglion radicis nervi Vagi, und theilt sich in einen vorderen und hinteren Zweig. Jener breitet sich am Kehlkopf und Schlund, dieser an Speiseröhre und Luftröhre aus. Einer Schlingenbildung unter dem Kehlkopf mit dem entsprechenden Nerven der anderen Seite wird nicht erwähut; ausserdem wird noch ein besonderer R. recurrens beschrieben (1. 1. pg. 7 und pg. 9). 
zwei, auch drei vor, die nach einander aus dem Vagus entspringen, und nach einander an die Aussenseite der Luftröhre sich anlegen. In diesem Falle nimmt jedesmal der nächst vordere Nerv da, wo er an die Trachea herantritt, das Ende des nächst vorhergehenden auf. - Immer aber treten die letzten Endzweige dieser Nerven in eine innige Verbindung mit dem R. laryngeus superior, (Ueber letzteren Punkt vgl. pg. 47, 48 dieser Schrift.) Letzterer entsendet die Zweige für die Muskeln, während der R. recurrens ausschliesslich für die Schleimhäute des Kehlkopfes bestimmt zu sein scheint.

Jenseits des Ganglion trunci entspringt der R. recurrens bei Lacerta ocellata, Euprepes Sebae, Salvator Merianae, Iguana tuberculata und Istiurus Amboinensis. *) Bei Lacerta ocellata und Euprepes Sebae ist der R. recurrens ein einfacher Nerv. Bei Salvator Merianae theilt er sich gleich nach seinem Ursprung in zwei feinere Nerven, die getrennt an das hintere Ende der Luftröhre herantreten, hier wieder zu einem Nerven verschmelzen, und nun als einfacher Nervenstamm nach vorn verlaufen.

Diese Andeutung einer Theilung des R. recurrens in zwei Nerven von gleicher Stärke ist völlig ausgeführt bei Iguana tuberculata und Istiurus Amboinensis. Bei beiden findet man zwei, ebenfalls erst jenseits des Ganglions nach einander aus dem Hauptstamm des Vagus entspringende feine Nervenzweige, von denen der hintere sich an das hintere Ende der Luftröhre anlegt, und an deren Aussenfläche dicht anliegend nach vorn verläuft. Wo dieser hintere $R$. recurrens am Anfang des letzten Dritttheils der Luftröhre fein endigt, tritt der vordere der beiden genannten Nerven an die Luftröhre heran, nimmt das letzte feine Ende des ersten auf, und setzt nun dessen Weg längs der äusseren Seite der ganzen Luftröhre bis zum Kehlkopf fort, um sich in der gewöhnlichen Weise mit dem $\mathbf{N}$. laryngeus superior zu verbinden.

Bei Varanus Bengalensis tritt der R. recurrens nicht jenseits des Ganglion trunci, sondern diesseits desselben aus dem Stamm des Vagus hervor. Es muss hier jedoch an unsere oben angeführte Beobachtung (pg. 56) erinnert werdeu, dass der Vagus bei Varanus Bengalensis noch vor seinem eigentlichen Ganglion trunci und vor Entsendung des $R$. recurrens schon eine erste, freilich äusserst schwache, Anschwellung in seinem Stamm an einem Punkte zeigt, wo mehrere feine Fäden aus dem grossen ersten Brustganglion des Sympathicus in denselben übertreten.**)

Dass bei den Krokodilen die für die Luftröhre und Speiseröhre bestimmten Fäden aus dem Ram. descendens des N. laryngopharyngeus austreten, ist oben (pg. 48) erwähnt. Dieser $\mathbf{R}$. descendens läuft bei den drei von mir untersuchten Arten als starker Nervenstamm unter der Speiseröhre und parallel mit der Trachea, aber von der letzteren einige Linien entfernt, nach hinten bis unter den Brustgürtel, beständig feine und stärkere Fäden aussendend, die sich geflechtartig an der ganzen Speiseröhre ausbreiten. Bei Crocodilus acutus entsendet dieser hintere Ast da, wo er unter die Speiseröhre tritt, um nach hinten zu verlaufen, ein Bündel stärkerer Fäden nach innen, von denen die meisten am Schlunde sich ausbreiten, einer jedoch, der unter rechtem Winkel von ihnen abgeht, nach innen senkrecht auf die Luftröhre zuläuft. An dem zwölften Ringe der letzteren legt dieser sich an dieselbe an, nimmt das letzte Ende des zweiten R. recurrens

*) Dies Verhalten wird auch für Lacerta agilis und Chamaeleo von Be ndz beschrieben.

**) Auch bei Amphisbaena alba bescbreibt Bendz (1.1.pg. 18) keinen jenseits des Ganglion trunci entsprungenen R. recurrens. Nach diesem Forscher giebt dagegen der Vagus schon viel früher einen Nerven ab, der längs der Luftröhre nach vorn läuft, und wohl dem R. recurrens analog sein dürfte. 
auf, und läuft nun, wieder nach vorn umbiegend, an der äusseren Seite der Luftröhre bis zum Kehlkopfe zurück, um hier mit dem N. laryngeus superior gerade da zu verschmelzen, wo dieser seine Schlinge mit dem entsprechenden Nerven der anderen Seite bildet. - Nach Abgabe des ersten R. recurrens läuft der $\mathbf{R}$. descendens Nervi laryngopharyngei in der erst angegebenen Weise nach hinten, viele Fäden an die Speiseröhre entsendend, um kurz vor seinem Eintritt in die Brust einen zweiten R. recurrens abzugeben, der, wie der erste, senkrecht an die Trachea herantritt, an deren achtundvierzigsten bis funfzigsten Ringe sich hart an sie anlegt, und nun an der äusseren Seite der Luftröhre ebenfalls zurückläuft. Auf diesem Wege wird der Nerv merklich feiner, - sein letztes Ende wird von dem ersten R. recurrens aufgenommen.

Aehnlich ist das Verhältniss bei Alligator punctulatus. Hier entlässt der R. descendens N. laryngopharyngei mehrere Nerven, die am zwanzigsten, sechsundzwanzigsten und vierunddreissigsten Ringe der Luftröhre senkrecht an dieselbe herantreten, und längs ihrer äusseren Fläche nach vorn zurücklaufen. Auch hier konnte ich den nach B endz (1.1. pg. 12) bei Alligator lucius aus dem Ganglion trunci entspringenden $R$. recurrens nicht auffinden. *)

3) Von den Zweigen an die Speiseröhre.

Nach dem $R$. recurrens sind dies diejenigen Aeste, die zuerst nach der Bildung des Ganglion trunci aus dem Stamm des Vagus hervor zu gehen pflegen. Nur in seltenen Fällen wiederholen sie den ausnahmsweise stattfindenden Ursprung des $R$. recurrens diesseits des Ganglions; eben so selten sind sie schon vom Ursprung des Vagus an von diesem getrennt, und in einem besonders verlaufenden N. laryngopharyngeus enthalten. Sie verbreiten sich an der Speiseröhre, und lassen sich nach hinten bis zum Magen, nach vorn häufig bis zum Schlunde verfolgen.

Bei Varanus Bengalensis gehen ausser dem R. recurrens noch zwei Nerven für die Speiseröhre aus dem Stamm des Vagus ab, bevor dieser unter den Brustgürtel tritt, um sein Ganglion trunci zu bilden. Der Stamm bildet schon vor ihrer Abgabe, wie erst erwähnt, nach Aufnahme feiner Fäden aus dem Sympathicus ein ganz kleines vorderes Ganglion. - Bei den Krokodilen treten die Speiseröhrenzweige in der erst beschriebenen Weise aus dem $\mathbf{R}$. descendens des $\mathbf{N}$. laryngopharyngeus aus.

4) Von den Zweigen an das Herz, die Lungen und den Magen.

Die für diese Organe bestimmten $Z$ weige gehen beständig bei allen Eidechsen und Krokodilen erst nach der Bildung des Ganglion trunci aus dem Vagus

*) Unter den Schlangen scheint bei Tropidonotus natrix (nach Bendz pg. 19) ein doppelter R. recurrens vorhanden zn sein. Der hintere entspringt ans dem Ganglion trunci, und verbindet sich auf seinem Wege längs der Carotis mit einem schon früher aus dem Stamm des Vagus ausgetretenen Nerven (dem vorderen R. recurrens?). - In den Beschreibungen, die Vogt von Python tigris, Crotalus horridus, Naja Haje, Coluher Siculus und Vipera prester gegeben, wird der R. recurrens gänzlich vermisst. - Von den Schildkröten wird von Bo ianus (fig. 107) in der Brusthöhle kein eigentliches Ganglion trunci angeführt, wohl aber giebt der Vagus zahlreiche Fäden ab, die mit $Z$ weigen des Sympathicus ein Geflecht um den linken Aortenbogen bilden. Mitten zwischen diesen Fälen geht der R. recurrens ab, der nach Abgabe kleiner Zweige an die Speiseröbre die Luftröhre in ihrer ganzen Länge mit Fäden versorgt. - Bei Testudo geht nach Bendz (1. 1. pg. 9) der R. recurrens jenseits des Ganglion trunci ab, als einfacher Nerv längs der Luftröhre zurücklaufend. 
hervor. Ihre Zahl ist so schwankend, ihre Form bei den verschiedenen Arten so wechselnd, dass eine ausführliche Schilderung ihrer Verhältnisse den Raum dieser Abhandlung bei Weitem überschreiten würde. Nur das möge hier bemerkt werden, dass die Zweige an's Herz gewöhnlich die ersten sind, die auf die Absendung des R. recurrens folgen, ja dass sie häufig mit diesem zugleich als ein gemeinschaftlicher feiner Nervenstamm entsendet werden, der sich erst bei der Krümmung um den Aortenbogen in diese beiden verschiedenen Elemente theilt. - Eine geflechtartige Verbindung dieser letzten Endzweige des Vagus mit Fäden des Sympathicus ward nicht beobachtet, wohl aber steht, wie oben erwähnt, das Ganglion trunci, aus dem der sie entsendende Stamm entspringt, durch eine starke Schlinge mit dem ersten Brustganglion des Sympathicus in Verbindung.

\section{Sechster Abschnitt.}

\section{Vom Nervus accessorius Willisii.}

Bei allen Sauriern und Krokodilen haben die Wurzeln des Accessorius die Form, die von Bisch off für einige von ihnen nachgewiesen ist. Fünf bis neun feine Wurzeibündel, meistens nach hinten an Stärke zunehmend, entspringen in einer schrägen Linie, die von der Ursprungsstelle des Vagus an der Seitenfläche des verlängerten Markes beginnend, sich nach hinten und oben zur Rückenfläche desselben bis hinter den zweiten Halsnerven erstreckt. Das letzte, am weitesten nach hinten reichende Wurzelbündel erscheint zugleich als das äusserste, und wird auf seinem Wege; anscheinend immer, durch neue aus der Markmasse austretende zarte Nervenbündel verstärkt.

Alle diese Wurzelbündel sammeln sich in der Gegend des Foramen lacerum zu einem feinen-Stamm, der in der Regel mit dem Nervus Vagus verschmilzt, sehr selten (Salvator nigropunctatus und Salvator Merianae) als getrennter Nerv neben dem Vagus durch die gemeinschaftliche Schädelöffnung austritt. *)

Die einzelnen Bündel der Nerven haften bei den Reptilien viel dichter an einander, und lassen sich viel schwieriger isoliren, als bei den Säugethieren, dies der Grund, weshalb sich bei den Sauriern nicht nachweisen lässt, einen wie grossen Antheil der Accessorius an der Bildung der Schlundzweige des Kehlkopfastes und des $R$. recurrens des Vagus hat. Dass indessen wirklich Fasem des Accessorius in die übrigen Parthieen des Vagus übergehen, lässt

*) Nach Bisch of (N. accessorii Anat. Darmst. 1832, pg. 46) findet sich dies Verhältuiss auch bei Amphisbaena alba, nach Be ndz (1. 1. pg. 6) bei Chelonia Mydas. - Boianus 1. I. fig. 108, v, $\xi$ bildete dasselbe schon früher ab bei Emys Europaea. 
sich mit Bestimmtheit aus der Bildung von Salvator nigropunctatus erweisen "), wo der Accessorius der Wurzel des Vagus innerhalb des sie beide umschliessenden Knochenkanals einen kurzen Verstärkungszweig, als $\mathbf{R}$. internus, giebt.

Nur die peripherische Ausbreitung derjenigen Fasern des Accessorius lässt sich mit Sicherheit ermitteln, die in dem R. externus, wenn er vorhanden ist, enthalten sind.

In der That scheint ein solcher R. externus nicht überall vorhanden zu sein. Ich habe denselben bei einem hinreichend grossen Exemplar von Chamaeleo vulgaris und bei Agama spinosa nicht finden können **). Mit Bestimmtheit habe ich ihn beobachtet bei Lacerta ocellata, Euprepes Sebae, Salvator nigropunctatus, Salvator Merianae, Istiurus Amboinensis, Platydactylus guttatus, Varanus Niloticus, Varanus Bengalensis und Iguana tuberculata. Bei den Krokodilen sind ebenfalls Nerven vorhanden, die dem R. externus Accessorii entsprechen, - ihr Verhältniss ist indessen schwieriger zu ermitteln, theils wegen der abweichenden Anordnung des Schultergerüstes, theils wegen des abnormen Ursprungs dieser Nerven nicht rom Stamm des Vagus, sondern aus dem gemeinschaftlichen Ganglion der hinteren Hirnnerven, aus dem noch ein anderer Muskelnerv, der Hypoglossus, hervorgeht.

Immer verbreitet sich dieser R. externus an solchen Muskeln, die sich vom Schädel und den Dornfortsätzen der Halswirbel an den vorderen Rand der eigentlichen Scapula (nicht der Cartilago suprascapularis) erstrecken, und die man dem M. cucullaris und dem M. omomastoideus zù vergleichen genöthigt ist. Eine Verzweigung an eigentlichen Nackenmuskeln, d. h. an solchen, die sich vom Schädel an den ersten Theil der Wirbelsäule erstrecken, wie Bischoff (Musculi cervicis) und Vogt überall angeben, habe ich niemals beobachtet. Diese Muskeln erhalten vielmehr beständig vom ersten und zweiten Halsnerven ihre Zweige ***). Eine Verwechselung des eigentlichen Accessoriuszweiges mit Aesten

*) Auch bei Chelonia Mydas sind die getrennt neben einander durch dieselbe Oeffnung austretenden Nerven durch einen kurzen Zweig mit einander verknüpft (B endz 1. 1. pg. 6).

**) B isch off (1. 1. pg. 46) die Accessorius-Wurzel von Iguana beschreibend, erwähnt keines R. exteruus, den derselbe Forscher dagegen von Lacerta ocellata (wo auch ich ihn gefunden; Vogt leugnet ihn hier mit Unrecht) und Amphisbaena alba mit Bestimmtheit beschreibt. Von Monitor Niloticus und einem Varanus vom Senegal führt Vogt einen dem R. externus Accessorii entsprechenden Nervenast an, der sich indessen in den Nackenmuskeln (?) verzweigen soll.

****) Der $M$. cucullaris ist besonders stark bei den dickhalsigen Gattungen Euprepes (Sebae) und Lacerta (ocellata), findet sich aber auch bei den übrigen Sauriern, vielleicht mit alleiniger Ausnahme der Chamaeleons und der Krokodile, wo ohnehin das Schultergerüst bekanntlich durch den Mangel einer Clavicula und einer Cartilago suprascapularis eine abweichende Anordnung zeigt. Der M. mylohyoideus setzt sich häufig noch eine Strecke am Hals fort als M. longissimus colli (Boianus), indem seine in der unteren Mittellinie mit denjenigen der anderen Seite zusammenstossenden Fasern quer um den Hals nach oben gehen, und sich mit einer sehr feinen Sehne an den Dornfortsätzen der Halswirbel befestigen. Schlägt man diesen Muskel, der seine Nerven theils vom Facialis, theils vorn dritten und vierten Halsnerven bekommt, von oben nach 
dieser Halsnerven mag freilich wohl wegen der benachbarten Lage derselben oft stattgefunden haben. - Auffallend ist übrigens eine deutliche Schlinge, welche, vielleicht beständig; die letzte, später nach innen wieder einbiegende Endigung dieses R. externus mit einem Aste des dritten Halsnerven bildet. Da, wie erst bemerkt, nicht immer der Accessorius mit dem Vagus verschmilzt, so findet natürlich auch in Bezug auf den Ursprung des $R$. externus ein doppeltes Verhältniss statt. Entweder derselbe entspringt aus dem freien, mit dem Vagus nicht verschmolzenen, Accessorius selbst, oder er tritt als Ast des herumschweifenden Nerven auf.

Ersteres Verhältniss findet sich am deutlichsten bei Salvator nigropunctatus. Nachdem nämlich, wie oben erwähnt, die fächerförmig zusammenstrahlenden, nach hinten stärker werdenden Elemente des Accessorius sich über der ersten Hirnwurzel des Hypoglossus (Taf. I, fig. 1, h') zu einem besonderen Strang vereint und im Foramen lacerum, das ihm und dem Vagus gemeinschaftlich ist, dem letzteren einen feinen Verbindungszweig gegeben, tritt derselbe über alle hinteren Hirnnerven fort nach hinten und aussen, und legt sich, an Stärke dem dritten Theile des späteren Vagus gleich, an den M. cucullaris an, giebt demselben sogleich einen feinen Zweig, und läuft an der Innenseite dieses Muskels in einer zu dessen Fasern senkrechten Richtung nach hinten. Unter dem diesen Muskel nach aussen hin durchbohrenden dritten Halsnerven tritt der R. externus Accessorii durch, verschmilat mit einem nicht unbeträchtlichen Ast dieses Nerven, und dringt nun zwischen die Muskelbïndel des Cucullaris ein, um sich in ihnen auszubreiten.

Dieselbe völlige Freiheit vom Vagus zeigt der R. externus des Accessorius bei Salvator Merianae. Auch hier breitet derselbe sich im M. cucullaris aus, gemeinschaftlich mit einem Aste des dritten Halsnerven.

Das zweite Verhältniss, nämlich völlige Verschmelzung des Accessorius mit dem Vagus, von welchem sein R. externus später als besonderer Ast ausgegeben wird, findet sich bei Istiurus Amboinensis, Lacerta ocellata, Platydactylus guttatus, Euprepes Sebae, Iguana tuberculata, Varanus Niloticus und Varanus Bengalensis.

Bei Istiurus Amboinensis entspringt der R. externus erst aus dem hier sehr deutlich vorhandenen Ganglion radicis nervi Vagi (Taf. III, fig. 1, E). Aus diesem gehen zwei Nerven hervor, der eigentliche Stamm des Vagus (v), und der feine Muskelast des Accessorius (y). Letzterer läuft mit dem ersteren eine Strecke parallel nach hinten, aber während dieser innerhalb des Hypoglossus (h) durchtritt, legt sich unser Nerv an die Innenseite des M. omomastoideus an, um eine Strecke parallel mit dessen Fasern schräg nach hinten und abwärts zu verlaufen, und demselben bald nach einander zwei deutliche Zweige zu geben. Bald darauf biegt der Nerv wieder nach

unten vollständig zurück, so sieht man darunter den M. cncullaris liegen. Dieser entspringt bei Lacerta ocellata, wo er am stärksten entwickelt ist, vom Processus mastoideus und von den. Dornfortsätzen sämmtlicher Hals- und der ersten Rückenwirbel bis hinter den Schultergürtel, und geht mit nach unten couvergirenden Fasern an den vorderen Rand des knöchernen Schulterblattes, wo er sich befestigt. - Die vordere Parthie dieses Muskels kommt auch isolirt und

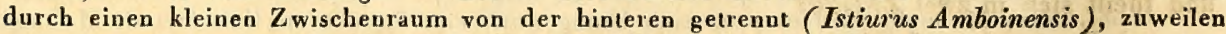
auch ganz allein ohne die hintere Parthie vor (Chamaeleo und Krokodile), und möcbte dem M. omomastoideus zu vergleichen sein. Die vordere Parthie bekommt ausschliesslich ihren Nerven rom Accessorius, die hintere wird ausserdem noch meist von dem, durch dieselbe nach aussen hindurch tretenden, dritten Halsnerven versorgt. 
innen und oben um, tritt dicht an den dritten Halsnerven heran (I5) und verschmilzt mit einem Aste desselben zu einer feinen, aber vollkommen deutlichen Schlinge.

Auch bei Lacerta ocellata entsteht der R. externus als Zweig des Vagus, und wird von dem letzteren erst abgegeben, nachdem derselbe schon mehrere Verbindungsfäden fïr den Halstheil des Sympathicus abgegeben hat. $\mathrm{Er}$ ist hier, entsprechend der Entwickelung des M. cucullaris, in dem er sich von innen her verbreitet, sehr stark.

Bei Iguana tuberculata entspringt der R. externus (Taf. II, fig. 3,y) Accessorii gerade da aus dem Stamme des Vagus, wo dieser seinen Verstärkungsast an den Glossopharyngeus (I) abgiebt. Er ist im Verhältniss zur Grösse dieser Eidechse sehr schwach, und wird von dem genannten Verstärkungsaste an den Glossopharyngeus um das Dreifache an Stärke übertroffen. Gleich nach seinem Ursprunge wendet er sich nach aussen und hinten, legt sich, wie gewöhnlich, an den vorderen Rand des M. cucullaris so an, dass er in einer zu den Fasern desselben senkrechten Richtung innerhalb dieses Muskels nach hinten verläuft. Nachdem er namentlich der vorderen dem Omomastoideus entsprechenden Parthie desselben mehrere Zweige gegeben, biegt sein letztes Ende in der Gegend des diesen Muskel durchbohrenden dritten Halsnerven an den letzteren heran, und verschmilzt völlig mit einem Zweige desselben zu einer deutlichen Schlinge.

Der R. externus von Euprepes Sebae erinnert durch seine bedeutende Stärke, die der beträchtlichen Entwickelung des M. cucullaris entspricht, an Lacerta ocellata. Er wird schon vom Stamme des Vagus ausgegeben, nachdem dieser eben den Schädel verlassen, läuft schräg nach hinten und aussen unter dem M. cucullaris, dessen Fasern er kreuzt, nach hinten, und breitet sich in demselben aus.

Bei Platydactylus guttatus tritt, wie beim Leguan, der R. externus Accessorii gerade da aus dem Stamme des Vagus als äusserst feiner Nerv ab (Taf. III, fig. 3, y), wo dieser seinen Verstärkungszweig zum Glossopharyngeus entsendet. Ausser der gewöhnlichen Ausbreitung an der Innenfläche des M. cucullaris ward auch hier eine deutliche Schlinge mit einem Zweige des dritten Halsnerven beobachtet.

Bei Varanus Niloticus tritt unser Nerv mit dem Stamme des Vagus zugleich aus dem Foramen lacerum hervor, liegt diesem Nerven anfangs sehr dicht an, tritt dann unter die vordere Parthie des M. cucullaris, giebt derselben zwei deutliche Zweige, und läuft, wie gewöhnlich, längs der Innenfläche dieses Muskels nach hinten. Sein letztes Ende biegt endlich wieder nach innen ein, und verschmilzt mit einem ihm entgegenkommenden Aste des dritten Halsnerven zu einer Schlinge.

Was endlich die Krokodile betrifft, so ist bei der Aufzählung der einzelnen in das grosse Ganglion der hinteren Hirnnerven eintretenden Wurzeln (pg. 54) schon erwähnt worden, dass die feinen Wurzeln des Accessorius, an der Rückenseite des verlängerten Markes in gewöhnlicher Weise entspringend, sich in der Gegend des Foramen lacerum zu einem feinen Nervenstamm sammeln, der von oben und hinten in den hinteren grösseren Theil des erwähnten Ganglions eintritt. Als einem Theil dieser Wurzeln entsprechender $\mathbf{R}$. externus ist nach unserer Ansicht ein aus dem Ganglion austretender Verbindungszweig an den ersten Halsnerven zu betrachten (Taf. III, fig. 5, y). Dieser erste Halsnerv (fig. 5, 13) entspringt bei Crocodilus biporcatus wie die freie Hirnwurzel des Hypoglossus (h') mit einfacher (unterer oder vorderer) Wurzel von der Grundfläche des verlängerten Markes, tritt zwischen Condylus occipitalis und erstem Halswirbel nach aussen, nimmt, aussen angelangt, einen Verbindungsast (z) von der freien Hirnwurzel des Hypoglossus (h') auf, und theilt sich in zwei Zweige:

a) Der stärkere (y") steigt hinter dem Schädel in die Höhe, geht zwischen den Bündeln des bei den Krokodilen sehr entwickelten M. splenius capitis (von den Dornfortsätzen der ersten neun Halswirbel an die Crista horizontalis ossis occipitis) nach hinten, beständig an die Fasern dieses Muskels Zweige gebend. Seine Aeste lassen sich bis zum sechsten Halswirbel verfolgen. 
b) Der feinere dieser beiden Zweige geht nach aussen und unten ( $\left.y^{\prime}\right)$, nimmt den erst erwähnten Verbindungszweig ( $y$ ) aus dem Ganglion auf, giebt feine Zweige an die unteren geraden Kopfmuskeln, verfolgt dann seinen Weg weiter nach aussen, und legt sich an einen schmalen, langen Muskel an, der vom vorderen Rande des Schulterblattes ausgehend, sich an das Lateralstïck des Hinterhauptsbeins befestigt (Omomastoideus?). Nachdenı er als äusserst feiner Nerv eine kurze Strecke diesen Müskel an dessen innerer Seite nach hinten begleitet hat, breitet er sich mit mehreren Zweigen in ihm aus.

Dieser letztere Nerv ( $\left.y^{\prime}\right)$ möchte als der dem R. externus Accessorii entsprechende Nerv zu betrachten sein. Seine Verbreitung bei den Sauriern in der vorderen Parthie des M. cucullaris, die, wie oben gezeigt wurde, als Omomastoideus betrachtet werden kann, machen diese Deutung wahrscheinlich. Hiernach würden die Fasern des Accessorius, um an ihren Muskel zu gelangen, bei den Krokodilen einen zwar nicht auffallenden, aber doch eigenthümlichen Umweg machen. Aus dem Ganglion als Verbindungszweig ( $y$ ) an den unteren Ast ( $\left.y^{\prime}\right)$ des ersten Halsnerven hiuübergetreten, werden sie durch diesen erst zu ihrer peripherischen Endigung geführt.

\section{Siebenter Abschnitt. Vom Nervus hypoglossus.}

\section{a. Vom Ursprung desselben.}

Der Hypoglossus zeigt sich bei den Sauriern sehr beständig in der Form seiner Wurzeln. Niemals wird er, wie bei den nackten Amphibien, ausschliesslich durch Zweige der Spinalnerven zusammengesetzt, niemals wird er ferner, wie bei vielen höheren Thieren, lediglich aus eigentlichen Hirnwurzeln gebildet, sondern immer tragen sowohl besondere Hirnwurzeln, als auch Zweige der Halsnerven zu seiner Bildung bei. Die Krokodile dagegen nähern sich auch hier wieder mehr der Form der höheren Wirbelthiere, sofern die beiden, den Hypoglossus bildenden Hirnwurzeln keinerlei Verstärkungszweige von Spinalnerven erhalten. Was übrigens die letzteren bei den Sauriern betrifft, so tragen höchstens die beiden ersten Halsnerven zur Bildung des Hypoglossus bei, werden aber dann durch die ihm zugesandten starken Aeste fast ganz consumirt, - nur einzelne $\mathrm{Z}$ weige in die oberen und unteren geraden Kopfmuskeln gehen ausserdem noch aus ihnen hervor.

Diese beiden verschiedenartigen Elemente (Hirnwurzeln und Zweige von Spinalnerven), zeigen indessen bei den Sauriern sehr mannigfache Formen. Bald ist nur eine Hirnwurzel vorhanden (Salvator nigropunctatus, Euprepes Sebae), bald werden deren zwei beobachtet (Lacerta ocellata, Iguana tuberculata, Varanus Bengalensis, Istiurus Amboinensis, Agama spinosa), ja bei Platydactylas guttatus ist ihre Zahl sogar auf drei erhöht. - Bei einigen Formen finden sich ferner nur Verstärkungen vom ersten Halsnerven (Lacerta, Istiurus, Euprepes, Agama, Platydactylus), bei anderen trägt auch der zweite mit zur Bildung des Hypoglossus bei (Varanus, Salvator, Iguana). 
Immer entspringen die Hirnwurzeln des Hypoglossus von der Grundfläche des verlängerten Markes nahe der Mittellinie (auf den Figuren mit h', h", h"” bezeichnet), lassen sich indessen nie bis zur letzteren selbst verfolgen. Wenn nicht der seltene Fall einer Verschmelzung mit dem Vagus vorkommt (Varanus Bengalensis), so tritt jede dieser Hirnwurzeln durch ein besonderes feines Loch nahe dem Condylus occipitalis im Os occipitale laterale aus dem Schädel. Auch die ersten beiden, zur Bildung des Hypoglossus beitragenden Halsnerven besitzen in der Regel nur untere (im Bellschen Sinne vordere), keine obere (hintere) Wurzeln, und zeigen kein Ganglion. Nur eine schwache Andeutung des letzteren und einer oberen Wurzel findet sich bisweilen beim zweiten Halsnerven. Der dritte Halsnerv dagegen, der einen viel ausgedehnteren Verbreitungsbezirk besitzt, sofern er sich nicht bloss in den tiefen, sondern auch in den oberflächlichen Halsmuskeln und in der Haut des Halses ausbreitet, hat immer eine sehr deutliche untere und obere Wurzel, und, analog den übrigen Spinalnerven, ein deutliches Ganglion.

Die grösste Zahl verbunden mit der grössten Freiheit der Wurzeln des Hypoglossus findet sich bei Iguana tuberculata (Taf. II, fig. 3). Hier sind vier Wurzeln vorhanden, von denen sich keine mit dem Vagus verbindet. Die beiden ersten sind eigentliche Hirnwurzeln ( $h$ ' und h"), die dritte und vierte werden durch Zweige des ersten und zweiten Halsnerven gebildet ( $k$ ' und $k$ "). Die beiden Hirnwurzeln entspringen beinahe in gleicher Höhe mit den mittelsten der fächerförmig zusammenstrahlenden Wurzeln des Vagus von der Grundfläche des verlängerten Marks. Sie treten schräg nach unten und hinten, jede durch ein besonderes Loch im Occipitale laterale aus dem Schädel. Die Oeffnung der vorderen, dünneren ( $h$ ') liegt etwas weiter nach innen als die der hinteren, stärkeren Wurzel (h"), - beide in gleicher Höhe in einer schmalen Knochenleiste an der genannten Schädelparthie. - Bald nach ihrem Austritt vereinigen sie sich zu dem vorderen Hauptstamm des Hypoglossus (h), der nach Abgabe eines starken in den Halstheil des Sympathicus eintretenden Fadens sich von aussen und vorn her um die vorderen geraden Kopfmuskeln nach hinten schlägt, um sich mit dem durch die beiden ersten Halsnerven gebildeten hinteren Hauptstamm (k) des Hypoglossus zu verbinden. - Zur Bildung dieses letzteren werden die beiden ersten Halsnerven fast ganz verwandt, - nur feine Zweige treten aus ihnen noch in die unteren graden Kopfmuskeln aus.

Auch Varanus Bengalensis hat zwei Hirnwurzeln des Hypoglossus, - starke Zweige der beiden ersten Halsnerven senden demselben fernere Elemente zu (vgl. Taf. II, fig. 2). Die erste Hirnwurzel (h') verschmilzt schon innerhalb des Schädels mit der Wurzel des Vagus zu einem Stamm, trennt sich jedoch wieder (h) gleich nach dem Hervortritt des letzteren (v). Die zweite Hirnwurzel ( $\left.h^{\prime \prime}\right)$, gleich hinter der vorigen von der Grundfläche des verlängerten Markes entspringend, theilt sich gleieh nach ihrem Hervortritt in zwei Zweige: Der eine verbindet sich mit einem nach vorn tretenden Zweige des ersten Halsnerven zu einem feinen Stamm (z), der sich im M. rectus eapitis anterior ausbreitet. Der zweite $\left(k^{\prime}\right)$ geht unter dem ersten Halsnerven durch nach hinten, und verbindet sich mit dem zweiten Halsnerven (14). Der erste Halsnerv (13) entsendet ausser zwei Aesten in die Nackenmuskeln einen Zweig (k"), der sich ebenfalls mit diesem zweiten Halsnerven verbindet. Letzterer endlich (14) nimmt die aus der zweiten Hirnwurzel (h") und dem ersten Halsnerven (13) stammenden Elemente auf, und bildet mit ihnen den zweiten 
Hauptstamm (k), der dem ersten vom Vagus abgehenden Hauptstamme (h) an Stärke fast gleichkommt. Er vereinigt sich indessen mit demselben nicht völlig, sondern sendet ihm nur zwei Verstärkungszweige (w) zu, selbst als R. descendens Hypoglossi (d) nach aussen und hinten verlaufend.

Bei Platydactylus guttatus ist die Zahl der Hirnwurzeln noch um eine vermehrt, dafür die Zahl der Halsnervenzweige um einen vermindert. Es finden sich nämlich drei eigentliche Hirnwurzeln (Taf. III, fig. 3, h', h", h"'), und nur der erste Halsnerv (13) trägt durch einen beträchtlichen Zweig zur Bildung des Hypoglossus bei. Jede der drei ersten tritt durch eine besondere feine Oeffnung aus dem Schädel. Gleich ausserhalb des letzteren vereinigen sich die beiden ersten Hinwurzeln ( $h$ ' und $h$ ") zu einem vorderen Hauptstamm (h), während die dritte sich mit dem ersten Halsnerven zu dem hinteren Hauptstamm (k) verbindet. Durch Verschmelzung beider Stämme wird der eigentliche Hypoglossus (h k) gebildet.

Drei Wurzeln, nämlich zwei eigentliche Hirnwurzeln und einen Zweig des ersten Halsnerven, zeigt Lacerta ocellata (Taf. II, fig. 1). Die erste Hirnwurzel ( $h^{2}$ ) bildet für sich den vorderen Hauptstamm (h), der hintere (k) wird durch die zweite Hirnwurzel (h") und den Ast des ersten Halsnerven (13) gebildet. Alle drei Nerven entspringen von der Grundfläche des verlängerten Markes; die beiden Hirnwurzeln gehen jede durch ein besonderes Loch aus dem Schädel hervor.

Dieselbe Zahl von Wurzeln (zwei Hirnwurzeln und einen Zweig des ersten Halsnerven) zeigt Euprepes Sebae. Auch hier bleibt die erste Hirnwurzel frei, und bildet für sich den vorderen Hauptstamm des Hypoglossus. Die zweite Hirnwurzel verbindet sich ausserhalb des Schädels mit einem Zweige des ersten Halsnerven zu dem hinteren Hauptstamm, der aber nicht ganz mit jenem vorderen verschmilzt, sondern (ähnlich wie bei Varanus) demselben einen beträchtlichen Verstärkungszweig zusendet, und dann sich als $R$. descendens verhält.

Auch bei Salvator nigropunctatus ist dieselbe Zahl von Wurzeln (zwei Hirnwurzeln und ein Zweig des ersten Halsnerven), nur ihr Verhältniss unter einander und zum Vagus ist verschieden. Die erste Hirnwurzel (Taf. I, fig. l, h') entspringt wie immer von der Grundfläche des verlängerten Markes, nahe der Mittellinie. Sie ist schräg nach vorn und aussen gerichtet, und tritt durch ein besonderes Loch nahe dem Condylus occipitalis aus dem Schädel, um unmittelbar ausserhalb desselben mit dem Vagus (r) zu verschmelzen. Die zweite Hirnwurzel (h") entspringt dicht hinter der vorigen, ebenfalls von der Grundfläche des verlängerten Markes. Ihre Schädelöffnung liegt etwas weiter nach innen als diejenige der ersten Wurzel. Gleich nach ihrem Austritt giebt sie einen $Z$ weig $a b$, der sich mit einem Zweige des ersten Halsnerven zu einem kurzen, in die oberen Nackenmuskeln gehenden Nerven vereinigt, und läuft dann nach hinten, dem vereinigten Stamme von Vagus und erster Hirnwurzel dicht anliegend, um ebenfalls in diesen Stamm einzumünden, unmittelbar nachdem derselbe den R. communicans internus (i), aus dem Ganglion petrosum (eigentlich aus dem R. palatinus) stammend, aufgenommen hat. — Der erste Halsnerv endlich (13), zwischen Condylus occipitalis und Atlas hervorgetreten, giebt einen Zweig nach vorn, der sich mit dem eben erwähnten Zweige der zweiten Hirnwurzel zu einem kurzen, in die oberen Nackenmuskeln gehenden Nervenstamm (z) vereinigt. Der Rest des Nerven geht schräg nach aussen und hinten, giebt noch einen feinen Zweig in die unteren Nackenmuskeln und senkt sich nun, der zweiten Hirnwurzel des Hypoglossus an Stärke gleich, in den vereinigten Stamm ein, welcher letzterer, wie oben erwähnt, ausserdem noch die Elemente des Vagus, einen Theil des Accessorius und den Sympathicus enthält. - Unmittelbar nach Aufnahme der zweiten Hirnwurzel und des ersten Halsnerven theilt sich dieser wiederum in zwei Stämme, von denen der eine (h) alle Elemente des Hypoglossus enthält, während der andere ( $\mathrm{v}$ ) sich bald in den Vagus und den Halsstamm des Sympathicus theilt. 
Auch bei Istiums Amboinensis wird der Hypoglossus durch zwei Hirnwurzeln und einen Zweig des ersten Halsnerven gebildet. Die erste Hirnwurzel (Taf. III, fig. 1, h') hat keine besondere Schädelöffnung, sondern, von der Grundfläche des verlängerten Markes in gewöhnlicher Weise entsprungen, tritt sie mit der Wurzel des Vagus aus einer gemeinschaftlichen Oeffnung hervor, ohne jedoch, wie bei Varanus, mit jener zu verschmelzen. Gleich nach ihrem Austritt wendet sie sich hinter dem Ganglion des Vagus (E) fort, und verschmilat vollständig mit der zweiten Hirnwurzel. Diese ( $h$ ") entspringt wie jene vor der Grundfläche des verlängerten Markes, aber eine ziemliche Strecke weiter nach hinten, so dass ihre Fasern im Schädel schräg nach vorn aufsteigen müssen, um die für sie hart am Condylus occipitalis gelegene Schädelöflnung zu gewinnen. Auch sie wendet sich nach ihrem Hervortritt schräg nach hinten und aussen und verschmilzt mit der ersten Hirnwurzel zu dem eigentlichen Stamm des Hypoglossus (h). - Der erste Halsnerv, ganz wie die Hirnwurzel mit einfacher vorderer Wurzel entspringend (13), giebt nach seinem Austritt (zwischen Hinterhauptsbein und Atlas) einen Zweig an den vorderen geraden Kopfmuskel, und legt sich, weiter nach aussen verlaufend, an den aus den beiden Hirnwurzeln gebildeten Stamm an, und empfängt von ihm, ohne vollständig mit ihm zu verschmelzen, zwei äusserst feine Nervenzweige (w). An der Stelle ihrer Aufnahme entlässt er einen feinen Nervenfaden nach hinten ( $z^{\prime}$ ), der sich in der Gegend des dritten Halsnerven wieder in zwei schwache Fäden theilt, von denen der eine mit einem Zweige dieses Nerven zu einer Schlinge zusammentritt, während der andere mit dem Halsstamm des Sympathicus verschmilzt. - Nach Abgabe dieses Fadens verfolgt unser Nerv seinen Weg nach aussen, und verhält sich- als $R$. descendens Hypoglossi (d), indem er zwischen die Mm. sternohyoideus und omohyoideus tritt und in ihnen sich ausbreitet.

Auch bei Agama spinosa findet sich dieselbe Zahl von Wurzeln (Taf. III, fig. 2). Die erste Hirnwurzel (h'), getrennt vom Vagus aus dem Schädel tretend, verschmilzt bald mit dem letzteren zu einem Stamme ( $\mathrm{hv}$ ), aus welchem die ihr angehörigen Elemente als kurzer Verstärkungszweig (h) an den hinteren Hauptstamm des Hypoglossus (gebildet aus der zweiten Hirnwurzel [h"] und dem ersten Halsnerven [13]) treten. Dieser, so verstärkt, nimmt bald nachher auch noch den Glossopharyngeus ( $\mathrm{gl}$ ) auf, und verfolgt dann seinen Weg nach aussen und unten.

Am kleinsten ist die Zahl der zur Bildung des Hypoglossus zusammentretenden Nervenstämme bei Chamaeleo vulgaris. Hier existirt nur eine Hirnwurzel, welche ausserdem nur vom ersten Halsnerven zwei schwache Verstärkungszweige erhält. - Die Hirnwurzel (Taf. II, fig. 4, h) entspringt, wie immer, von der Grundfläche des verlängerten Marks, aber weiter von der Mittellinie entfernt, als bei den übrigen Eidechsen, tritt durch eine besondere Oeffnung aus dem Schädel, und mündet von innen her in den Stamm des Vagus da ein, wo dieser seinen starken Zweig (l) an das Ganglion petrosum entlässt. Vor ihrer Einsenkung in den Vagus empfängt dieselbe jedoch noch zwei feine Verstärkungszweige von dem ebenfalls an dem seitlichen Theil der Grundfäche entspringenden, und kein Ganglion zeigenden ersten Halsnerven (13).

Letzterer entlässt gleich nach seinem Hervortritt fünf feine Nerven:

1) und 2) Die beiden ersten sind die beiden eben erwähnten Verstärkungszweige an die Hirnwurzel des Hypoglossus.

3) und 4) Zwei dieser Nerven vertheilen sich an die unteren geraden Kopfmuskeln.

5) Der fünfte (Taf. III, fig. 6, z) läuft unter den Wirbelkörpern der zwei ersten Halswirbel nach hinten, empfängt eine. Verstärkung vom dritten Halsnerven, und wird so zu einem feinen Stamm (Taf. III, fig. 6, z'), der sich theils in den unteren Nackenmuskeln vertheilt, theils den später zu erwähnenden tiefen Halsstamm des Sympathicus bildet. -

Die auf die eben angegebene Weise verstärkte Hirnwurzel des Hypoglossus mündet mit der Wurzel des Vagus (10) zu einem kurzen, aber starken Nervenstamm zusammen, der dem Ganglion 
petrosum (D) einen Verstärkungsast giebt (I), dann hinter diesem Ganglion nach aussen läuft, und sich sehr bald in zwei Stämme theilt, deren stärkerer (h g) nach Aufnahme eines kurzen Verstärkungsastes aus dem Ganglion petrosum sich als vereinigter Stamm von Glossopharyngeus und Hypoglossus zu erkennen giebt.

So ist es bei den Sauriern. Bei den Krokodilen fehlen dagegen die Verstärkungszweige von den Halsnerven gänzlich, und nur Hirnwurzeln sind vorhanden. Von diesen mündet die erste bei Crocodilus biporcatus in das grosse Ganglion der hinteren Hirnnerven ein (Taf. 11I, fig. 5, l'), während die zweite (h") bei demselben vorbeigeht, und mit einem aus dem Ganglion hervorgehenden Nerven (jener ersten Hirnwurzel entsprechend) den Stamm des Hypoglossus (h) bildet. - Bei Crocodilus acutus mündet auch die erste Hirnwurzel nicht in das Ganglion ein, sondern geht an der hinteren Seite desselben vorbei, nur an einem Punkte damit verwachsend. -

\section{b. Vom Verhalten des Hypoglossus zu anderen Hirnnerven.}

Die Fälle, wo der Hypoglossus mit anderen Hirnnerven (Vagus und Glossopharyngeus) innigere Verbindungen eingeht, sind theils bei Gelegenheit der letzteren, theils bei der Schilderung der Wurzelverhältnisse des Hypoglossus selbst erörtert worden, so dass es hier nur einer kurzen Recapitulation bedarf.

Vollkommen von den übrigen Hirnnerven frei verläuft der Hypoglossus bei Iguana tuberculata, Lacerta occellata, Euprepes Sebae, Platydactylus guttatus. Nur

durch feine Fäden steht derselbe hier sehr beständig mit dem Halstheil des Sympathicus in Verbindung.

Der Glossopharyngeus verschmilzt mit dem Hypoglossus bei Istiums Amboinensis, Agama spinosa und Chamaeleo vulgaris. Diese Verschmelzung erfolgt nie innerhalb des Schädels, sondern immer erst, nachdem der Glossopharyngeus sein Ganglion petrosum gebildet.

Eine völlige Vereinigung mit dem Vagus ausserhalb des Schädels erfolgt bei Salvator nigropunctatus. Nur theilweise (mit der ersten Hirnwurzel) verschmilzt der Hypoglossus mit dem Vagus schon innerhalb der Schädelhöhle bei Varanus Bengalensis.

Mit beiden Nerven endlich (Glossopharyngeus und Vagus) verbindet sich derselbe zu einem gemeinschaftlichen Stamm bei Salvator Merianae.

Bei den Krokodilen bleibt der eigentliche Stamm des Hypoglossus frei, nur das ist zu bemerken, dass er, wenigstens theilweise, wie vorhin erwähnt ist, aus dem gemeinschaftlichen Wurzelganglion der hinteren Hirnnerven entspringt, und in seinem Verlaufe durch Verstärkungszweige an den Glossopharyngeus mit diesem verbunden ist.

Dass indessen sehr häufig die letzten Endzweige des Hypoglossus mit feinen Aesten vom R. lingualis Trigemini communiciren, und meist mit diesem zusammen in die Zunge dringen, wird später näher erörtert werden. 


\section{c. Vom Verlaufe des Hypoglossus im Allgemeinen.}

Meist nur eine kurze Strecke verläuft der Hypoglossus mit Vagus und Halstheil des Sympathicus längs des Halses nach hinten. In der Regel trennt er sich von denselben schon gleich nach Aufnahme seines zweiten, meist aus Zweigen der beiden ersten Halsnerven gebildeten, Hauptstammes, um sich über und ausserhalb des Vagus und des sympathischen Halstheiles fortzuschlagen, und nach Abgabe seines R. descendens an die hintere Spitze des hinteren Zungenbeinhorns heranzutreten. Dieser R. descendens geht beständig nach aussen und hinten, tritt zwischen die M. omohyoideus und sternohyoideus, und breitet sich in denselben aus. Nach seiner Abgabe wendet sich der eigentliche Hauptstamm des Hypoglossus nach vorn, um die Spitze des Zungenbeinhorns herum, eine schräge Richtung nach innen beibehaltend, und beständig über den $M$. mylohyoideus und geniohyoideus verlaufend. Letzterer Muskel sowohl, als auch der M. hyomaxillaris, wenn er vorhanden ist, erhält Zweige. Nach ihrer Abgabe tritt der Stamm von aussen und von unten her an den M. hyoglossus, um sich hier in mehrere Zweige zu theilen. Einige dringen in diesen Muskel ein, um sich theils in ihm zu verzweigen, theils zwischen seinen Fasern bis in die Zunge zu verlaufen; andere wenden sich nach aussen, um ausserhalb des M. lingualis mit dem $R$. lingualis Trigemini sich zu verbinden, - während die letzten Endzweige nach vorn gehen, und in dem M. genioglossus endigen.

\section{d. Von der Verzweigung des Hypoglossus im Besonderen.}

1) Vom Ramus descendens.

Welche der drei oder vier Wurzeln des Hypoglossus zu der Bildung jedes der eben aufgezählten $Z$ weige beitragen, lässt sich auf anatomischem Wege mit Sicherheit nur für den R. descendens ermitteln, dessen bei allen Sauriern gleicher Verlauf eben angegeben wurde. Für die übrigen Aeste des Zungenfleischnerven würde dieselbe Frage sich nur durch Reizungsversuche an lebenden Thieren entscheiden lassen.

Bei Lacerta ocellata, Iguana tuberculata, Salvator Merianae, Salvator nigro. punctatus, Platydactylus guttatus, Agama spinosa und Chamaeleo vulgaris erscheint der R. descendens als wirklicher Ast des Hypoglossus. Bei Varanus Bengalensis, Euprepes Sebae und Istiurus Amboinensis hat er dagegen einen mehr selbstständigen Verlauf, aus dem sich ergiebt, dass die ersten (Hirn-) Wurzeln des Hypoglossus zu seiner Bildung nicht beitragen, seine Fasern vielmehr wohl ausschliesslich von den beiden mit dem letzteren verknüpften ersten Halsnerven abzuleiten sind.

Bei Varanus Bengalensis (Taf. II, fig. 2) ist, wie vorhin schon erwähnt, die erste Hirnwurzel (h') mit dem Vagus verschmolzen, und trennt sich eben ausserhalb des Schädels von demselben, um als vorderer Hauptstamm des Hypoglossus (h) zu verlaufen. Die zweite Hirnwurzel (h"), der 
Zweig vom ersten (13) und derjenige vom zweiten Halsnerven (14) bilden einen eigenen zweiten Stamm (k), der sich zwar dicht an den ersten anlegt, und ihm bei dessen Biegung nach innen zwei beträchtliche Verstärkungszweige (w) giebt, aber doch seinen gesonderten Verlauf beibehält, und als $\mathbf{R}$. descendens (d) sich nach hinten zwischen die Mm. sternohyoideus und omohyoideus schlägt, um in diesen beiden zu endigen.

Vollkommen auf dieselbe Weise verhält sich Euprepes Sebae, wo statt der beiden Verstärkungszweige aus dem zweiten Stamm in den ersten nur ein einziger, aber sehr beträchtlicher vorhanden ist.

Da in diesen beiden Fällen der zweite als R. descendens verlaufende Stamm des Hypoglossus nur von der zweiten Hirnwurzel und von Zweigen der ersten Halsnerven gebildet wird, so folgt, dass wenigstens die erste Hirnwurzel von der Bildung des $\mathbf{R}$. descendens ausgeschlossen ist. ton

Es lässt sich dasselbe aber auch für die zweite Hirnwurzel beweisen. Bei Istiurus Amboinensis (Taf. III, fig. 1) bilden die beiden Hirnwurzeln (h' und h") allein den eigentlichen (vorderen) Hauptstamm des Hypoglossus (h). Der erste Halsnerv (13) dagegen steht mit den beiden Hirnwurzeln nur durch zwei ungemein feine Fäden (w) in Verbindung, und verhält sich sonst ganz frei, - nach aussen als eigentlicher R. descendens zwischen die Mm. omohyoideus und sternohyoideus tretend, und in ihnen sich verbreitend.

Namentlich aus der letzten Bildung folgt, dass der Beitrag, den die Halsnerven zur Bildung des Hypoglossus liefern, hauptsächlich in den Fasern besteht, die durch Vermittelung des $R$. descendens an die Brustbein- und Schulterblatt-Zungenbeinmuskel geführt werden.

2) Von dem vorderen oder Hauptstamm des Hypoglossus.

Nach Abgabe seines R. descendens zeigt der Hypoglossus fast bei allen Sauriern dieselbe Form. Abweichungen von dem oben angegebenen Verlauf finden sich nur, wo eine abweichende Bildung der Zungenbein- und ZungenMuskeln vorkommt.

Bei Salvator Merianae entsteht, wie oben erwähnt, der Hypoglossus, der hier auch noch den Glossopharyngeus enthält, als der stärkere der beiden Hauptzweige (Taf. III, fig. $4, \mathrm{hg}$ ), in die sich der vereinigte Stamm der hinteren Hirnnerven (F) theilt. (Der zweite schwächere Theil [ $\mathrm{vs}$ ] enthält den Vagus und den Halsstamm des Sympathicus [ $\mathrm{v}$ und s]). Er krümmt sich innerhalb des M. cucullaris und bedeckt von diesem Muskel nach aussen, und theilt sich in der Gegend der hinteren Spitze des hinteren Zungenbeinhorns in drei Zweige:

a) Der dritte derselben ist der erstbeschriebene, R. descendens;

b) der zweite, schwächer als der vorige, ist der oben erörterte, hier als Ast des Hypoglossus erscheinende Glossopharyngeus, der, wie ebenfalls oben gesagt, hier zugleich den N. laryngeus superior nervi vagi enthält;

c) der erste, stärkste (noch einmal so stark als $a$ und $b$ zusammengenommen), tritt über die hintere, nach aussen gekrümmte Spitze des vorderen Zungenbeinhorns nach innen an die äussere Seite des walzenförmigen M. hyoglossus heran*), und biegt mit ihm nach vorn um. Vor dieser Biegung giebt er einen starken $Z$ weig an den unter ihm liegenden Geniohyoideus, nach

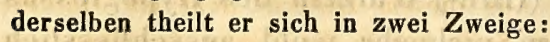

*) Bei den Spaltzünglern hat der M. hyoglossus eive walzenförmige Gestalı. Bei ihnen ist der hintere Ansatzpunkt des M. genioglossus nicht die Zungenwurzel selbst, sondern derselbe setzt sich sehr weit nach binten über die Fasern des M. hyoglossus fort, so dass auch er. beinahe die Spitze des binteren Zungenbeinhorns erreicht. Der Hyoglossus spielt alsdann in dem ihn umgebenden Genioglossus wie in einer Scheide. 
a) Der dünnere liegt der unteren Fläche der vereinigten Hyoglossus und Genioglossus hart an, und folgt denselben bis zur vorderen Ausbreitung des an den Unterkieferrand sich festsetzenden Genioglossus, wo er sich in diesem, verzweigt.

ß) Der Hauptstamm giebt, nahe seiner Biegung, nach vorn noch einen $Z$ weig ab, etwas stärker als $\alpha$, der sich um die Mm. Genioglossus und Hyoglossus nach innen schlägt, und über ihn fort tritt, um mit dem Hauptstamm selbst in den letzteren Muskel einzudringen, und nach Abgabe von Zweigen an denselben, zwischen dessen Fasern bis in die Zunge zu verlaufen.

Eine Schlingenbildung von Endzweigen des Hypoglossus mit Endzweigen des R. lingualis Trigemini, ward nicht beobachtet.

Auch bei Agama spinosa enthält der Hypoglossus den Glossopharyngeus und den mit letzterem verbundenen Laryngeus superior. Der Verlauf des Nerven zeigt keine wesentliche Abweichung. Nach Abgabe des Glossopharyngeus tritt der Stamm durch die Fasern des M. hyoglossus und des darunter liegenden Geniohyoideus nahe bei deren Insertion am hinteren Zungenbeinhorn nach unten, um unter letzterem Muskel, zwischen ihm und dem M. mylohyoideus nach vorn zu verlaufen. Eben unter diesem Muskel angelangt, dem er zahlreiche Fäden giebt, theilt er sich in drei Zweige :

a) Der mittlere, schwächste, dringt von unten her in den M. hyoglossus ein, und endigt in ihm.

ß) Der äussere, noch einmal so stark, als jener, geht unter dem M. hyoglossus gerade aus nach vorn, legt sich dicht an den $R$. lingualis Trigemini an, ohne jedoch mit ihm zu verschmelzen, und geht nach vorn in den M. genioglossus, in welchem er sich ausbreitet.

$\gamma$ ) Der innere, stärkste, schlängelt sich unter vielfachen Windungen zwischen den Fasern des M. hyoglossus nach vorn, und verschmilzt an dem vorderen Drittheil des Unterkiefers mit dem Zungenast des Trigeminus, Aus dieser Verbindung entstehen zwei Nerven von ungleicher Stärke, welche beide von der Seite her in die Zunge eindringen.

Auch bei Istiurus Amboinensis verbindet sich der durch einen Zweig des Vagus (dem Kehlkopfszweige entsprechend) verstärkte Glossopharyngeus mit dem Hypoglossus, doch unterscheidet sich diese Art von der vorigen durch den oben erörterten selbstständigen Verlauf des $R$. descendens. Nachdem der Hypoglossus an seiner Biegungsstelle den Glossopharyngeus wieder entlassen, tritt er von der Seite her zwischen die Fasern des Geniohyoideus, giebt demselben mehrere Zweige, und geht alsdann durch diesen Muskel nach oben an den über demselben liegenden M. hyoglossus, um sich hier in zwei Nerven zu theilen. Der stärkste dringt in den Hyoglossus ein, giebt ihm Zweige, und verläuft zwischen seinen Fasern bis zur Zunge. Der schwächere läuft ebenfalls zwischen den Fasern des M. hyoglossus nach vorn, nimmt den R. lingualis Trigemini vollständig auf, entsendet dann mehrere von der Seite her in die Zunge eindringende Zweige, und endigt vorn im M. genioglossus.

Von Platydactylus guttatus giebt Vog t ebenfalls eine Verschmelzung von Glossopharyngeus und Hypoglossus an. Ich finde diese Bildung an meinem Exemplar nicht, wo vielmehr der erstere in seinem ganzen Verlauf von dem letzteren getrennt bleibt. Die Verzweigung des Hypoglossus ist ganz dieselbe wie bei den übrigen Eidechsen. Einige seiner letzten Endzweige vereinigen sich mit Zweigen des R. lingualis Trigemini geflechtartig. Aus diesem Geflecht geht ein stärkerer und mehrere schwächere Nerven hervor, die sich von der Seite her in die Zunge einsenken.

Auch bei Salvator nigropunctatus nimmt der Hypoglossus den Glossopharyngeus nicht auf, entlässt daher auch später nicht die demselben und dem Laryngeus superior entsprechenden Zweige, wie bei Salvator Mevianae. Sonst ganz derselbe Verlauf wie bei dieser Art. Eine Verbindung seiner Endzweige mit Aesten des Trigeminus ward nicht beobachtet. 
Das eigenthümliche Verhalten des R. descendens bei Varanus Bengalensis ist oben erwähnt. Mit Ausnahme dieser Abweichung stimmt das übrige Verhalten des Hypoglossus ganz mit dem der anderen Eidechsen überein. Einer seiner letzten Endzweige bildet mit einem Zweige des $\mathbf{R}$. lingualis Trigemini eine deutliche Schlinge.

Auch bei Iguana tuberculata findet sich keine wesentliche Abweichung. Sehr entwickelt ist hier das feine Geflecht zwischen den letzten Zweigen des Hypoglossus und des Zungenastes des Trigeminus. In den Maschen dieses Geflechtes wurden sogar kleine Ganglien beobachtet.

Euprepes Sebae wiederholt die eigenthümliche Form des R. descendens von Varanus Bengalensis, zeigt aber sonst vollkommen die oben angegebene Verzweigung.

(Ueber die specielle Form der hier angegebenen Verbindungen mit Endästen des Trigeminus vergleiche oben pg. 22 ff.)

Von dieser Form des Hypoglossus bei den Eidechsen zeigt diejenige der Krokodile mehrere wesentliche Unterschiede. Einer derselben, dass nämlich seine Wurzeln nur Gehirnwurzeln sind, und keine Verstärkungen von Spinalnerven erhalten, ward schon früher hervorgehoben (pg. 70). Ferner fehlt den Krokodilen der Form nach ein eigentlicher R. descendens, obgleich auch hier der Brust-Zungenbeinmuskel vom HypogIossus seinen Nerven erhält. Endlich ist beständig das letzte Ende des Zungenfleischnerven der einen Seite durch eine (von Vogt entdeckte) Schlinge mit demjenigen der anderen Seite verbunden.

Alligator punctulatus zeigt folgende Form: Der Nerv steigt, wie gewöhnlich, hinter der Unterkieferecke nach unten ausserhalb des M. sternohyoideus ${ }^{*}$ ) und des M. coracohyoideus ${ }^{* *}$ ), tritt über den M. sternomaxillaris ${ }^{* * *}$ ), und theilt sich hier in drei Aeste:

a) Der mittlere, schwä̀chste, geht in den $M$. sternomaxillaris und endigt in ihm.

b) Der innere, stärkere, giebt ebenfalls noch einzelne Fäden an den genannten Muskel, geht dann zwischen diesem und dem M. coracohyoideus nach innen, und breitet sich in dem letzteren und im M. sternohyoideus aus. (Dieser Nerv würde, seiner Ausbreitung nach, dem R. descendens der Saurier analog sein.)

c) Der äussere, stärkste dieser drei Nerven, läuft über dem M. sternomaxillaris, zwischen ihm und dem darïberliegenden Coracohyoideus nach vorn, und giebt in der Gegend des hinteren Zungenbeinhorns, um welches er sich herumschlingt, zwei Zweige ab;

a) einen Ast in die vordere Parthie des M. hyomaxillaris $\dagger$ );

ß) einen anderen in die vordere Parthie des M. sternomaxillaris.

Nach ihrer Abgabe theilt sich der Rest des Nerven $e$ in zwei gleich starke Zweige:

a $\alpha$ ) Der eine derselben dringt von aussen und unten her in den M. hyoglossus $+t$ ) ein, und breitet sich darin aus.

* Vom Manubrium sterni als schmaler langer Muskel nach vorn an den binteren Rand der schildförmigen Erweiterung des Zungenbeinkörpers.

**) Vom Os coracoideum an den hinteren und unteren Rand des hinteren Zungenbeiuhorns.

****) Vom Brustbein nach vorn und dann schräg nach aussen, setzt sich an den inneren Rand des letzten Drittheils des Unterkiefers. Er läuft ausserhalb vom Coracohyoideus und Sternohyoidens, beide theilweise von unten her bedeckend.

†) Vom vorderen Rand des hinteren $Z$ ungenbeinhorns schräg nach vorn und aussen an den inneren Rand des letzten Dritheils des Unterkiefers.

t†) Ein breiter Muskel vom vorderen Rand des hinteren Zungenbeinhorns nach vorn und innen an den Boden der Mundhöhle. Wird, von unten gesehen, vóm Hyomaxillaris und Genioglossns bedeckt, nur die mittlere Parthie ist frei. 
$\beta \beta)$ Der zweite geht weiter, unter dem Hyoglossus und parallel mit dessen Fasern schräg nach vorn und innen verlaufend; er tritt endlich über den M. genioglossus*), und bildet hier mit dem entsprechenden Nerven der anderen Seite eine Xförmige Schlinge, aus welcher feine Fäden in den letztgenannten Muskel hervorgehen.

Bei Crocodilus biporcatus wendet sich der Hypoglossus gleich vom Ganglion. aus nach vorn, tritt über den Laryngopharyngeus und Glossopharyngeus fort, biegt sich mit dem letzteren zugleich nach vorn, indem er an dessen äusserer Seite verläuft, und giebt in der Gegend der hinteren Ecke des hinteren Zungenbeinhorns, ïber welche er sich zugleich mit dem Glossopharyngeus herumschlägt, einen, und bald darauf noch zwei neue Zweige in den vorderen Theil des langen und schmalen M. sternomaxillaris, und theilt sich, am M. hyomaxillaris angelangt, in zwei $Z$ weige:

a) Der sehwächere tritt mit einem Aste des Glossopharyngeus zu einem in den Mm. Hyoglossus und Genioglossus sich ausbreitenden Zweige zusammen.

b) Der stärkere läuft weiter schräg nach innen und vorn bis zu dem Punkt, wo die Fasern des Hyoglossus sich an dem Boden der Mundhöhle befestigen. Hier bildet er eine Hförmige Schlinge mit dem Nerven der anderen Seite, aus welcher da, wo der Nerv jeder Seite zu der Bildung derselben nach innen einlenkt, ein $Z$ weig nach vorn und aussen an den Boden der Mundhöhle und an den M. genioglossus geht. - Es muss noch bemerkt werden, dass einzelne dieser, an dem Boden der Mundhöhle sich verbreitenden Fäden mit den letzten Endzweigen des Alveolaris inferior nervi Trigemini ein feines Geflecht bilden.

Crocodilus acutus zeigt keinen Verstärkungszweig des Hypoglossus an den Glossopharyngeus, weicht aber sonst nicht wesentlich von der vorigen Form ab.

\section{Achter Abschnitt.}

\section{Vom Sympathicus.}

Die Entwickelung sympathischer Nervenverbindungen ist bei den Sauriern sehr beträchtlich, wenn es bis jetzt auch nicht möglich war, eine Theilnahme sämmtlicher Nerven an denselben nachzuweisen. Ich wage nicht zu behaupten, dass einer der drei Augenmuskelnerven an diesen sympathischen Schlingen Theil nimmt, obgleich Vogt dies, wenigstens vom Abducens, mit Entschiedenheit behauptet. Mit Ausnahme des letzteren stehen aber vom Trigeminus abwärts alle Gehirnnerven unter einander und mit den eigentlichen Spinalnerven durch eigenthümliche Schlingen in Verbindung. Fassen wir die Summe dieser Schlingen, ohne vorläufig auf die Frage nach der Selbstständigkeit eines sympathischen Systems einzugehen, unter dem Namen des Sympathicus zusammen, so zeigt derselbe eine, von der Form der warmblüthigen Wirbelthiere in manchen Punkten abweichende Gestalt.

* Ein schmaler Muskel, mit schwach divergirenden Fasern, vom Boden der Mundhöhle, da, wo die Hyoglossi beider Seiten noter spitzem Winkel zusammentreten, gerade ans nach vorn, an den inberen Rand der Unterkieferspitze; er bedeckt von unten her die vordere Parthie der beiden Hyoglossi. 
Der Kopftheil zunächst besteht aus zwei grossen, bogenförmigen Schlingen. Die eine, welche man den oberflächlichen Kopftheil nennen könnte, erstreckt sich vom ersten und zweiten Ast des Trigeminus über die Aussenseite des Kopfes nach hinten an den hinteren Hauptstamm des Facialis, und geht von hier, meist durch Vermittelung des Ganglion petrosum, in den Halstheil über. Die zweite (der tiefe Kopftheil) geht vom zweiten Ast des Trigeminus unterhalb des Schädels an den vorderen Hauptstamm des Facialis (den R. palatinus), und geht von hier ebenfalls an das Ganglion petrosum. So wird meist dies Ganglion, das indessen einigen Sauriern fehlt, bei einigen anderen ausserhalb der Bahn der sympathischen Stämme liegt, der Sammelpunkt der beiden Kopfstämme. Von ihm aus erstrecken sich in einem grossen Stamme, (wenn mehrere solche Stämme da sind, so sind sie geflechtartig unter einander verbunden) die sympathischen Fasern bis zum Armgeflecht, ohne dass diese Stämme mit den auf ihrem Wege liegenden Spinalnerven (mit Ausnahme der zur Bildung des Hypoglossus beitragenden beiden ersten Halsnerven) in Verbindung ständen, und ohne dass sie bis nahe zum Armgeflecht Spuren gangliöser Anschwellungen zeigten. Diese vom Ganglion petrosum bis zum Armgeflecht sich erstreckenden, unterwegs nicht unterbrochenen starken Schlingen, bilden denjenigen Theil des Sympathicus, den man wegen seiner entfernten Lage von der Wirbelsäule den oberflächlichen Halstheil nennen könnte:). Erst in der Gegend des Plexus brachialis liegen beständig an dem letzteren unmittelbar hinter einander mehrere platte, ovale, grosse Ganglien, welche mit den Armnerven in Verbindung stehen, und feine Fäden an die Eingeweide der Brusthöhle ausstrahlen. - Ausser diesem oberflächlichen Halstheil, der mit den eigentlichen Halsnerven selbst in keiner Verbindung steht, bilden noch die vorderen Zweige der letzteren gleich nach deren Austritt ein meist unter den Muskeln der Wirbelsäule verstecktes System von Schlingen, das man wegen dieser Lage den tiefen Halstheil nennen könnte. Auch der aus diesem letzteren zuweilen (Chamaeleo) hervorgehende einfache Stamm mündet, wo er vorhanden ist, in das erste der eben berührten Brustganglien am Armgeflechte ein. Wie das Ganglion petrosum oft für die beiden Kopftheile, so wird also dies Ganglion thoracicum primum der Sammelpunkt für die beiden Halstheile.

Von den starken Ganglien am Armgeflecht abwärts nimmt die Entwickelung der bis hieher so bedeutenden sympathischen Schlingen ungemein ab. Von hier an liegt der ausserordentlich feine Grenzstrang den vorderen $\mathbf{Z}$ weigen der Spinalnerven ziemlich nahe, und erinnert durch die Schlingen mit denselben an die Formen der höheren Thiere, von denen er sich jedoch durch den Mangel eigent-

*) Nicht zu verwechseln mit Vog ts Sympathicus superficialis der Krokodile. Dieser gehört, wie Stannius bernerkt, nicht dem sympathischen System an. Wir haben ihn als $R$. descendeus uervi laryngopharyngei oben beschrieben. 
licher Ganglien unterscheidet, die ihm bei jenen gerade die Gestalt einer Ganglienkette geben. Schon an den vier bis fünf nächsten, auf das Armgeflecht folgenden Spinalnerven wird in der Regel dieser Grenzstrang so fein, dass es kaum möglich ist, ihn weiter zu verfolgen.

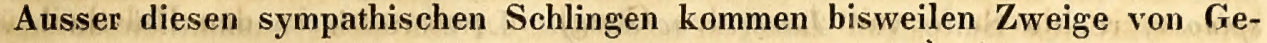
hirnnerven vor, die ganz die Form und Verbreitung von Nerven haben, wie wir sie bei den sogenannten sympathischen Nervenzweigen zu finden gewohnt sind, die aber mit jenem System von Schlingen in durchaus keiner anderen Verbindung stehen, als dass sie als peripherische Endzweige desselben Nerven erscheinen, aus dem die beiden grossen sympathischen Kopfschlingen ihren Ursprung nehmen. Hieher gehört namentlich der (zuweilen gangliöse) Drüsenzweig vom zweiten Aste des Trigeminus, dessen specielle Formen oben (pg. 13, 14) abgehandelt worden sind.

\section{Vom Kopftheil des Sympathicus. \\ 1) Vom oberflächlichen Kopftheil.}

Der oberflächliche Kopftheil des Sympathicus besteht bei den Sauriern, wie oben bemerkt, constant aus zwei Schlingen.

Die erste derselben entspringt beständig als feiner Nervenfaden aus dem zweiten Aste des Trigeminus, da, wo dieser hinter dem Auge seine $\mathbf{Z}$ weige für die Stirnhaut und die Augenlider, sowie seinen Drüsenast entlässt. Es ist der oben ausführlich abgehandelte Ramus recurrens ad nervum facialem (pg. $10 \mathrm{ff})$. Dieser, der bisweilen einzelne Fäden aus dem ersten Aste des Trigeminus aufnimmt, steigt bis zur Stirn in die Höhe, wendet sich dann rückwärts, gewöhnlich unter die Knochenleiste, die vom Scheitelbein bis zum Querfortsatz des Hinterhauptsbeins sich erstreckt, um unter derselben an der Seite der nach vorn verlaufenden Arteria temporo-muscularis (Boianus) nach hinten, zu verlaufen, und, hinter dem Schädel abwärts steigend, sich in den hinteren Hauptstamm des Facialis gewöhnlich da einzusenken, wo dieser sich in die Chorda tympani und den Muskelast theilt. *)

Vom hinteren Hauptstamm des Facialis, der bei den Sauriern gewissermassen eine Station bildet auf dem Wege, den dieser äussere sympathische Bogen nach hinten verfolgt, setzt sich der letztere als der bei allen Sauriern, und, wie es scheint, auch bei den Schlangen vorhandene R. communicans externus nervi facialis cum Glossopharyngeo bis zum Glossopharyngeus fort. (Auf den Abbildungen mit $e$ bezeichnet). Entweder mündet er in

*) Dieser, an seiner Einmündungsstelle in den Facialis auf den Figuren der zweiten Tafel angedeutete Nerv ist überall mit $x$ bezeichnet. Auf den Umstand, dass von ihm, durch Vermittelung der Chorda tympani, wahrscheinlich auch sympathische Fasern an die Zunge gelangen, ist oben (pg. 36) bingewiesen worden. 
das Ganglion petrosum desselben ein, (Iguana tuberoulata, Salvator nigropunctatus, Chamaeleo vulgaris, Istiumis Amboinensis, linke Seite meines Exemplars von Lacerta ocellata), oder verbindet sich, ohne dasselbe zu berühren, direct mit dem Stamme des neunten Paares (Euprepes Sebae, Platydactylus guttatus, Agama spinosa, rechte Seite von Lacerta ocellata). Letzteres ist namentlich auch dann der Fall, wenn ein Ganglion petrosum ganz fehlt (Salvator Merianae, Varanis Bengalensis).

Indem wir uns in Bezug auf die speciellen Formen dieser beiden Nerven auf unsere früheren ausführlichen Darstellungen beziehen, bleibt nur noch übrig zu beweisen, dass die durch dieselben hergestellte bogenförmige Schlinge zwischen Trigeminus und Glossopharyngeus wirklich eine der sogenannten sympathischen Schlingen ist. Der Beweis wird geliefert sein, wenn erstens gezeigt ist, dass der R. communicans externus nervi facialis cum Glossopharyngeo wirklich die Fortsetzung jenes $R$. recurrens nervi Trigemini ad nervum facialem ist, und wenn zweitens dargethan ist, dass der Ramus communicans nervi Facialis cum Glossopharyngeo sich vom Glossopharyngeus an in den Halstheil des Sympathicus fortsetzt.

Das enstere folgt aus der Bildung einzelner Eidechsen, bei denen ein directer Uebergang des $R$. recurrens Trigemini in den $R$. communicans nervi Facialis beobachtet wird.

Bei Euprepes Sebae z. B. tritt, wie oben erinnert, der R. recurrens unter rechtem Winkel an die als Zweig des hinteren Hauptstammes des Facialis auftretende Chorda tympani an, lässt sich von ihr ab als feine Nervenbrücke an den benachbarten Muskelast des Facialis verfolgen, den er, verstärkt, ebenfalls . sogleich wieder verlässt, um als $R$. communicans externus an den Glossopharyngeus sich anzulegen, und mit diesem zu verschmelzen. Mit Hülfe einer scharfen Loupe lässt sich der vom Trigeminus entsprungene Nerv über den hinteren Hauptstamm des Facialis fort, vón dem er durch neue Fasern verstärkt wird, bis zum Glossopharyngeus als ein continuirlicher Nervenzug verfolgen. - Dass hiebei ausserdem wenigstens die Möglichkeit eines Ueberganges sympathischer Fasern an die Chorda tympani, und durch ihre Vermittelung an die Zunge zugegeben werden muss, ist oben erinnert.

Als Beweis für den zweiten Theil unserer Behauptung, dass nämlich der R. communicans externus nervi facialis cum Glossopharyngeo sich in den Halstheil des Sympathicus fortsetze, lassen sich die Formen von Platydactylus guttatus und Lacerta ocellata geltend machen.

Bei dem ersteren verschmilzt dieser Nery (Taf. III, fig. 3, e) nicht wie gewöhnlich mit dem Ganglion petrosum (D), sondern kreuzt den eben aus diesem Ganglion hervorgetretenen Stamm des Glossopharyngeus ( $\mathrm{g}$ ) unter rechtem Winkel, und setzt sich von ihm ab als einfacher (oberflächlicher) Halsstamm des Sympathicus fort (s). - Bei einem Exemplar ferner von Lacerta ocellata habe ich eine Form dieses Nerven gefunden, die unsere Behauptung noch klarer beweist. Während nämlich der R. communicans internus nervi palatini cum Glossopharyngeo (Taf. II, fig. 1, i), von dem gleich weiter die Rede sein wird, sich nicht mit dem Glossopharyngeus (9) verbindet, 
sondern sich direct ins sympathische Halsgeflecht verfolgen lässt, mündet unser $\mathbf{R}$. communicans externus in der Regel in das Ganglion petrosum ein (rechte Seite der Figur, e'). Einmal glückte es mir, an der rechten Seite eines grossen Exemplars (linke Seite der Figur) diesen Verbindungszweig von einer anderen, sehr instructiven Form zu finden. Kaum aus dem hinteren Hauptstamm des Facialis (f) hervorgetreten, theilt er sich (e) in zwei feine Nerven, von denen einer durch eine Schlinge $(\beta)$ mit dem Vagus in Verbindung steht. Beide vereinigen sich wieder in der Gegend des Ganglion petrosum (D) zu einem nach hinten verlaufenden Stamme, der aber nicht mit dem genannten Ganglion verschmilzt, sondern nur durch zwei Nervenzweige (d) mit ihm in Verbindung steht, und sich in seinem Verlauf nach hinten als einer der Hauptstämme (e e) erweist, aus denen hier der (oberflächliche) Halsstamm des Sympathicus (s) zusammengesetzt wird.

Es schien passend, zuerst diejenigen Gründe anzuführen, die sich aus der Bildung der Saurier selbst für unsere Behauptung ergeben. Aus der Bildung anderer Reptilien lässt sich dieselbe ebenfalls bis zur Evidenz erweisen.

Bei Chelonia Mydas, wo Bendz, wie erst erwähnt, zuerst diesen Nervenbogen auffand, wird von diesem Autor*) durchaus keine Verbindung mit dem Facialis, wie sie allen Sauriern eigen ist, beschrieben; der Nerv geht vielmehr vom zweiten Aste-des Trigeminus in derselben Weise, wie bei den Sanriern, nach hinten, und setzt sich, nur unter Abgabe einiger Zweige an's Ganglion petrosum, in den Sympathicus fort. - Aus dieser Bildung bei Chelonia ergiebt sich offenbar nicht nur der erste Theil unserer Behauptung, dass der R. recurrens Trigemini ad Facialem und $R$. communicans externus nervi Facialis cum Glossopharyngeo ein und derselbe Nervenzug ist, bei den Sauriern nur unterbrochen von dem hinteren Hauptstamm des Facialis: es folgt auch zweitens daraus, dass diese bogenförmige Schlinge den eigentlichen sympathischen Schlingen angehört **).

Auch bei den Krokodilen existirt diese vom Trigeminus an die hinteren Hirnnerven gehende sympathische Schlinge, - auch hier kreuzt dieselbe die Fasern des hinteren Hauptstammes des Facialis, so dass sie, wie bei den Sauriern, eigentlich aus zwei Schlingen besteht: einer vorderen vom Trigeminus zum Facialis und einer hinteren vom Facialis zum Ganglion der hinteren Hirnnerven.

Einen wesentlichen Unterschied zeigt der R. recurrens Trigemini hier (Crocodilus biporcatus) insofern, als er nicht aus dem zweiten Aste des Trigeminus da abgeht, wo dieser hinter dem Auge sich theilt, sondern aus dem Ganglion des zweiten und dritten Astes selbst entspringt (Taf. III, fig. 5, x). Er wendet sich dem Schädel dicht anliegend nach oben und hinten, trifft vor der Paukenhöhle mit dem hinteren Hauptstamm des Facialis (f) unter spitzem Winkel zusammen, und verschmilzt mit ihm vollständig. Letzterer (f) setzt aus der Verbindungsstelle seinen Weg in unveränderter Richtung fort, bald darauf in Chorda tympani (?) und Muskelast sich theilend,

*) Bidrag til den sammenlignende Anatomie af N. Glossopharyngeus, Vagus og Hypoglossus pg. 5.

**) Diese eine Hälfte des sympathischen Kopftheils der Saurier scheint auch bei den Schlangen zu existiren. In ihrer Vollständigkeit ist dieselbe allerdings noch nicht aufgefunden, sofern alle Beobachtungen eines $R$. recurrens nervi Trigemini ad nervum Facialem von der Form der Sanrier hier fehlen. Aber unser R. communicans externus nervi Facialis ad Glossopharyngeum, der eben die Fortsetzung jenes R. recurrens ist, ist vou M äll er (vergl. Neurol. der Myxinoiden, Taf. IV, fig. 3 und 4) bei Python tigris und Crotalus horridus abgebildet, und Bendz erwähnt (1. 1. pg. 18) eines Nervenzweiges, den bei Tropidonotus natrix der Glossopharyngeus gleich nach seinem Austritt aus dem Schädel vom Facialis empfängt. 
während ersterer als $R$. communicans externus (e) nach innen einlenkt, in einen besonderen Knochenkanal tritt, und von oben und vorn her in den vorderen Theil des den hinteren Hirnnerven gemeinschaftlichen Ganglions einmündet. *)

2) Vom tiefen Kopftheil.

Auch die zweite der beiden grossen sympathischen Kopfschlingen besteht aus zwei Bogen. Die Fasern des ersten gehen vom zweiten Aste des Trigeminus $_{s}$ aus, und treten als $R$. communicans posterior nervi maxillaris superioris zum Ramus palatinus nervi Facialis hinüber. Vom R. palatinus setzen sie sich als zweiter Bogen in der Form des R. communicans internus rami palatini cum Glossopharyngeo nach binten fort, und münden entweder in den Stamm des Glossopharyngeus oder ins Ganglion petrosum ein, _ in einigen Fällen lassen sie sich auch direct in den (oberflächlichen) Halstheil des Sympathicus verfolgen.

Die speciellen Formen beider Nerven sind früher (pg. 15, $25 \mathrm{ff}$ und pg. $30 \mathrm{ff}$ ) ausführlich erörtert worden. Was namentlich den ersten Theil dieser Schlinge betrifft (den Verbindungszweig zwischen Maxillaris superior und Ramus palatinus), so ist früher (pg. 15) dargethan, dass er entweder eine einfache Verbindungsschlinge zwischen zweitem Aste des Trigeminus und R. palatinus bildet (Varanus Bengalensis), oder dass auf dem Boden der Orbita ein eigenthümliches Sphenoidalgeflecht zwischen Fasern des Trigeminus und R. palatinus existirt (Salvator nigropunctatus, Salvator Merianae, Iguana tuberculata). Crocodilus (Taf. III, fig. 5, pl) besitzt ein Sphenoidalgeflecht, das aber ausschliesslich aus Zweigen des Trigeminus gebildet zu sein scheint, - aus ihm geht ein einfacher Nervenzweig quer hinüber an den $R$. palatinus.

Ob indessen diese Nervenschlingen oder Geflechte den Zweck haben, Fasern aus dem Maxillaris superior hinüber zu führen an den R. palatinus, oder ob das Gegentheil der Fall ist, lässt sich auf anatomischem Wege nicht entscheiden. Das eine liefert die Beobachtung, dass, wenn alle Fasern des R. palatinus als vom Facialis entspringend betrachtet werden, der Verbreitungsbezirk des letzteren übermässig gross erscheint in Vergleich mit seiner immer sehr feinen Wurzel. Unsere Ansicht ist, dass die Fasern dieses Verbindungszweiges nicht aus dem R. palatinus entspringen, sondern dass dieser nur gewissermassen die Brücke ist, durch welche die aus dem Maxillaris " superior entsprungenen Fasern nach hinten laufen, um dann, meist vor dem Ganglion des Facialis, den R. palatinus wieder zu verlassen, und in das Ganglion petrosum des Glossopharyngeus sich

*) Bei Alligator lucius, wo nach Bendz (1. 1. pg. 10) ein gesondertes Ganglion petrosum und ein Ganglion cervicale supremum vorhanden ist, sah dieser Forscher einen aus beiden Ganglien entstandenen Nerven in die Gehörkapsel treten. B endz selbst hält diesen Nerven für einen Theil des N. vidianus, und jene Verbindung mit dem Ganglion petrosum für die Jakobsonsche Anastomose. - Vogt (l. l. pg. 33) erwähnt ebenfalls dieses Nerven als eines (des vorderen) Astes des Glossopharyngens. 
einzusenken. Letzteres geschieht durch den R. communicans internus, über dessen specielle Formen früher (pg. 30 ff.) gehandelt worden ist. Hier möge nur wiederholt werden, dass dieser, meist in mehreren Fäden aus dem Anfange des R. palatinus, bisweilen (Iguana tuberculata Taf. II, fig. 3, i) aus dem Ganglion des Facialis entspringende Nerv meist mit dem Ganglion petrosum sich verbindet, sich aber dann oft unter diesem Ganglion durch in den Halstheil des Sympathicus verfolgen lässt (Salvutor nigropunctatus, Taf. I, fig. 1, i; auch bei Varanus Bengalensis [Taf. II, fig. 2, i], wo kein deutliches Ganglion petrosum gefunden wurde, setzt sich unser Nerv unter dem Stamm des durch Zweige aus dem Vagus verstärkten Glossopharyngeus durch in den Halstheil des Sympathicus fort). Ja, in einigen Fällen (Lacerta ocellata, Taf. Il, fig. 1, i) findet sogar eine gänzliche Umgehung des Ganglion petrosum und des Glossopharyngeus statt, und der aus dem $R$. palatinus entsprungene Nerv geht direct in den sympathischen Halstheil über. Letztere Form, so wie diejenige von Salvator nigropunctatus und Varanus Bengalensis, liefert den directen Beweis für unsere Behauptung, dass überall, wo eine solche Verbindung zwischen Glossopharyngeus und $\mathbf{N}$. palatinus gefunden wird, dieselbe nicht als vom ersteren ausgehend und zum letzteren sich erstreckend aufgefasst werden darf. *)

Auch den Schlangen, die, wie oben gezeigt, wahrscheinlich den ersten, oberflächlichen Bogen besitzen, fehlt dieser zweite tiefe Kopftheil des Sympathicus nicht. Die vortrefflichen Abbildungen von Müller (vgl. Neurologie der Myxinoiden Taf. IV) geben namentlich in der dritten Figur (Python tigris) eine klare Vorstellung von demselben. Unser R. palatinus ist dargestellt, wie er, von der Wurzel des Facialis entsprungen, sich nach hinten schlägt, ganz wie bei den Sauriern in einem Knochenkanal des Keilbeins ( $a \sim b$, Canalis Vidianus) eintritt, ausserhalb desselben durch unseren R. communicans posterior (5") mit dem zweiten Aste des Trigeminus in Verbindung steht, und vorn unter Bildung eines Ganglions (6, Ganglion sphenopalatinum) an den letzteren selbst sich anlegt. Müller bezeichnet denselben in seiner mittleren Parthie, da, wo er im Knochenkanal verläuft, als N. Vidianus, in seiner hinteren Parthie, wo er eben aus der Wurzel des Facialis entspringt, als Verbindungszweig des N. Vidianus zum Facialis, und vorn als Fortsetzung des Vidianus. Unser innerer Verbindungszweig des R. palatinus mit dem Glossopharyngeus ist hier ebenfalls als vom R. palatinus (N. Vidianus) ausgehend und in's Ganglion petrosum (Ganglion cervicale supremum) einmündend dargestellt. Es findet sich also, abgesehen von Müllers verschiedener Auffassungsweise, bei Python ganz dasselbe Verhalten, wie bei den Sauriern, - Auch Crotalus horridus zeigt nach Müller (l. l. fig. 4) eine ganz ähnliche Form. Der R. palatinus (66, als Zweig des N. Vidianus zum Facialis bezeichnet) geht durch seinen Kanal, und steht, wie immer, mit dem zweiten Aste des Trigeminus in Verbindung. (Ein hier abgebildeter

*) Dieser Ansicht zu folgen, zu welcher Stannius sich bei der Deutung ähnlicher Nervenzweige beim Stör bekennt (d. periph. Nervens. d. Fische pg. 78), könnte man sich 2 war leicht anch durch die Formen einiger Eidechsen bewogen füblen. Bei Chamaeleo vulgaris (Taf. II, fig. 4, i) läuft dieser feine, mit zwei Zweigen aus dem R. palatinus entspringende, Nerv nach hinten, passirt sogar um ein Geringes das Ganglion petrosum (D), biegt dann knieförmig nach innen und etwas nach vorn um, und mündet in die äussere, hintere Spitze des Ganglion petrosum so ein, dass er ganz wie ein aus dem letzteren ausgesandter Nerv erscheint. 
Verbindungszweig aus der Pars motoria des Trigeminus an den R.palatinus [N. Vidianus] verlässt den letzteren bald wieder, um in den Adductoren des oberen Kieferapparates sich auszubreiten. Derselbe Zweig findet sich, wie oben gesagt (pg. 18), anch bei allen Sauriern und Krokodilen, verschmilzt aber nie mit dem R. palatinus.) Ein unserem R. communicans internus rami palatini cum Glossopharyngeo entsprechender Nerv ist hier indessen nicht abgebildet, - es scheint nur e in Verbindungsnerv (unser $\mathbf{R}$. communicans externus) zwischen beiden Nerven zu existiren.

3) Ueber die Beziehung des R. palatinus zum tiefen Kopftheil des Sympathicus.

Bei dem innigen Verhältniss, in welchem der $R$. palatinus zum Kopftheil des Sympathicus steht, kann gefragt werden, ob nicht dieser ganze Nerv, der von uns als vom Wurzelganglion des Facialis entstehend, und nach vorn sich erstreckend geschildert wurde, als ein rücklaufender Nervenzug zu betrachten sei, bestimmt, die aus dem Trigeminus und dem Sphenoidalgeflecht entstehenden sympathischen Fasern rückwärts, zunächst an den Facialis (unseren hinteren Hauptstamm des Facialis) zu führen. Dass diese Ansicht in Bezug auf einen Theil seiner Elemente die unsrige ist, ergiebt sich aus den vorhergehenden Erörterungen. Die vom Trigeminus entsprungenen Easern treten als R. communicans posterior an den $\mathbf{R}$. palatinus, laufen in der Bahn desselben rückwärts, und verlassen dieselbe bald wieder, um als $R$. communicans internus vom $R$. palatinus aus durch Vermittelung des Glossopharyngeus in den Halstheil des Sympathicus überzugehen. Dass aber ausser diesen fremden Elementen noch eigene nach vorn verlaufende Fasern des Facialis im R.palatinus enthalten sind, wird aus folgenden Gründen mehr als wahrscheinlich:

1) Der R. palatinus entspringt beständig aus dem Wurzelganglion des Facialis, die fremden, ihm von vorn her (vom Trigeminus) beigemengten Elemente berühren meist die Wurzel des siebenten Paares nicht, sondern verlassen den $R$. palatinus in der Regel schon vor derselben (als R. communicans internus).

2) Der R. palatinus erscheint immer stärker als die Summe der Verbindungszweige zwischen ihm und dem Trigeminus.

3) Er entlässt constant Zweige (diesem Mehr von Fasern entsprechend) in die Gaumenhaut, ja, was ein Hauptpunkt ist, Zweige, die sich mit dem Trigeminus oder dessen Aesten zu Gaumenhautzweigen verbinden (unsern R. communicans anterior).

4) Bei vielen anderen Wirbelthieren, z. B. den nackten Amphibien, welche letztere sämmtlich den R. palatinus besitzen, treten die Verbindungsäste mit dem Trigeminus hinter der zuletzt erwähnten Ausbreitung an der Gaumenhaut so sehr zurück, dass sie bei einigen sogar gänzlich zu fehlen scheinen (Bufo, Rana, Hyla, Pipa, Salamandra, Triton); nur bei Pelobates und Bombinator wurden dieselben, und zwar sehr schwach entwickelt, gefunden.*)

*) Vergl. meine frühere Schrift Amphibiorum nudorum neurologiae specimen I pg. 22. 
Es fragt sich nun, welchen Nervenzügen der höheren Wirbelthiere die erst beschriebenen beiden sympathischen Kopftheile der Reptilien zu vergleichen sind. Müller (vgl. p. 81) betrachtet bei Python tigris einen Theil des inneren Bogens (letzterer allein wird von diesem Forscher erörtert) als N. Vidianus, nämlich den Theil unseres R. palatinus, der im Knochenkanal des Keilbeins verläuft. Ebenso Vogt, der indessen nur einen Theil dieses inneren Bogens gekannt zu haben scheint. - Bendz dagegen beschreibt einen Theil des äusseren Bogens (unsein R. recurrens Trigemini ad $\mathrm{N}$. facialem) bei Chelonia Mydas als $\mathrm{N}$. Vidianus, und ebenso scheint Bonnsdorf (bei Grus und Corvus), dessen R. recurrens dem unsrigen analog sein dürfte, diesen Theil des äusseren Bogens als N. Vidianus aufzufassen.

Es scheint, als ob jede dieser Ansichten, abgesehen von den sympathischen Verbindungen mit anderen Hirnnerven, auf den Durchgang der entsprechenden Nervenzüge durch besondere Knochenkanäle sich stützt, - und in der That ist ein solcher Durchgang durch einen Knochenkanal, den man dem Canalis Vidianus vergleichen könnte, dem einen sowohl wie dem anderen Bogen eigen.

Was zunächst den inneren Kopftheil betrifft, so verläuft immer bei den Sauriern der R. palatinus selbst durch einen Kanal des Keilbeins nach vorn. Die in der Bahn des R. palatinus rücklaufenden sympathischen Fasern gehen also ebenfalls durch diesen Kanal, und sondern sich oft noch in diesem selbst vom R. palatinus $a b$, um (als unser $R$. communicans internus) nach hinten zu verlaufen. Müller bezeichnet diesen Kanal als Canalis Vidianus, und den in demselben liegenden Theil des $R$. palatinus als $N$. Vidianus. Hiernach würde unser $R$. communicans in tern us rami palatini cum nervo glossopharyngeo als Jakobsonsche Anastomose zu bezeichnen sein. - Auch ein Theil des oberflächlichen Bogens aber (unser $R$. recurrens) durchläuft, wie Bendz zuerst bei Chelonia entdeckte, einen Kanal, den der genannte Forscher als Canalis caroticus bezeichnet. Bendz betrachtet daher unseren $R$. recurrens als $N$. Vidianus, und demzufolge würde unser R. communicans externus nervi facialis cum glossopharyngeo die Jakobsonsche Anastomose sein, was Bendz auch für Chelonia, wo eine Unterbrechung des Nervenzuges durch den Facialis zu fehlen scheint, andeutet.

Wir möchten, immer an der Selbstständigkeit des $R$. palatinus als eines Astes des Facialis festhaltend, uns für die erste Ansicht entscheiden, und die aus dem Maxillaris superior Trigemini stammenden, in der Nervenscheide des R. palatinus durch den erwähnten Knochenkanal nach hinten tretenden Fasern für ein Analogon des N. Vidianus halten, und zwar zum Theil wegen ihres tiefen Verlaufes, zum Theil auch, weil von Vogt bei Chelonia und einigen Sauriern ein Verbindungszweig aus dem Abducens beobachtet ist, der jenem zweiten oberflächlichen Bogen sicher fehlt. 


\section{4) Vom Ganglion petrosum.}

Der Sammelpunkt des doppelten Kopftheils ist, wie vorhin dargethan, meistens ein in der Bahn des Glossopharyngeus gelegenes Ganglion, von uns nach Bendz' Vorgange als Ganglion petrosum bezeichnet, - diese Anschwellung ist zugleich meist der Punkt, von wo aus der (oberflächliche) Halstheil des Sympathicus beginnt*). Aus dieser Einmündung und Ausstrahlung sympathischer Fasern scheint zu folgen, dass das Ganglion selbst ein Knotenpunkt im System der sympathischen Schlingen sei, und etwa als Ganglion cervicale supremum aufgefasst werden müsse. Müller ${ }^{* *}$ ) ist (für Python) in der That dieser Ansicht. Da indessen das Ganglion cervicale supremum eine Anschwellung ist, die im Grenzstrange selbst liegt, und von dem aus Manche den Kopftheil des Sympathicus nach vorn (oben), den Halstheil nach hinten (unten) ausstrahlen lassen, so widersteht der Deutung unseres Ganglions als Ganglion cervicale supremum der Umstand, dass nicht immer die Kopftheile des Sympathicus in dasselbe einmünden, sondern zuweilen diese Anschwellung umgehend, und nur durch feine Verbindungszweige oder gar nicht mit ihm verknüpft, sich direct in den Halstheil des Sympathicus fortsetzen. Da hingegen dies Ganglion, wo es auch sei, immer in der Bahn des Glossopharyngeus liegt, so scheint die Bezeichnung desselben als Ganglion petrosum die einzig richtige zu sein.

Bei Euprepes Sebae verbindet sich die feine Wurzel des Glossopharyngeus mit den beiden hinteren Schlingen der sympathischen Kopftheile (mit dem R. communicans internus rami palatini und mit dem R. communicans externus nervi facialis) zu einem feinen kurzen, nach aussen verlaufenden Stamm ohne Spur eines Ganglions. Dieser Stamm theilt sich in zwei Theile, von denen der innere gerade nach hinten verläuft, und sich als einfacher Halsstamm des Sympathicus zu erkennen giebt, während der andere bald nach seiner Entstehung ein kleines halbmondförmiges Ganglion bildet, und als eigentlicher Glossopharyngeus sich nach aussen, unten und vorn wendet. So liegt dies Ganglion hier ganz ausserhalb des sympathischen Nervenzuges in der Bahn des eigentlichen Glossopharyngeus, und ist mit jenem, wie es scheint, nicht einmal durch Verbindungszweige verknüpft. -

An meinem Exemplar von Lacerta ocellata mündet an der linken Seite zwar (Taf. II, fig. 1, rechte Seite der Figur) der äussere Verbindungszweig aus dem Facialis (e') in das Ganglion (Dd)

*) Ueber die speciellen Formen dieses Ganglions und die in dasselbe einmündenden und aus ihm austretenden Nerven vgl. pg. $39 \mathrm{ff}$. -

**) 1. 1. Taf. IV, fig. 3. In dies Gauglion (6) münden von innen her ein: 1) unser R. communicans internus rami palatini (s), hier als Zweig aus dem Ganglion $2 \mathrm{~nm} \mathbf{N}$. Vidianus bezeichnet; 2) unser R. communicans externus nervi facialis (8), hier ebenfalls als Verbindungszweig zum Facialis aufgeführt; 3) die Wurzel des Glossopharyngeus; 4) ein in der Beschreibung nicht aufgeführter Verbindungszweig rom Vagus [dem R. laryngeus superior entsprechend]; 5 ) in die äussere Spitze des Ganglions tritt endlich noch ein zweiter Verbindungszweig vom Facialis ein. - Als a ustretend sind aufgeführt: 1) ein in eine Oeffung im hinteren Vorsprung des Unterkiefers eintretender Nerv (Chorda tympani?), [der offeubar einem der Verbindungszweige aus dem Facialis entspricht]; 2) der Stamm des Glossopharyngens [mit einem Theil des Vagns, dem N. laryngeus superior, vereint]; 3) ein Zweig zum Stamm der Kopfarterie. 
ein (der innere Verbindungszweig aus dem R. palatinus [i] geht auch hier an demselben vorbei); an der rechten Seite aber (linke Seite der Figur) umgeht auch der äussere Verbindungsast (e) das lediglich in der Bahn des Glossopharyngeus (9) liegende Ganglion, um sich, nur durch zwei Verbindungsfäden $(\alpha)$ mit ihm verknüpft, in einen der Hauptstämme fortzusetzen, aus denen hier, in der Form eines Geflechtes, der (oberfächliche) Halstheil des Sympathicus aus den Kopftheilen und den Verbindungszweigen der hinteren Hirnnerven entsteht.

Bei Platydactylus guttatus (Taf. III, fig. 3) findet sich das umgekehrte Verhältniss von Lacerta ocellata. Hier mündet der innere Verbindungsast aus dem R. palatinus (i) mit dem Glossopharyngeus (9) zusammen in jenes Ganglion (D) ein, während der ä ussere (e) an dem letzteren vorbeigeht, und den aus demselben hervorgegangenen Stamm des Glossopharyngeus kreuzt.

Auch bei Agama spinosa (Taf. III, fig. 2) liegt das Ganglion ausserhalb der Bahn der sympathischen Schlingen. Die beiden Kopftheile treten in ihren Enden (e und i) noch vor ihrer Verschmelzung mit dem Glossopharyngeus zu einem kurzen Nervenstamm zusammen. Weder hier noch nach dessen Verbindung mit dem Stamm des neunten Paares (9) zeigt sich die geringste Spur einer Anschwellung. Erst nachdem der sympathische Halsstamm (s) sich wieder vom Glossopharyngeus getrennt, um (ohne Bildung eines Ganglions) nach hinten zu verlaufen, zeigt sich in dem, einen Verbindungszweig (1) aus dem Vagus aufnehmenden, und bald darauf sich in den Hypoglossus einsenkenden Glossopharyngeus ein kleines, längliches Ganglion (D).

\section{5) Vom oberflächlichen Halstheil des Sympathicus.}

Mit diesem Namen bezeichnen wir die mehr oder minder stark entwickelten Nervenstämme, welche sich vom Ganglion petrosum bis zum Plexus brachialis erstrecken, und welche in der Form einer grossen bogenförmigen Schlinge die hinteren Hirnnerven mit den Nervenstämmen des Armgeflechts zu verbinden den Zweck haben. Da die früheren Autoren unseren tiefen Halstheil unbeachtet gelassen, so wurden diese Nervenstämme meist schlichtweg mit dem Namen des Halstheils des Sympathicus bezeichnet, - einem Namen, der auch in dieser Schrift der Kürze wegen meistens angewandt wurde. Mit den Halsnerven (mit Ausnahme des ersten und zweiten) steht diese Halsschlinge nicht in Verbindung, gerade die beiden ersten Halsnerven aber sind, wie oben gezeigt, ihrer Function nach durch ihren Beitrag zur Bildung des Hypoglossus den Hirnnerven innig verwandt. Die Entstehung der Halsschlinge aus den Kopftheilen, welche beide immer in diesen oberflächlichen Halstheil sich fortsetzen, und ihre Verbindung mit den hinteren Hirnnerven erfolgt auf verschiedene Weisen.

Wenn die letzteren nahe an ihrem Ursprunge mit einander verschmolzen sind (Salvator Merianae, Salvator nigropunctatus, und nach Müller Crotalus horridus), so sammeln sich in diesem Stamm auch die beiden bogenförmigen Kopftheile des Sympathicus. In diesem Falle geht der oberflächliche Halstheil des Sympathicus mit dem Vagus zu einem Stamme vereint, als hintere Hälfte (Taf. III, fig. 4, vs) aus diesem gemeinschaftlichen Strang hervor, um bald sich auch von dem Vagus (v) wieder $z u$ trennen, und nun als einfacher Nervenstamm (s) bis zum ersten Brustganglion $\left(\mathrm{g}^{1}\right)$ zu verlaufen. In diesem einzigen Falle 
wird eine Verstärkung des aus dem Kopftheil entstandenen Halstheiles durch Verstärkungsfäden aus dem Glossopharyngeus, Vagus und Hypoglossus nicht beobachtet, und zwar aus dem ganz natürlichen Grunde, weil jene Verschmelzung sämmtlicher hinterer Hirnnerven zu einem auch den Anfang der sympathischen Halsschlinge enthaltenden Stamme die Entsendung besonderer Verbindungsfäden völlig entbehrlich macht.

Sind dagegen die hinteren Hirnnerven nicht zu einem Stamme verbunden, und ist namentlich der Glossopharyngeus, mit dem, wie erst erwähnt, der Kopftheil des Sympathicus gewöhnlich sich verbindet, von den übrigen frei, so lassen sich in der Regel mehrere Hauptstämme des oberflächlichen Halstheils unterscheiden, von denen einige oft als directe Fortsetzung der Fasern des Kopftheils erscheinen, und vom Glossopharyngeus oder vom Ganglion petrosum auszugehen pflegen, während andere die aus dem Vagus und Hypoglossus abgegebenen Verbindungszweige enthalten.

Es würde unmöglich sein, bei der grossen Zahl und der verschiedenen-Form der zwischen diesen Halsstämmen vorkommenden Verbindungsfäden, die noch dazu sich nicht einmal bei verschiedenen Individuen derselben Art auf gleiche Weise verhalten, eine ganz erschöpfende Schilderung der beobachteten Formen zu geben. Nur die Hauptformen können hier eine Darstellung finden, - die wichtigsten derselben sind zugleich durch Abbildüngen erläutert worden.

Die einfachste Form findet sich bei Agama spinosa. Obgleich die hinteren Hirnnerven, nur hin und wieder mit einander verwachsen, nicht zu einem einfachen Stamme verschmolzen sind, zeigen sich doch keine Verbindungszweige derselben an den mit dem Glossopharyngeus innig sich verbindenden einfachen Halstheil. Der doppelte Kopftheil (Taf. III, fig. 2, e und i) bildet einen kurzen Stamm (a), der sich mit dem eben aus dem Schädel getretenen Glossopharyngeus zu einem nach hinten gehenden. Nervenstamm (gs) verbindet. Dieser entlässt bald darauf deñ Glossopharyngeus (99) und sétzt sich dann als einfacher Halsstamm (s) nach hinten fort. Der Mangel aller Verbindungszweige aus dem Vagus und Hypoglossus erklärt sich leicht aus der früher (pg. 69) beschriebenen Art der Verknüpfung dieser beiden Nerven unter einander und mit dem Halsstamm des Sympathicus.

Auch bei Chamaeleo vulgaris (Taf. III, fig. 6) entsteht ein einfacher (oberflächlicher) Halsstamm (s) aus dem Ganglion petrosum (D), welches letztere indessen, wie früher erwähnt, selbst mit Vagus und Hypoglossus in Verbindung steht. Er läuft ohne Aufnahme neuer Zweige bis zum ersten Brustganglion ( $\mathrm{g}^{1}$ ) hinab, in welches auch der tiefe Halsstamm ( $\mathrm{z}^{\prime}$ ), von dem gleich weiter die Rede sein wird, einmündet.

Auch Varanus Niloticus hat einen einfachen, aus dem Ganglion petrosum entspringenden Halsstamm. Er erhält bis zur Bildung des Brustganglions, wie es scheint, keine Verstärkungsfäden, wohl aber ist das Ganglion petrosum mit Vagus und Hypoglossus dưrch Fäden verknüpft.

Bei Varanus Bengalensis (Taf. II, fig. 2) zeigt der oberfächliche Halstheil schon stärkere Neigung, durch Theilung in mehrere Längsfäden in eine geflechtartige Bildung überzugehen. Finer dieser im Ganglion thoracicum primum $\left(\mathrm{g}^{1}\right)$ erst sich vereinenden Fäden ( $\left.\mathrm{s}^{\prime}\right)$ lässt sich als directe Fortsetzung des tiefen Kopftheils (i) erkennen; vom Vagus und den Hirnwurzeln des Hypoglossus werden zwar keine besonderen Verbindungszweige bemerkt, doch muss wenigstens die Möglichkeit zugegeben werden, dass einzelne Fäden des sympathischen Halstheils aus diesen Nerven stammen, 
da Vagus und ein Theil des Hypoglossus anfangs, wie oben bemerkt, verschmolzen sind, und starke Verbindungszweige (Fig. 2, 1) aus dem Vagus in den Glossopharyngeus gesandt werden, ehe die sympathischen Elemente von diesem sich trennen. In das Ganglion thoracicum primum mündet ferner ein vom R. descendens Hypoglossi stammender Faden ein.

Bei Istiurus Amboinensis, Iguana tuberculata und Platydactylus guttatus trennt sich der oberflächliche Halstheil des Sympathicus schon vom Glossopharyngeus, ehe dieser den (dem Laryngeus superior entsprechenden) Verbindungsast aus dem Vagus erhalten hat. Es ist daher unmöglich, dass durch Vermittelung dieses Verbindungszweiges zugleich Fäden aus dem Vagus in den Halstheil des Sympathicus gelangen. Daher die Nothwendigkeit besonderer Verbindungsfasern aus dem Vagus an den letzteren. Diese finden sich bei Istiurus Amboinensis und Iguanatuberculata (Taf. II, fig. 3) in der Form eines feinen Geflechtes, aus welchem sich bei der letzteren ein zweiter feiner Halsstamm ( $\mathrm{s}^{\prime)}$ ) zusammensetzt. Ja der aus diesen beiden Stämmen gebildete Nervenzug (s', s") wird noch durch einen dritten Stamm (s"') verstärkt, der theils aus dem Hirnwurzelstamm (h), theils aus dem Halsnervenstamm (k) des Hypoglossus entspringt. Diese drei Stämme, die beim Leguan sich erst in der Mitte des Halses zu einem einfachen Nerven verbinden, lassen sich bei Istiurus und Platydactylus nicht mit derselben Deutlichkeit unterscheiden; es scheinen hier vielmehr nur zerstreute, minder regelmässig vertheilte Verbindungsfasern aus Vagus und Hypoglossus an den einfachen, vom Glossopharyngeus ausgehenden Halsstamm vorhanden zu sein.

Am stärksten ist diese geflechtartige Bildung des oberflächlichcn Halstheils, die bei den drei letzten Formen schon sehr hervortritt, ausgeführt bei Lacerta ocellata. Unsere Abbildung zeigt diese Bildung der rechten Seite (linke Seite der Figur Taf. II, fig. 1) mit allen Verbindungsfäden. - Aus dem R. palatinus (p) entsteht einer der Nebenstämme (i) des Halsgeflechtes (unser R. communicans internus, hier nicht mit dem Glossopharyngeus verbunden, sondern direct in's Halsgeflecht übergehend). Mit diesem ersten Nebenstamme verbindet sich ein zweiter (e), aus dem hinteren Hauptstamme (f) des Facialis hervorgehend (unser äusserer Verbindungsast mit dem Glossopharyngeus, hieb ebenfalls, wenigstens an der rechten Seite, am Ganglion petrosum vorbeigehend), der durch Verbindungsfäden einerseits mit dem Ganglion petrosum (D), andererseits mit dem Vagus (v) verknüpft ist. Beide Nebenstämme vereinen sich zu einem der beiden Hauptstämme (s') des Halsgeflechtes. Ein dritter Nebenstamm endlich ( $~($ ) entsteht aus dem Yagus (v), ein vierter ( $\left({ }^{\prime}\right)$ aus dem Hypoglossus, - und diese beiden sind es, die den zweiten Hauptstamm ( $\left(\mathrm{s}\right.$ ") zusammensetzen. Beide so entstandenen Hauptstämme ( $\mathrm{s}^{\prime}$ und $\mathrm{s}^{\text {") }}$ ) sind mit einander durch mehrere Verbindungsfäden verknüpft, und verschmelzen mit einander erst tief unten am Halse.

Die sympathischen Halstheile der Krokodile sind durch Vogt so ausführlich bekannt geworden, dass es unnöthig scheint, die auffallende Bildung derselben, und ihre von Stannius hervorgehobene Aehnlichkeit mit der Form der Vögel nochmals zu erörtern. Nur darauf mag nochmals hingewiesen werden, dass Vogt's Sympathicus superficialis dem sympathischen System nicht angehört, sondern als $\mathbf{R}$. descendens des $\mathbf{R}$. laryngopharyngeus (Bendz) aufzufassen ist. - Mit dem oberflächlichen Halstheil der Saurier möchten wir den Sympathicus profundus der Krokodile vergleiclen, während der Sympathicus medius oder impar der letzteren dem tiefen Halstheil der Saurier analog sein dürfte. - Es unterscheidet sich dann der erstere durch folgende Punkte: 1) Durch seinen versteckten Verlauf im Kanale der Halsrippen; 2) durch die unterwegs stattfindenden Verbindungen mit den vorderen Zweigen der Halsnerven und mit dem Sympathicus medius (unserem Sympathicus profundus); 3) durch die Bildung kleiner Ganglien beim Eintrittspunkt dieser Verbindungszweige. 


\section{6) Vom tiefen Halstheil des Sympathicus.}

Ausser der eben erörterten grossen bogenförmigen Halsschlinge, welche, ohne auf ihrem Wege mit Spinalnerven in Verbindung zu stehen, sich bei den Sauriern von den hinteren Hirnnerven bis zum Armgeflecht in einem oder mehreren Stämmen erstreckt, besitzt diese Ordnung der Reptilien noch ein zweites System von Schlingen am Halse, welches wir, wegen seiner versteckten Lage zwischen den Fasern der vorderen tiefen Halsmuskeln mit dem Namen des tiefen Halstheiles bezeichnen. Die Form dieser Schlingen ist eine solche, dass man anfangs wenig geneigt ist, sie für eigentlich sympathische Schlingen zu erklären: sie entstehen meist dadurch, dass ein Zweig des vorderen Astes eines Halsnerven mit einem $Z$ weig des nächstfolgenden zu einem kurzen, in den tiefen Halsmuskeln sich ausbreitenden, Stamme zusammentritt. (Mehrere Schlingen dieser Form sind auf den Abbildungen der zweiten und auch auf derjenigen der ersten Tafel mit $z$ bezeichnet.) Es lässt sich indessen beweisen, dass diese Schlingen nicht bloss Fasern von motorischer Natur, sondern auch sympathische Elemente enthalten. Bei Chamaeleo vulgaris setzt sich nämlich (Taf. III, fig. 6) aus denselben ein wirklicher zweiter Halsstamm zusammen ( $\left.z^{\prime}\right)$, der zwischen den Fasern der tiefen Halsmuskeln nach hinten verlaufend endlich von der Seite her in dasselbe erste Brustganglion einmündet $\left(g^{1}\right)$, das auch den ersten (oberflächlichen) Halsstamm aufnimmt, und das somit in derselben Weise den Sammelpunkt für die beiden Halstheile abgiebt, wie das Ganglion petrosum es für die beiden Kopftheile zu sein pflegt.

Die Schlingen dieses zweiten, tiefen Halstheiles stehen mit den meisten Hirnnerven in keiner Verbindung, - die sympathischen Fasern der letzteren scheinen vielmehr beständig in den oberflächlichen Halstheil überzugehen. Der Hypoglossus macht hievon insofern eine Ausnahme, als einerseits nicht nur sein Hauptstamm, sondern auch sein R. descendens in der Regel mit dem oberflächlichen Halstheil durch Schlingen communicirt*), andererseits aber die beiden ersten Halsnerven, die zu seiner und namentlich zur Bildung' des $\mathbf{R}$. descendens beitragen, gewöhnlich diejenigen sind, mit denen dies System tiefer Halsschlingen beginnt. Ob der $\mathrm{N}$. accessorius Willisii mit dem oberflächlichen Halstheil in Verbindung stehe, lässt sich bei seinem in der Regel sehr innigem Verhältniss zum Vagus und bei der Feinheit seines R. externus nicht entscheiden: um so auffallender ist die sehr häufig, vielleicht beständig, vorhandene Schlinge $*$ ), die dieser Muskelast desselben mit dem dritten Halsnerven bildet, und die vielleicht,

*) Vgl. namentlich die Abbildungen von Iguana tuberculata (Taf. II, fig. 3) und Lacerta ocellata (Taf. II, fig. 1).

**) Vergl. über dieselbe pg. 64,65 dieser Schrift. 
da der letztere immer mit dem System der tiefen Halsschlingen in Verbindung steht, ebenfalls zu diesem letzteren System zu zählen sein möchte.

Dass indessen in den Schlingen des tiefen Halstheils keine Ganglien beobachtet werden, ist eine Eigenthümlichkeit, die der letztere mit dem oberflächlichen Halstheil (der Saurier, nicht, wie schon oben bemerkt, der Krokodile) gemein hat. Eigentliche Ganglien werden auch in dem Rumpftheile des Sympathicus (vom letzten Brustganglion am Armgeflecht an gerechnet) nicht beobachtet, und möchten überhaupt nicht als nothwendiger Charakter des sympathischen Grenzstranges gelten dürfen. Auch dem von Müller entdeckten tiefen Halstheile der Schlangen scheinen deutliche Ganglien zu fehlen, und der Sympathicus medius oder impar der Krokodile lässt dieselben ebenfalls nicht wahrnehmen. Letzteres sowohl, als auch der Verlauf zwischen den Fasern der vorderen tiefen Halsmuskeln ist der Grund, weshalb sowohl der Halstheil des Sympathicus der Schlangen, als auch der Sympathicus medius oder impar der Krokodile mit diesem System tiefer Halsschlingen der Saurier zu vergleichen sein dürfte. Ist dies der Fall, so wäre als oberflächlicher Halstheil des Sympathicus der Krokodile, wie schon vorhin erwähnt, ihr im Canalis vertebralis verlaufender Sympathicus profundus zu betrachten, während man bei den Schlangen zu der Annahme einer Verschmelzung desselben mit dem Vagus sich hingedrängt fühlt. Die Andeutung einer solchen Verschmelzung des oberflächlichen Halsstammes mit dem herumschweifenden Nerven findet sich, wie Müller hervorhebt, schon hier und da bei den Sauriern (Salvator nigropunctatus [Taf. II, fig. 5, vs], Salvator Merianae [Taf. IU, fig. 4, vs] und nach Müller Ameiva Teguixin).

Bei Chamaeleo vulgaris entlässt der erste Halsnerv fünf Zweige: zwei derselben gehen nach vorn, und verstärken die Wurzel des Hypoglossus; zwei andere gehen nach aussen, und breiten sich in den tiefen Halsmuskeln aus. Der fünfte endlich (Taf. III, fig. 6, z) läuft zwischen den Bündeln der vorderen geraden Kopfmuskeln nach hinten, nimmt einen Zweig (c) des zweiten Halsnerven (14) auf, und verbreitet sich, jedoch nur zum kleineren Theil, in den tiefen Halsmuskeln. Der Hauptstamm ( $\left.z^{\prime}\right)$ geht weiter nach hinten, entlässt zwei schwache Zweige $(\alpha)$ an den ersten Stamm ( $\left.b^{1}\right)$ des Armgeflechtes, und senkt sich dann von der Seite her in das erste Brustganglion $\left(g^{1}\right)$ ein.

\section{Vom Brusttheil des Sympathicus.}

Der Brusttheil des Sympathicus beginnt nahe am Armgeflecht mit mehreren grossen unmittelbar hinter einander liegenden Ganglien. Er erscheint beständig als die Forsetzung des oberflächlichen Halstheiles.

Das Ganglion thoracicum primum (auf der fünften Figur von Taf. II, und der vierten und sechsten Figur von Taf. III, mit $g^{x}$ bezeichnet) liegt in der Regel in gleicher Höhe mit dem Ganglion trunci nervi vagi, und erscheint als eine 
ovale, platte Anschwellung des oberflächlichen Halsstammes selbst. Bisweilen (Chamaeleo vulgaris) wird es, wie eben gesagt, auch der Sammelpunkt des tiefen Halstheiles. Mit den Stämmen des Armgeflechtes (auf den Abbildungen mit $b^{1}, b^{2}$ etc. bezeichnet), denen es nahe zu liegen pflegt, ist es niemals durch Verbindungszweige verknüpft. Dagegen steht dies Ganglion in der Regel (z. B. Chamaeleo vulgaris, Salvator. Merianae u. A.) mit dem benachbarten Ganglion trunci des $\mathrm{N}$. vagus durch mehr oder minder starke Nervenzweige in Verbindung. (Auf Taf. VII, fig. 6 und fig. 4 mit $\beta$ bezeichnet.) Liegt das Ganglion trunci nervi vagi nicht in gleicher Höhe mit diesem ersten sympathischen Brustganglion (Varanus Bengalensis), so treten die aus dem letzteren hervorgehenden Verbindungsfäden in den Stamm des Vagus selbst ein, der aber dann an dieser Stelle schon eine vordere ganz kleine Anschwellung zeigt. In seltenen Fällen (z. B. Salvator nigropunctatus) fehlt diese Verbindung des ersten Brustganglions mit dem Vagus, und dasselbe (Taf. II, fig. $5, g^{1}$ ) liegt vollkommen frei in der Bahn des sympathischen Halsstammes selbst, - dann aber findet sich in der aus dem ersten Brustganglion hervorgehenden Fortsetzung des Stranges unmittelbar darauf ein zweites $\left(\mathrm{g}^{2}\right)$, ebenfalls noch nicht mit den Stämmen des Armgeflechtes verbundenes Ganglion, aus welchem der Verbindungszweig (a) mit dem Vagus entspringt.

Unmittelbar auf dies erste, oder diese beiden ersten, nicht mit dem Armgeflecht, sondern nur mit dem Vagus verknüpften Brustganglien folgen in der Fortsetzung des sympathischen Stranges mehrere andere, den Stämmen des Armgeflechtes (auf Taf. II, fig. 5, Taf. III, fig. 4 und fig. 6 mit $b^{1}, b^{2}, b^{3}$ etc. bezeichnet) sehr nahe liegende, und beständig mit denselben durch Nervenzweige in Verbindung stehende Ganglien $\left(\mathrm{g}^{2}, \mathrm{~g}^{3}\right.$ etc.). In der Zahl und Form derselben sowohl, als auch der aus ihnen hervorgehenden Nervenfäden herrscht die grösste Verschiedenheit. Bald ist nur ein solches Ganglion vorhanden (Chamaeleo), bald finden sich deren zwei, drei, auch mehrere. Selten erscheinen sie oval, wie das erste Brustganglion (Taf. III, fig. 6, $\mathrm{g}^{2}$ ), öfter haben sie eine unregelmässig drei- oder mehreckige Gestalt. Zuweilen gehen aus jedem derselben nur einzelne Fäden hervor (Taf. II, fig. 5, $\gamma$ ), während in anderen Fällen einzelne (Taf. III, fig. $4, \mathrm{~g}^{2}$ ) ein kleines Centrum für sich bilden, von dem aus nach allen Richtungen Fäden hervorgehen. Nur darin herrscht bei den verschiedenartigsten Formen eine sehr grosse Uebereinstimmung, dass die Zweige $(\gamma)$, wodurch dieselben mit den Stämmen des Armgeflechtes verbunden sind, niemals als Nerven erscheinen, die aus den letzteren hervorgehen, und in diese Ganglien sich einsenken, sondern 'umgekehrt von den letzteren aus beständig in centrifugaler Richtung verlaufen, sich an die Stämme des Plexus brachialis anlegen, 
diese in peripherischer Richtung bisweilen eine Strecke begleiten, und dann mit ihnen verschmelzen. Der auf das letzte dieser Ganglien am Armgeflecht hervorgehende Grenzstrang erscheint gegen seine frühere Stärke immer ungemein schwach. - Aus allen diesen Brustganglien gehen feine Zweige hervor, die sich zwischen den Eingeweiden der Brust verlieren, - sie sind indessen überall zu schwach, um bis an's Ende verfolgt werden zu können.

Aus diesen stark entwickelten Brustganglien setzt sich ein feiner Grenzstrang (Taf. III, fig. 4 und fig. 6, $s^{\prime \prime}$ ) längs der Wirbelsäule nach hinten fort, mit dem vorderen $\mathbf{Z}$ weige jedes der nächst folgenden Spinalnerven durch einen schwachen Faden $(\delta)$ in Verbindung stehend. Schon nach dem dritten, bisweilen erst nach dem fünften der auf das Armgeflecht folgenden Spinalnerven wird indessen seine Fortsetzung so fein, dass es unmöglich erscheint, ihn, selbst mit Hülfe starker Loupen, weiter zu verfolgen. 


\title{
Erklärung der Kupfertafeln.
}

\author{
Tafel \\ Tafel I, Fig. 1.
}

Verbreitung der Gehirnnerven an der unteren Fläche des Kopfes von Salvator nigropunctatus.

$G, G$, Unterkieferhälften, nach aussen zurückgeschlagen. - Die Knochen des Gaumengewölbes und die inneren Hebemuskeln des Unterkiefers (Mm. pterygoidei) sind entfernt, der Wirbelkanal vom Hinterhauptsbeine an ist geöffnet.

$K$, Rechtes Auge, von unten her vom M. adductor maxillae superioris überzogen. $K^{\prime}, M$. adductor maxillae superioris, am Keilbeinstiel abgeschnitten, und nach aussen zurückgeschlagen, - $L$, Linker Augapfel. - $M$, Musculus obliquus inferior. $-N$, Musculus rectus inferior. - $\boldsymbol{O}$, Musculus suspensorius bulbi. $-P$, Musculus rectus externus, an seinem inneren Ansatzpunkte gelöst und zurückgeschlagen. - $Q$, Hardersche Drüse. - $\boldsymbol{R}, \boldsymbol{R}^{\prime}$, Aeussere Hebemuskeln des Unterkiefers. - $\boldsymbol{S}$, Medulla oblongata. $T$, Aeussere tiefe Halsmuskeln.

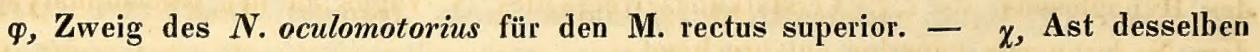
für den M. rectus inferior. - $\omega$, Ast desselben für den M. obliquus inferior. $\psi$, Ast desselben für den M. rectus internus.

$q$, Zweig des $N$. trigeminus für den M. adductor maxillae superioris. $-\boldsymbol{B}$, Ganglion des zweiten und dritten Astes. - $n$, Zweiter Ast des Trigeminus. - $\lambda$, Derselbe als $\mathbf{N}$. infraorbitalis. $-\mu$, Derselbe als $\mathbf{N}$. alveolaris superior $-\alpha$, Zweige des zweiten Astes für die Haut der Stirn (durchgeschnitten). $-\beta, \beta, Z_{w e i g}$ für die Haut des unteren Augenlides. - $\gamma$, Drüsenast des $N$. maxillaris superior, unterwegs durch feine Fäden aus letzterem verstärkt (vgl. d. rechte Seite der Abbildung). $-\delta, \delta, \delta^{\prime}$, Zweige aus dem zweiten Aste des Trigeminus zum Plexus sphenopalatinus. $-\varepsilon$, Truncus sphenopalatinus, gebildet aus Zweigen $\left(\delta^{\prime}, \delta^{\prime}\right)$ des $\mathbf{N}$. maxillaris superior und aus Zweigen $(g, g)$ des Ramus palatinus $(p)$. $-\zeta$, Zweig aus diesem Stamm zurück an den $\mathbf{N}$. infraorbitalis. - $\zeta^{\prime}$, Z weig aus demselben zurück an den R. palatinus. $\eta$, Zweig des $\mathbf{N}$. maxillaris superior an die Haut des Oberkiefers. - $\vartheta^{\prime \prime}$, Nerv für die den Zahnrand des Oberkiefers bedeckende innere Mundhaut, gebildet aus $\vartheta$, einem 
Aste des N. infraorbitalis, und $\vartheta^{\prime}$, dem R. communicans anterior rami palatini cum nervo maxillari superiore.

o, Dritter Ast des $\boldsymbol{N}$. trigeminus. - $\varrho$, Zweig desselben für die vorderen Hebemuskeln des Unterkiefers. - $\pi$, Nerv für die Mm, pterygoidei: - $\sigma$, Nerv für die hinteren Hebemuskeln des Unterkiefers. - $\tau$, R. recurrens cutaneus (vgl. über denselben pg. 20.)

$C$, Ganglion des $\boldsymbol{N}$. facialis. - $p, p, \mathbf{R}$. palatinus, unter $\boldsymbol{B}$ durch einen Knochenkanal des Keilbeins (Canalis Vidianus auct.) nach vorn tretend. - $g, g$, R. communicans posterior rami palatini cum nervo maxillari superiore (mit den vorhin beschriehenen Zweigen $\delta^{\prime}, \delta^{\prime}$ den Truncus sphenopalatinus $\varepsilon$ zusammensetzend.) $-\boldsymbol{p}^{\prime}$, Vordere Endigung des R. palatinus, für den vorderen Theil der Gaumenhaut bestimmt. $f$, Hinterer Hauptstamm des N. facialis, über das (linke Seite der Figur) zwischen $t$ und $x$ abgebildete Gehörknöchelchen forttretend. $-x$, Ramus recurrens ex nervo trigemino ad nervum facialem. - $t$, Chorda tympani. - $m$, Muskelast des Facialis. $e$, Ramus communicans externus nervi facialis cum Glossopharyngeo (in das Ganglion petrosum, $D$, einmündend). $-i, i, R$. communicans internus rami palatini cum Glossopharyngeo (mit der unteren Fläche des Ganglion petrosum eng verschmelzend, und in den vereinigten Stamm $(F)$ der hinteren Hirnnerven einmündend).

9, Nervus glossopharyngeus. - D, Ganglion petrosum. - $g l$, Der aus letzterem hervorgehende Stamm des Glossopharyngeus.

10, Wurzel des N. vagus, mit $h^{\prime}$, der ersten Hirnwurzel des N. hypoglossus, eben ausserhalb des Schädels verschmelzend, und den $R$. internus des $\mathbf{N}$. accessorius Willisii (11) aufnehmend. - $r$, Vereinigter Stamm von Vagus und erster Hirnwurzel des Hypoglossus. - $l, l$, Verstärkungszweige des $\mathrm{N}$. vagus an den Glossopharyngeus, dem N. laryngeus superior entsprechend.

11, Wurzeln des $N$. accessorius Willisii. $-y$, Ramus externus nervi accessorii (linke Seite der Figur).

$h^{\prime}$, Erste Hirnwurzel des Nervus hypoglossus, mit dem N. vagus verschmelzend. $h^{\prime \prime}$, Zweite Hirnwurzel des N. hypoglossus, später ebenfalls mit dem vereinigten Stamm $F$ sich verbindend. -13 , Erster Halsnerv. $-k$, Dessen Hauptzweig, dem R. descendens nervi hypoglossi entsprechend, mit dem vereinigten Stamm der hinteren Hirnnerven verschmelzend. - $u, \mathbf{Z}_{\text {weig }}$ des $\mathbf{N}$. vagus für die Carotidendrüse. $F$, Vereinigter Stamm der Nn. Vagus, Hypoglossus und Sympathicus. - $h$, Stamm des N. hypoglossus. - $d$, R. descendens desselben. - vs, Vereinigter Stamm von Vagus und oberflächlichem Halstheil des Sympathicus. (Ueber die Fortsetzung des letzteren vgl. Taf. II, Fig. 5.) - $z$, $z$, Schlingen des tiefen Halstheils des Sympathicus. 


\section{$-94-$ \\ Tafel II. \\ Tafel II, Fig. 1. \\ Lacerta ocellata.}

Gehirn und Ursprünge der Gehirnnerven von

1, N. olfactorius. - 2, N. opticus. - 3, N. oculomotorius. - 4, N.pathetieus.

5 , Wurzel des $N$. trigeminus. - $A$, Ganglion des ersten Astes, durch einen Einschnitt vom Ganglion des zweiten Astes getrennt. - 5', Erster Ast des Trigeminus. - $c$, Ramus ciliaris desselben. - rf, R. frontalis desselben. - $n$, R. nasalis desselben. - B, Ganglion des zweiten und dritten Astes. - $q$, Nerv für den M.

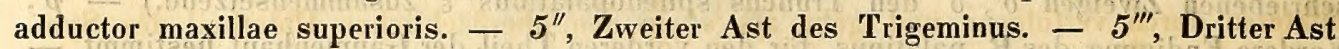
des Trigeminus. - $r$, Z weig desselben für die Haut der Wange. - 6, Nervus abducens.

7, Wurzel des Nervus facialis. - $C$, Ganglion desselben. - $p$, Ramus palatinus. $i$, Ramus communicans internus rami palatini cum Glossopharyngeo (hier nicht mit dem Glossopharyngeus sich verbindend, sondern als erster Nebenstamm des oberflächlichen Halstheils des Sympathicus auftretend [vgl. pg. 87]). $-x$, Ramus recurrens nervi trigemini ad nervum facialen. - $e$, $R$. communicans externus nervi facialis cum Glossopharyngeo, auf der rechten Seite (linke Seite der Figur) mit dem Glossopharyngeus nicht verschmelzend, sondern nur durch einzelne Verbindungsfäden $\alpha, \alpha$ mit dem Ganglion petrosum $D$ verbunden, und von da $a b(e e)$ als der zweite Nebenstamm des sympathischen Halsgeflechtes sich fortsetzend. Er verbindet sich mit $i$ zu dem ersten Hauptstamm $s^{\prime}$ des Halstheils des Sympathicus. Derselbe Nerv mündet auf der linken Seite des untersuchten Exemplars (rechte Seite der Figur, $e^{\prime}$ ) in das Ganglion petrosum $(\boldsymbol{D} d)$ ein, von wo er als $e^{\prime} e^{\prime}$ ebenfalls in den sympathischen Halstheil übergeht. - $t$, Chorda tympani. - $m$, Muskelast des Facialis.

9, Wurzel des $N$. glossopharyngeus. - D, Dd, Ganglion petrosum. - gl, Stamm des Glossopharyngeus.

10 und 11, Wurzeln der N. N. Vagus und Accessorius Willisii. - v, Stamm des $\mathbf{N}$. vagus. - $\beta, \beta^{\prime}, \beta^{\prime \prime}$, Verbindungsfäden zwischen dem letzteren und dem sympathischen Halsgeflecht. $-y, R$. externus N. accessorii Willisii. $-\vartheta$, Dritter Nebenstamm des sympathischen Halsgeflechtes, aus dem Stamm des N. vagus entspringend. Derselbe verbindet sich mit dem aus dem $\mathbf{N}$. hypoglossus hervorgehenden vietten Nebenstamm, $\vartheta^{\prime}$, zum zweiten Hauptstamm, $s^{\prime \prime}$, des sympathischen Halsgeflechtes. Die beiden Hauptstämme, $s^{\prime}$ und $s^{\prime \prime}$, bilden zusammen den oberflächlichen Halsstamm, $\boldsymbol{s}$, des Sympathicus.

$h^{\prime}$, Erste Hirnwurzel des $N$. hypoglossus, den vorderen Theil, $h$, desselben bildend. - $h^{\prime \prime}$, Zweite Hirnwurzel des N. hypoglossus, mit dem Hauptstamm des ersten Halsnerven, 13, den hinteren Theil, $k$, des Hypoglossus zusammensetzend. $h k$, Stamm des N. hypoglossus, aus $h$ und $k$ gebildet. 


\section{Tafel II, Fig. 2. \\ Gehirn und Ursprünge der Gehirnnerven von \\ Varanus Bengalensis.}

Die Zeichen 1 bis $13,5^{\prime}, 5^{\prime \prime}, 5^{\prime \prime \prime}, A, B, C, q, p, f, x, t, m, g l, v$ habeu dieselbe Bedeutung, wie bei Fig. 1.

$\alpha$, Ein aus dem hinteren Hauptstamm, $f$, des Facialis hervorgehender Nerv; von seinen beiden $Z_{w e i g e n ~ i s t ~} t$ die Chorda tympani, während $\beta$ wieder mit $f$ verschmilzt. $-i$, R. communicans internus rami palatini cum nervo glossopharyngeo, verschmilzt mit der unteren Fläche des Glossopharyngeus, lässt sich aber unter dem letzteren durch verfolgen, und geht als $s^{\prime}$ in den oberflächlichen Halstheil des Sympathicus über.

8, N. acusticus. - $h$, Erste Hirnwurzel des $N$. hypoglossus, mit der Wurzel des $N$. vagus schon im Schädel verschmelzend. $-h$, Der derselben entsprechende vordere Theil des Hypoglossus, ehen ausserhalb des Schädels vom Stamm des Vagus (v) sich trennend. - $l, l, \mathbf{Z}_{\text {wei }}$ Verstärkungsäste des N. vagus an den Glossopharyngeus, dem N. laryngeus superior entsprechend. - $h^{\prime \prime}$, Zweite Hirnwurzel des N. hypoglossus. Diese setzt durch ihren Zweig $k^{\prime}$ mit dem Aste $k^{\prime \prime}$ des ersten Halsnerven (13) und mit dem zweiten Halsnerven (14) den zweiten Theil $(k)$ des Hypoglossus zusammen, der mit dem ersten Theil $(h)$ durch zwei kurze Nerven (w) in Verbindung steht, und den R. descendens (d) des Hypoglossus bildet.

$s^{\prime}, s^{\prime \prime}$, Oberflächlicher Halstheil des Sympathicus, $s^{\prime}$ aus dem Ramus palatinus, die übrigen aus dem Glossopharyngeus entspringend. - $g^{1}$, Ganglion thoracicum primum des Sympathicus. Dieses empfängt einen feinen Nervenfaden $\left(\vartheta^{\prime}\right)$ aus dem R. descendens $(d)$ des Hypoglossus, und giebt selbst einige kurze und feine Fäden an den benachbarten Stamm $(v)$ des Vagus $a b$, welcher letztere an der Stelle ihrer Aufnahme eine sehr unbedeutende Anschwellung zeigt.

\section{Tafel II, Fig. 3. \\ Gehirn und Ursprünge der Gehirnnerven von Iguana tuberculata.}

Die Zeichen 1 bis $13,5^{\prime}, 5^{\prime \prime}, 5^{\prime \prime \prime}, A, B, C, D, q, n, r f, p, x, t, m, i, e, v$, $l, g l, y$ haben dieselbe Bedeutung, wie in Fig. 1 und Fig. 2.

$m^{\prime}, m^{\prime \prime}$, Muskelzweige aus dem dritten Aste des Trigeminus. - $h^{\prime}$ und $h^{\prime \prime}$, Erste und zweite Hirnwurzel des Hypoglossus, den vorderen Theil, $h$, dieses Nerven zusammensetzend. - 13 und 14, Erster und zweiter Halsnerv, durch ihre Zweige $k^{\prime}$ und $k^{\prime \prime}$ den zweiten Theil, $k$, des Hypoglossus bildend. $-h$ und $k$ verschmelzen zu dem Stamm des Hypoglossus, $h k$. 
$\boldsymbol{s}^{\prime}$, Erster Hauptstamm des oberflächlichen sympathischen Halstheiles, aus dem Ganglion petrosum, $\boldsymbol{D}$, entspringend. - $s^{\prime \prime}$, Zweiter Hauptstamm desselben, mit $\alpha$ und $\gamma$ aus dem Ganglion petrosum, mit $\beta$ aus dem Vagus, mit $\delta$ aus dem Hypoglossus entstehend. - $s^{\prime \prime \prime}$, Dritter Hauptstamm desselhen, mit $\varepsilon$ aus dem Hirnwurzelstamm (h), mit $\zeta$ aus dem Halsnervenstamm $(k)$ des Hypoglossus hervorgehend. - $s^{\prime}, s^{\prime \prime}$, $s^{\prime \prime \prime}$ verschmelzen zu' dem einfachen oberflächlichen Halsstamm $(s)$ des Sympathicus.

\section{Tafel II, Fig. 4. \\ Gehirn und Ursprünge der Gehirnnerven von \\ Chamaeleo vulgaris.}

Die Zeichen $1-13,5^{\prime}, 5^{\prime \prime}, 5^{\prime \prime \prime}, B, C, D, p, i, f, x, t, m, e$, haben dieselbe Bedeutung, wie auf den vorigen Figuren.

9, Wurzel des Glossopharyngeus. - D, Ganglion petrosum. - $g$, Schlundast des Glossopharyngeus, bis zur Kehlkopfsblase sich ausbreitend. - o, Verstärkungsast des Glossopharyngeus an den Hypoglossus, dem Zungenast des ersteren entsprechend. 10, Wurzeln des Vagus. - $l$, Verstärkungsast des letzteren an den Glossopharyngeus (in das Ganglion petrosum eintretend). - $h$, Hirnwurzel des N. hypoglossus. $h g$, Vereinigter Stamm von Glossopharyngeus und Hypoglossus. - $d$, Ramus descendens nervi hypoglossi. - v, Stamm des N. vagus. - 13, Erster Halsnerv, der Hirnwurzel des $\mathbf{N}$. hypoglossus zwei kurze und feine Verstärkungszweige gebend. $s$, Oberflächlicher Halstheil des Sympathicus, aus dem Ganglion petrosum hervorgehend. - $z$, Schlingen des tiefen Halstheils des Sympathicus. (Ueber die Fortsetzung des letzteren vgl. Taf. III, Fig. 6.)

\section{Tafel II, Fig. 5. \\ Brusttheil des Sympathicus von \\ Salvator nigropunctatus.}

vs, Vereinigter Stamm von Vagus und oberflächlichem Halstheil des Sympathicus. $v$, N. Vagus. - gv, Ganglion trunci nervi vagi. - $s$, Oberflächlicher Halstheil des Sympathicus. - $g^{1}$, Erstes Brustganglion des Sympathicus. - $s^{1}$, Die aus demselben hervorgehende Fortsetzung des letzteren. $-g^{2}$, Zweites Brustganglion, durch eine Nervenschlinge $(a)$ mit dem Stamm des Vagus verbunden. $-g^{3}, g^{4}, g^{5}$; Drittes, viertes, fünftes Brustganglion. - $b^{1}, b^{2}, b^{3}$, Stämme des Armgeflechtes. - $c^{1}, c^{2}$, Die auf das Armgeflecht folgenden Spinalnerven. - $\gamma, \gamma$, Verbindungszweige aus dem Brustganglion an die Stämme des Armgeflechtes. - $s^{\prime \prime \prime}$, Fortsetzung des sympathischen Grenzstranges jenseits des Armgeflechtes. - $\delta, \delta$, Zweige an die folgenden Spinalnerven. 


\section{Tafel II.}

Auf dieser Tafel sind, wo in der Beschreibung nicht ausdrücklich das Gegentheil bemerkt ist, folgende Zeichen für alle Figuren gleich bedeutend:

$M$, Medulla oblongata. -7 , Wurzel des N. facialis. - $C$, Ganglion desselben. $p$, R. palatinus. - $i$, R. communicans internus rami palatini cum Glossopharyngeo. $f$, Hinterer Hauptstamm des Facialis. - $x$, R. recurrens nervi Trigemini ad nervum facialem. - $t$, Chorda tympani. - $m$, Muskelast des Facialis. - $e, \mathbf{R}$. communicans externus nervi facialis cum Glossopharyngeo. - $8, \mathrm{~N}$. acusticus. - 9 , Wurzel des Glossopharyngeus. - $\boldsymbol{D}$, Ganglion petrosum. - $g l$, Stamm des Glossopharyngeus. 10, Wurzeln des Vagus. - $\boldsymbol{E}$, Ganglion radicis nervi vagi. - $v$, Stamm des $\mathbf{N}$. vagus. - $l$, Verstärkungsast des letzteren an den Glossopharyngeus, dem N. laryngeus superior entsprechend. - $y$, Ramus externus nervi accessorii Willisii. $h^{\prime}$, Erste Hirnwurzel des Hypoglossus. - $h^{\prime \prime}$, Zweite Hirnwurzel desselben. 13, Erster, - 14, zweiter, - 15, dritter Halsnerv. - $h$, Stamm des $\mathbf{N}$. hypoglossus. - $h g$, Vereinigter Stamm von Glossopharyngeus und Hypoglossus. $\boldsymbol{d}$, R. descendens nervi Hypoglossi. - $w$, Verbindungszweige zwischen diesem und dem Hauptstamm des Hypoglossus. - $s$, Oberflächlicher Halstheil des Sympathicus. $z$, Schlingen des tiefen Halstheils.

\section{Tafel III, Fig. 1.}

\section{Ursprünge und Verbindungen der hinteren Gehirnnerven von}

\section{Istiurus Amboinensis.}

Ueher die meisten Zeichen dieser Figur vgl. die eben gegebene allgemeine Beschreibung.

$z^{\prime}$, Nervenfaden aus dem R. descendens Hypoglossi $(d)$ an den oberflächlichen Halstheil des Sympathicus $(s)$. $-\boldsymbol{y}, \mathbf{R}$. externus nervi accessorii; sein letztes Ende verschmilzt mit einem Zweig des dritten Halsnerven (15) zu einer Schlinge.

\section{Tafel III, Fig. 2.}

\section{Ursprünge und Verbindungen der hinteren Gehirnnerven von Agama spinosa.}

Ueber $7, \boldsymbol{C}, p, i, f, e, t, m, \boldsymbol{g}, \boldsymbol{D}, \mathrm{gl}, \mathrm{hg}, \boldsymbol{E}, \mathbf{1 0}, h^{\prime}, h^{\prime \prime}, 13, h, k, v, s$ siehe Oben.

$a$, Vereinigter Stamm der beiden Rami communicantes (internus [ $i]$ und externus $[e]$ ) nervi facialis cum Glossopharyngeo. - $g s$, Vereinigter Stamm von Glossopharyngeus 
und Sympathicus. - 99, Glossopharyngeus, aus gs hervorgehend. - E, Ganglion radicis nervi Vagi. - 10, Der aus $\boldsymbol{E}$ hervorgehende Stamm des Vagus, mit der ersten Hirnwurzel $\left(h^{\prime}\right)$ des Hypoglossus zu einem Stamm $(h v)$ versehmelzend. - $h$, Verstärkungszweig aus diesem Stamm an den zweiten Theil (k) des Hypoglossus, der ersten Hirnwurzel $\left(h^{\prime}\right)$ des letzteren entsprechend. - $l$, Verstärkungsast des Vagus an den Glossopharyngeus, mit letzterem (99) in das Ganglion petrosum (D) ein. tretend. - $g l$, der aus diesem Ganglion hervorgehende Stamm des Glossopharyngeus, mit dem Hypoglossus zu einem gemeinschaftlichen Stamme (hg) verschmelzend. Der aus $h v$ bervorgehende Stamm des Vagus $(v)$ verschmilzt mit dem aus $g s$ entspringenden oberflächlichen Halstheil $(s)$ des Sympathicus zu einem kurzen Stamm $(v s)$, der sich bald wieder in seine beiden Elemente theilt. - Der aus der zweiten Hirnwurzel $\left(h^{\prime \prime}\right)$ und dem ersten Halsnerven (13) gebildete zweite Theil $(k)$ des Hypoglossus nimmt aus $h v$ den der ersten Hirnwurzel $\left(h^{\prime}\right)$ entsprechenden Nerven $h$, später auch den aus dem Ganglion petrosum $(D)$ hervorgehenden Glossopharyngeus $(g l)$ auf.

\section{Tafel III, Fig. 3.}

\section{Ursprünge und Verbindungen der hinteren Hirnnerven von}

\section{Platydactylus guttatus.}

Ueber $3,5,5$ ', 5", 5'”, $A, B, r f, n$ vgl. die Beschreibung von Taf. II, Fig. 1. Ueber $M, 7, C, p, i, f, t, e, m, 9,10, h^{\prime}, h^{\prime \prime}, 13, v, k, k, D, g l, l, y, s$, siehe oben den Anfang der Erklärung von Tafel III.

em, Vereinigter Stamm des Muskelastes $(m)$ und des R. communicans externus (e) des N. facialis. $-e$ verschmilzt hier nicht mit dem Ganglion petrosum $(D)$, sondern kreuzt den aus letzterem hervorgehenden Stamm $(g l)$ des Glossopharyngeus; seine directe Fortsetzung ist $s$, der oberflächliche Halstheil des Sympathicus. - $h^{\prime \prime \prime}$, Dritte Hirnwurzel des Hypoglossus; die beiden ersten, $h^{\prime}$ und $h^{\prime \prime}$, bilden den Stamm $h$, die dritte $\left(h^{\prime \prime \prime}\right)$ und ein beträchtlicher Zweig des ersten Halsnerven (13) den Stamm $k$; $h$ und $k$ bilden zusammen den Hypoglossus, $h k$.

\section{Tafel III, Fig. 4.}

\section{Verbindungen der hinteren Hirnnerven und Brusttheil des Sympathicus von Salvator Merianae.}

F, Vereinigter Stamm sämmtlicher hinteren Hirnnerven. In denselben treten ein: 1) $e$, R. communicans externus nervi facialis cum Glossopharyngeo; 2) 9, Wurzel des Glossopharyngeus, einen Verstärkungszweig, $l$, aus dem Vagus aufnehimend, welcher dem N. laryngeus superier entspricht; 3) 10 , Vagus; 4) $h^{\prime}$, Hypoglossus. 
Aus dem Stanm $\boldsymbol{F}$ gehen hervor: 1) $h g$, Der vereinigte Stamm von Glossopharyngeus und Hypoglossus ; 2) vs, Der vereinigte Stamm von Vagus und Sympathicus. $h$, Stamm des $\mathbf{N}$. hypoglossus. - $g$, N. laryngeus superior. $-d$, Ramus descendens nervi Hypoglossi.

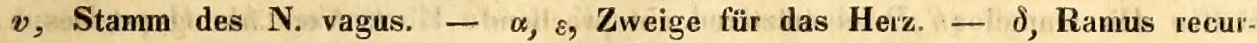
rens nervi Vagi. $-\zeta$, $\eta$, Zweige für die Speiseröhre. $-\vartheta, \vartheta^{\prime}$, Zweige für Magen und Lunge. - $s$, Oberflächlicher Halsstamm des Sympathicus. - $g^{1}, g^{2}, g^{3}, g^{4}$, Brustganglien des Sympathicus. - $b^{1}, b^{2}, b^{3}, b^{4}$, Stämme des Armgeflechtes. $c$, Der auf das Armgeflecht folgende Spinalnerv $-\gamma, \gamma, \gamma$, Verbindungsfäden zwischen dem zweiten, dritten und vierten Brustganglion. $-\gamma, \gamma^{\prime}$, Verbindungsfäden des zweiten Brustganglions mit den Stämmen des Armgeflechtes. _ $s^{\prime \prime}$, Fortsetzung des Grenzstranges.

\section{Tafel III, Fig. .5.}

\section{Hauptzüge der Gehirnnerven von \\ Crocodilus biporcatus.}

3, Wurzel des $N$. oculomotorius. - gc, Ganglienartig angeschwollener Stamm desselben. - $a$, Nerv für den M. rectus inferior. $-a^{\prime}$, Nerv für den M. rectus internus. - $a^{\prime \prime}$, Nerv für den M. obliquus inferior.

5, Wurzel des $N$. trigeminus (mit zwei Portionen entspringend). - 5', Erster Ast des Trigeminus. - $\boldsymbol{A}$, Ganglion des ersten Astes. - $r f^{\prime}, r f^{\prime}$, Fäden für die Haut der Stirngegend. - $c$, Ramus ciliaris des ersten Astes, mit dem ganglienartig angeschwollenen Stamm des $\mathbf{N}$. oculomotorius sich verbindend. $\rightarrow \boldsymbol{B}$, Ganglion des zweiten und dritten Astes des Trigeminus. - $n$, Zweiter Ast des letzteren. $\lambda$, Nervus infraorbitalis. $-\varepsilon, Z$ weig aus dem letzteren an den Plexus sphenopalatinus. $\gamma$, Drüsenzweig des zweiten Astes. - $\vartheta, \vartheta^{\prime \prime}$, Gaumenhautzweige des zweiten Astes, verbunden mit dem R. communicans anterior $\left(\vartheta^{\prime}\right)$ rami palatini. - $\mu^{\prime}$, Vordere Endigung des $\mathbf{N}$. infraorbitalis als $\mathbf{N}$. alveolaris anterior. $-d^{\prime}, d^{\prime}$, Rami dentales. - $\mu$, Ramus alveolaris posterior des zweiten Astes. - $\delta, \delta^{\prime}$, Zweige desselben zum Plexus sphenopalatinus. - $p l$, Plexus sphenopalatinus. $-\zeta$, Zwei feine Nerven, aus dem letzteren nach innen umbiegend, und mit $g$, dem $R$. communicans posterior rami palatini, verschmelzend. - $d$, Rami dentales nervi alveolaris posterioris. $-x, \mathbf{R}$. recurrens ad nervum facialem, aus dem Ganglion $B$ hervorgehend.

5"', Dritter Ast des Trigeminus. - $q$, Nerv für den M. adductor maxillae superioris, aus der Portio motoria der Trigeminus. Wurzel hervorgehend. $-m^{\prime}, m^{\prime}$, Nerven für die Hebemuskeln des Unterkiefers.

7, Wurzel des $N$. facialis. - C, Ganglion desselben - $p, p$, Ramus palatinus. - $g$, Ramus communicans posterior rami palatini cum nervo maxillari superiore. - 
$\vartheta^{\prime}$, Ramus communicans anterior. - $f$, Hinterer Hauptstamm des Facialis. - $e$, Verbindungsast aus dem letzteren an das Ganglion $(D)$ der hinteren Hirnnerven. $t$, Chorda tympani (?). - $m$, Muskelast des Facialis.

10, Wurzeln des $\mathbf{N}$. vagus und $\mathbf{N}$. glossopharyngeus, in die innere kleinere Hälfte des Ganglions $D$ einmündend. - $h$, Erste Hirnwurzel des Hypoglossus, in die äussere grössere Hälfte des Ganglions $D$ sich einsenkend.

$D$, Ganglion der hinteren Hirnnerven. - Aus demselben gehen hervor: 1) $g l$, Stamm des Glossopharyngeus. - $\xi$, Zweig desselben an den vorderen Ast des $\mathbf{N}$. laryngopharyngeus. - 2) $l p$, Nervus laryngopharyngeus. - $l s$, Dessen vorderer Ast, nach Aufnahme des Zweiges $\xi$ als $\mathbf{N}$. laryngeus superior sich verhaltend. $-l d, \mathbf{A b}$ steigender Ast des N. laryngopharyngeus, an der Speiseröhre sich ausbreitend, und die Rami recurrentes nervi Vagi entsendend. - 3) $v$, Stamm des Vagus. - 4) $k$, Erster Theil des Hypoglossus, der ersten Hirnwurzel $h^{\prime}$ desselhen entsprechend. Derselbe vereint sich mit einem Zweige der zweiten Hirnwurzel $(k)$ zum Stamme $(h)$ des Hypoglossus. - 5) $y$, Feiner Verstärkungszweig an den Ast $y^{\prime}$ des ersten Halsnerven (13), dem Ramus externus nervi accessorii entsprechend. - 6) $s$, Sympathicus impar.

Der erste Halsnerv ist mit 13 bezeichnet. Dieser nimmt den Zweig $z$ aus der zweiten Hirnwurzel auf, und entsendet den mit $y$ sich verbindenden Zweig $y^{\prime}$ in den MI. omomastoideus, den Zweig $y^{\prime \prime}$ in den MI. splenius capitis.

\section{Tafel III, Fig. 6.}

\section{Der oberflächliche und tiefe Halstheil und der Brusttheil des Sympathicus von Chamaeleo vulgaris.}

Ueber die Bedeutung der Zeichen 9, 10, h, $l, D, i, e, h g, v$, vgl. Taf. II, Fig. 4. $s$, Oberflächlicher Halstheil des Sympathicus. - $g^{1}$, Erstes Brustganglion desselben. - $\beta$, Verbindungsschlinge mit dem Stamm des Vagus. - $z^{\prime}$, Tiefer Halstheil des Sympathicus, aus einem Zweige ( $z$ ) des ersten Halsnerven (13), und einem Zweige (c) des zweiten Halsnerven (14) gebildet. - Derselbe entlässt zwei Zweige $(\alpha)$ an den ersten Stamm $\left(b^{1}\right)$ des Armgeflechtes, und senkt sich in die Mitte des ersten Brustganglions $\left(g^{1}\right)$ ein.

$s^{\prime}$, Fortsetzung des Sympathicus zwischen dem ersten $\left(g^{1}\right)$ und dem zweiten Brustganglion $\left(g^{2}\right)$. - $\gamma$, Verbindungszweig aus dem zweiten Brustganglion an den auf das Armgeflecht folgenden Spinalnerven, $c$. $-s^{\prime \prime}$, Fortsetzung des Grenzstranges jenseits des Armgeflechts. - $\delta, \delta^{\prime}$, Verbindungszweige an die folgenden Spinalnerven. 


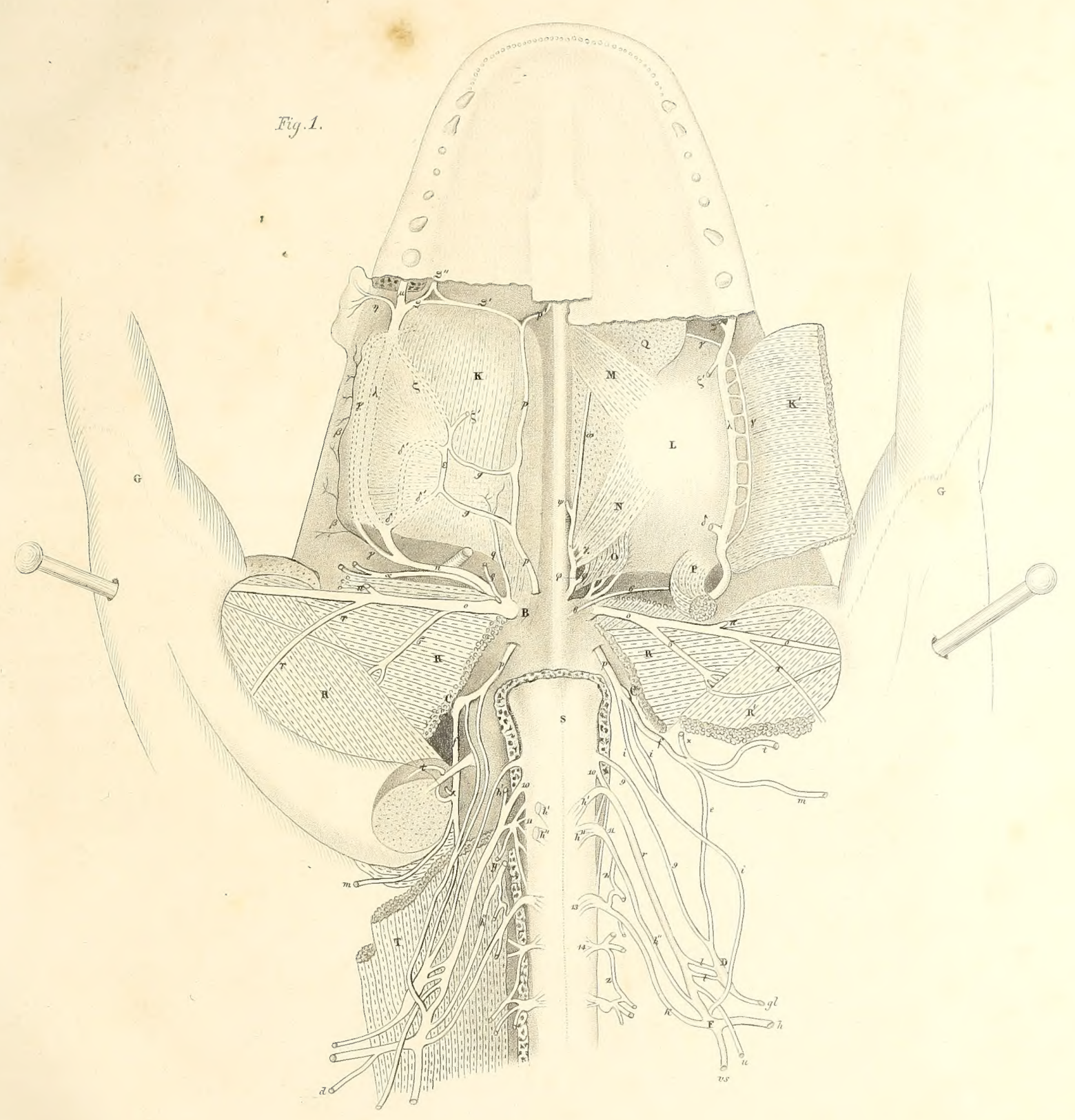



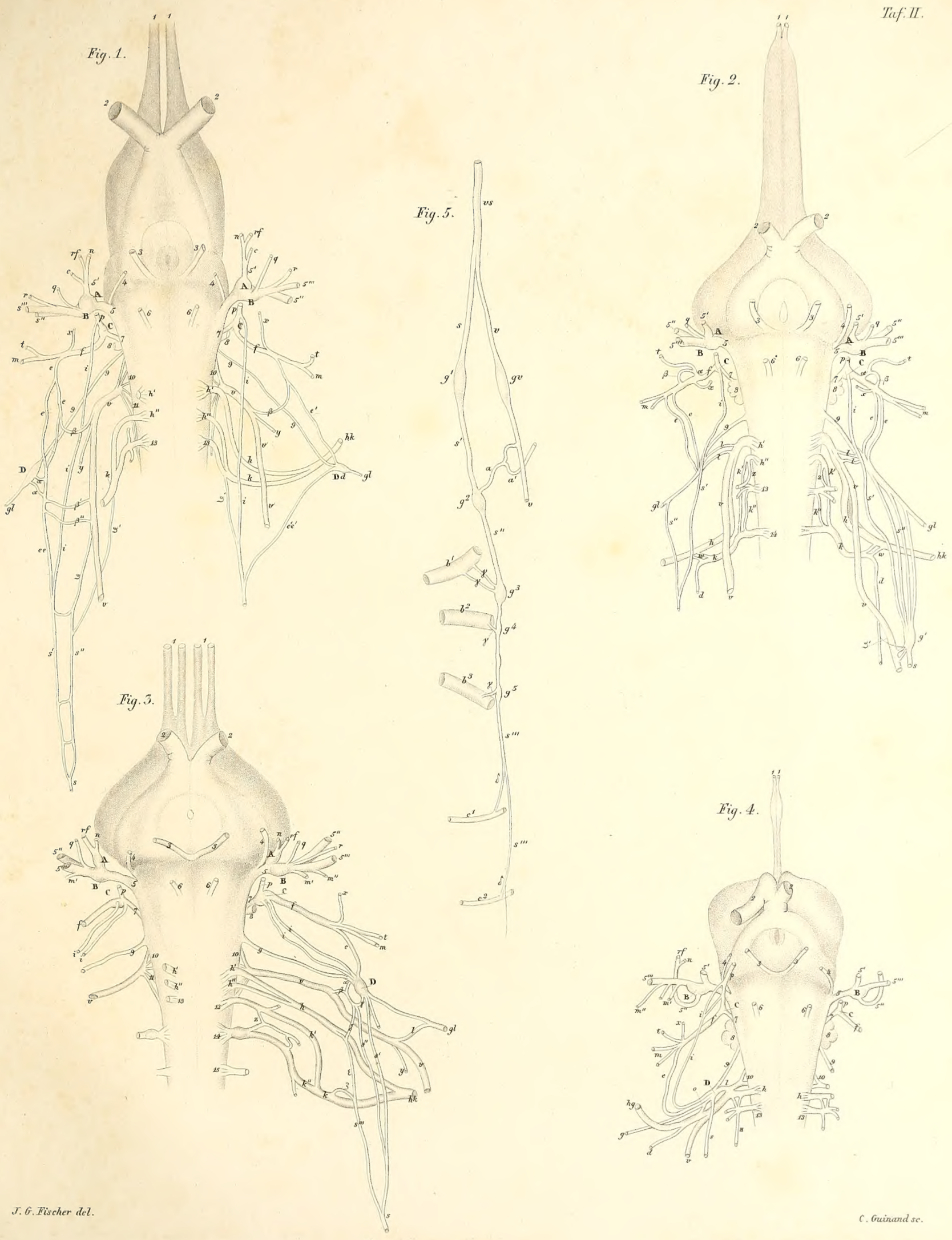


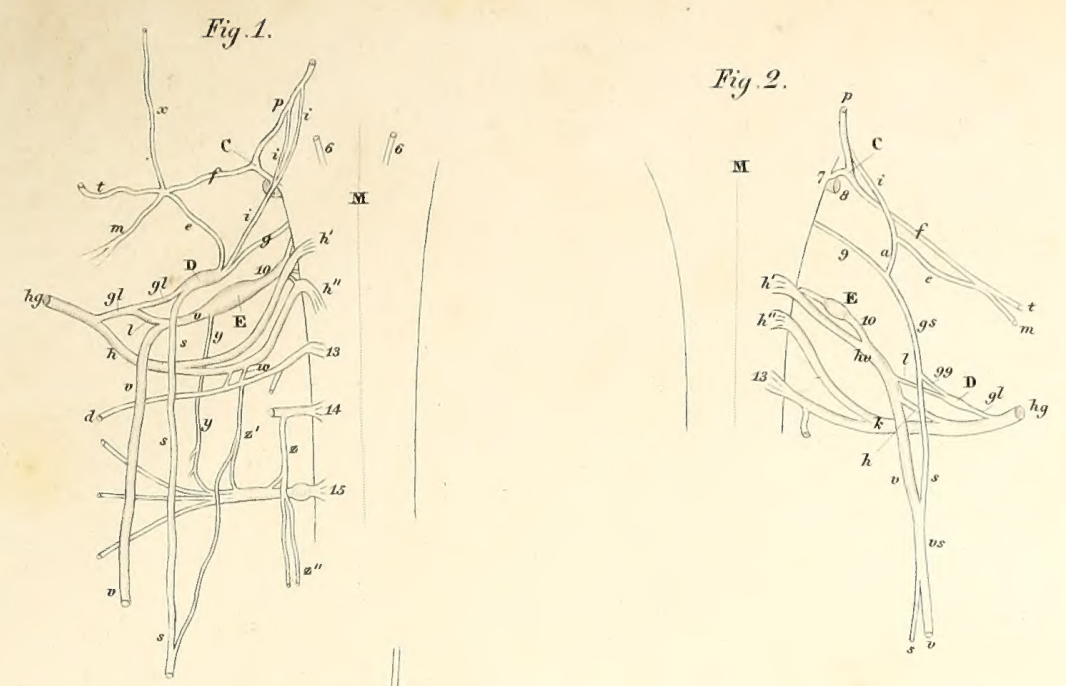

Taf.III.
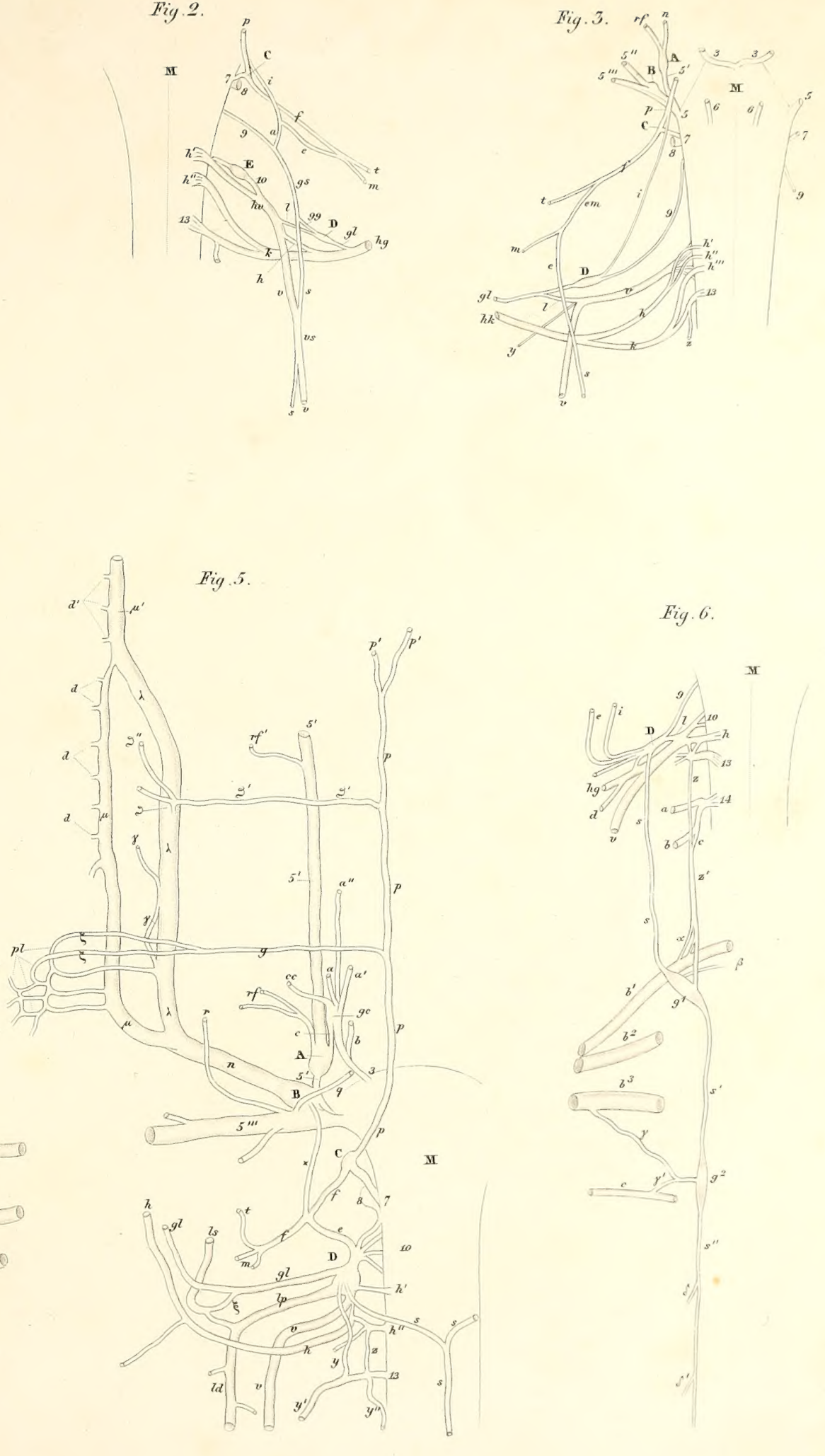

Fig. 6 .

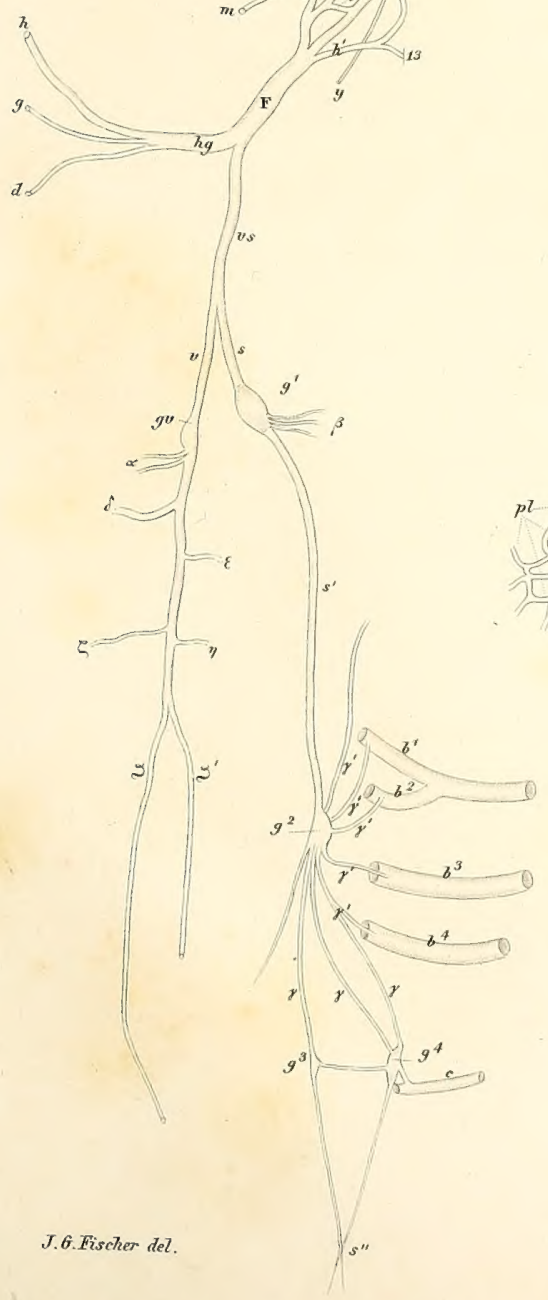




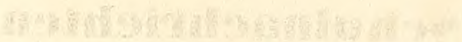



